Florida International University FIU Digital Commons

$10-26-2011$

\title{
Diversity and Knowledge in the Age of Nation- Building: Space and Time in the Thought of Yanagita Kunio
}

Takehiko Kojima

Florida International University, tkoji001@fiu.edu

DOI: $10.25148 /$ etd.FI11120601

Follow this and additional works at: https://digitalcommons.fiu.edu/etd

\section{Recommended Citation}

Kojima, Takehiko, "Diversity and Knowledge in the Age of Nation-Building: Space and Time in the Thought of Yanagita Kunio" (2011). FIU Electronic Theses and Dissertations. 495.

https://digitalcommons.fiu.edu/etd/495 


\section{FLORIDA INTERNATIONAL UNIVERSITY}

Miami, Florida

\section{DIVERSITY AND KNOWLEDGE IN THE AGE OF NATION-BUILDING:}

SPACE AND TIME IN THE THOUGHT OF YANAGITA KUNIO

A dissertation to submitted in partial fulfillment of the

requirement of the degree of

DOCTORS OF PHILOSOPHY

in

POLITICAL SCIENCE

by

Takehiko Kojima

2011 
To: Dean Kenneth G. Furton

College of Arts and Sciences

This dissertation, written by Takehiko Kojima, and entitled Diversity and Knowledge in the Age of Nation-Building: Space and Time in the Thought of Yanagita Kunio, having been approved in respect to style and intellectual content, is referred to you for judgment.

We have read this dissertation and recommend that it be approved.

Clement Fatovic

Eduardo Gamarra

Steven Heine

John F. Stack, Major Professor

Date of Defense: October 26, 2011

The dissertation of Takehiko Kojima is approved.

\begin{tabular}{r}
\hline $\begin{array}{c}\text { Dean Kenneth G. Furton } \\
\text { College of Arts and Sciences }\end{array}$ \\
\hline Dean Lakshmi N. Reddi \\
University Graduate School
\end{tabular}

Florida International University, 2011 
CCopyright 2011 by Takehiko Kojima

All rights reserved. 


\section{DEDICATION}

I dedicate this dissertation to the memory of my father. 


\section{ACKNOWLEDGMENT}

I wish to thank my committee for their unwavering support, patience, and dedication. I am fortunate in availing myself of their diverse expertise in my rash attempt to get over disciplinary boundaries. In spite of their different intellectual and professional backgrounds, Dr. Clement Fatovic, Dr. Eduardo Gamarra, Dr. Steven Heine, and Dr. John F. Stack are at one in their open-mindedness and tolerance toward the meandering and unfocused experiments of this immature student. Without their patience and encouragement, this dissertation certainly would not have been written.

I am also hugely benefited from my coursework, which familiarized me with different intellectual traditions that I had never imagined existed. My experience as an international student during the past seven years has almost completely altered my view of the world and the relevance of knowledge in it. The dissertation is written partly as a testament to this enormously enriching experience.

The substantial part of my research in this project is supported by Florida International University Dissertation Evidence Acquisition Fellowship. I wish to express my deepest gratitude for the generosity. 
THE ABSTRACT OF DISSERTATION

DIVERSITY AND KNOWLEDGE IN THE AGE OF NATION-BUILDING:

SPACE AND TIME IN THE THOUGHT OF YANAGITA KUNIO

\author{
by \\ Takehiko Kojima \\ Florida International University, 2011 \\ Miami, Florida \\ Professor John F. Stack, Major Professor
}

The study examines the thought of Yanagita Kunio (1875-1962), an influential Japanese nationalist thinker and a founder of an academic discipline named minzokugaku. The purpose of the study is to bring into light an unredeemed potential of his intellectual and political project as a critique of the way in which modern politics and knowledge systematically suppresses global diversity. The study reads his texts against the backdrop of the modern understanding of space and time and its political and moral implications and traces the historical evolution of his thought that culminates in the establishment of minzokugaku.

My reading of Yanagita's texts draws on three interpretive hypotheses. First, his thought can be interpreted as a critical engagement with John Stuart Mill's philosophy of history, as he turns Mill's defense of diversity against Mill's justification of enlightened despotism in non-Western societies. Second, to counter Mill's individualistic notion of progressive agency, he turns to a Marxian notion of anthropological space, in which a laboring class makes history by continuously transforming nature, and rehabilitates the common people (jōmin) as progressive agents. Third, in addition to the common people, 
Yanagita integrates wandering people as a countervailing force to the innate parochialism and conservatism of agrarian civilization. To excavate the unrecorded history of ordinary farmers and wandering people and promote the formation of national consciousness, his minzokugaku adopts travel as an alternative method for knowledge production and political education.

In light of this interpretation, the aim of Yanagita's intellectual and political project can be understood as defense and critique of the Enlightenment tradition. Intellectually, he attempts to navigate between spurious universalism and reactionary particularism by revaluing diversity as a necessary condition for universal knowledge and human progress. Politically, his minzokugaku aims at nation-building/globalization from below by tracing back the history of a migratory process cutting across the existing boundaries. His project is opposed to nation-building from above that aims to integrate the world population into international society at the expense of global diversity. 


\section{TABLE OF CONTENTS}

CHAPTER

PAGE

I. INTRODUCTION: SPACE, TIME, AND GLOBAL DIVERSITY .............

Theses and Methods of the Study...................................... 7

Significance of the Study.................................................. 13

Space, Time, and Political Order..........................................26

Spatiotemporal Order and the Question of Others............................37

Yanagita and Minzokugaku..............................................43

Plan of the Dissertation.............................................50

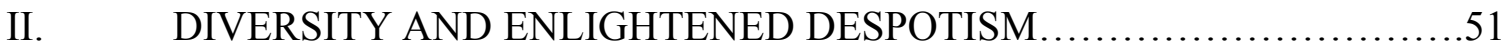

Two Faces of On Liberty .................................................56

Despotism of Enlightened Bureaucracy in Japan...........................62

Progress and Policy Science...........................................68

The State and the Household.......................................... 77

Yanagita's Critique of Enlightened Despotism............................85

Turning Mill against Mill............................................104

III. THE HISTORY OF HISTORYLESS PEOPLE ..........................111

Yanagita, Marx, and Marxism......................................113

Stagnant Space and Labor........................................... 121

Time, Nature, and Human Space..................................... 125

History without Proper Nouns.........................................129

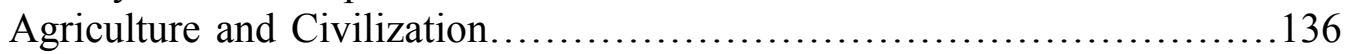

The Concept of Jömin............................................ 146

Diversity in Uniformity.......................................... 155

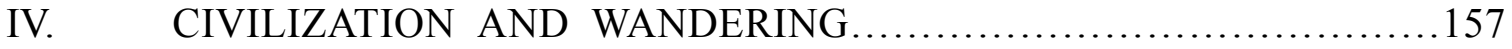

Spatial Limit to Progress............................................... 165

History of Migration and Resettlement............................... 176

Settlers and Wanderers.................................................. 187

Travel as a Method...............................................200

Particular Experience and Universal Knowledge.........................2 210

V. CONCLUSION.................................................. 214

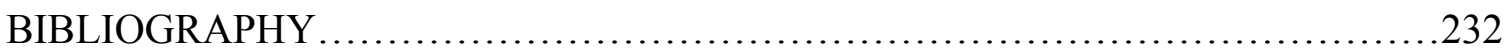

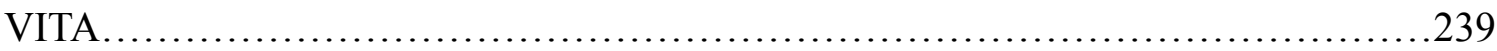




\section{CHAPTER I}

\section{INTRODUCTION: SPACE, TIME, AND GLOBAL DIVERSITY}

The fact that supposedly common humanity has diverse historical expressions has long constituted a puzzle for any social or political theory that claims universal validity, but the early twenty-first century witnesses a renewed consciousness of the limitation of modern theoretical knowledge in dealing with the intellectual challenge. What is more, the modern methods of knowledge production have been accused of being positively hostile to diversity and too eagerly lendingd a hand in the suppression of it. Critics contend that instead of directly counting diversity as a fundamental condition of humanity and a potentially beneficial common stock for enriching existing knowledge, they tend to belittle its significance for theorization by arbitrarily drawing a line between what is and is not relevant to universal knowledge. This demarcation is carried out by the conceptual manipulation of space and time. Spatially, persistent difference within tends to be externalized and banished into rigidly confined places, either physically or metaphorically, so that the fiction of internal homogeneity and unity is created and maintained. Temporally, any difference, or deviation from the established standards, is distanced as a sign of imperfection or immaturity, which is supposed to disappear in time.

In the context of the global hegemony of the West, the combination of those practices is often translated into the apotheosis of the nation-state as the most advanced stage of human progress with which any other form of social organization is unfavorably compared in most, if not all, aspects. In this way, diverse experiences in non-Western space are arbitrarily sifted out and are reduced to the expressions of imperfect conditions 
to be overcome in the course of time. As time goes by, it has been thought, diversity gradually gives way to unity, as human conditions approach its perfection. As critical scholarship from various disciplines documents, knowledge informed by such a conceptual manipulation of space and time plays an active role in justifying imperialism, the discrimination and forced assimilation of minorities, or other forms of suppression of diversity (e.g., Said 1979; Said 1993; Tully 1995: Mehta 1999; Fabian 2002; Inayatullah and Blaney 2004; Bowden 2009). Moreover, when a difference proves to be too persistent, the essentialist notion of race, ethnicity, or culture is invoked to contain it within timeless space. In this sense, racism, ethnic nationalism, or other forms of exclusionary thoughts or practices make strange bedfellows with the inclusionary thrust of cosmopolitanism in either explaining away persistent diversity as a recalcitrant residue of the past or justifying it as permanent reality to live with. In this vicious circle of spurious universalism and reactionary particularism feeding on each other, modern theoretical knowledge find it increasingly difficult to maintain its claim that it is a neutral arbiter between contenting parties.

Diverse historical expressions of common humanity are by no means a new challenge for modern theoretical knowledge. Rather, theorizing activities in the modern period were, to a substantial degree, motivated by the recognition of such diversity. Especially, the discovery by the Europeans of the New World and the inhabitants thereof, whose existence had been totally unexpected by the former, provided direct incentives and materials for theorizing, laying foundations of modern disciplinary fields, such as political theory, international law, economics, history, sociology, and anthropology (Meek 1976; Jahn 2000; Blaney and Inayatullah 2004: 47-92). In a sense, modern knowledge's 
claim for universal validity drives from the fact that, unlike premodern knowledge, it does account for the empirical fact of global diversity. However, the way modern knowledge incorporate diversity into its fold can be called, at least with hindsight, imperialistic in a double sense of the term: It unilaterally incorporates the unfamiliar into a preconceived spatial or temporal order and it has intimate connections with imperialistic practices exercised by coercive power.

What went wrong with those pioneers of modern knowledge and what alternatives could have been available to them are the questions that motivate this study. The point here is not that Hobbes, Locke, Adam Smith, or other Western thinkers, who pioneered the idea that unfamiliar peoples they found in unfamiliar lands were comparable to their own past, should be held responsible for subsequent imperialism because they neglected or suppressed the voice of unfamiliar others. The voice was not there even if those thinkers had been disposed to hear it, and even if they had had opportunities to hear it, they would have had difficulty in understanding it. Probably, they were no more concerned with understanding unfamiliar peoples than with understanding and changing their own societies. Why they were so prejudiced against unfamiliar peoples, which without doubt they were, is an important question, but there are even more important questions: What was the appropriate attitude that they could have adopted in front of such opacity and uncertainty created by encounters with radical others? What kind of alternative methods could have been available to them to produce theoretical knowledge on the basis of bewildering diversity? And what consequences such alternative methods would have had on the substance of knowledge, especially on our understanding of diversity, history, and political order? 
I believe that addressing those questions not only retains relevance but also has become a matter of some urgency today, especially after September 11, 2001, because, if those great minds of the Western intellectual tradition did not know answers, neither do we-i.e., the contemporary scholars, Western or non-Western — seem to know any better. Moreover, given the intimate relations between knowledge and political power, the questions do not remain purely academic. Regardless of the extent to which theoretical knowledge scholars and intellectuals produce actually matters in legitimating or delegitimating certain institutions or practices, at least there must be decent efforts on the part of the members of the intellectual community to reflect on what we are doing and what implications our activities could possibly carry in a larger historical context.

To addresses those questions, this study turns to a somewhat unlikely place: The intellectual biography of Yanagita Kunio (柳田國男, 1875-1962), ${ }^{1}$ a Japanese nationalist thinker best known as a founder of Japanese folklore (minzokugaku 民俗学). ${ }^{2}$ His long

${ }^{1}$ All Japanese names in this study are written in the Japanese customary order. That is, a family name comes first, and a given name second.

${ }^{2}$ Minzokugaku (民俗学) is composed of three Chinese ideographs. Min (民) stands for people or folk, zoku (俗) customs or traditions, and gaku (学) study. The standard understanding is that minzokugaku is the Japanese counterpart of the European discipline of folklore, but that interpretation fails to capture the ideological aspect of minzokugaku. Some scholars attach importance to the influence of Japanese nativist thought (kokugaku 国学) of the late Edo period on minzokugaku (e.g., Harootunian 1988: 407-439), and the best translation of minzokugaku is perhaps Marilyn Ivy's "nativist ethnology" (Ivy 1995). Yanagita's own understanding of minzokugaku is that it is the application of the methods of ethnology to the questions of folklore, but he invests it with a very unique mission of being a national political science (Teihon 25: 248-259). He had tried various names, such as kyōdo kenkyū (郷土研究 hometown studies), nōmin seikatushi (農民生活誌 the ethnography of rural life), minkan denshō ron (民間伝承論 the study of popular oral traditions), or simply fokuroa (フォクロア folklore) to refer to the academic discipline he tried to establish, but reluctantly accepted minzokugaku after his colleagues christened 
intellectual career can be summarized as an inquiry into the basis of the historical diversity of common humanity and its implications for knowledge and politics. The major premise of my study is that Yanagita's intellectual project can be interpreted as both defense and critique of the Enlightenment tradition and, as such, suggests a possible path the latter could have taken but did not take. On the one hand, he firmly believed that there is but one world history retrievable by means of scientific methods and vehemently opposed cultural exceptionalism that tried to isolate Japan or any other spatial unit from world history. On the other hand, he was equally wary of spurious universalism that tends to assimilate the world into Western civilization. The attempt to navigate between the Scylla of cultural exceptionalism and the Charybdis of spurious universalism led him into the question of space and time that runs through the ideological and disciplinary divides. Against the tide of the specialization and professionalization of knowledge production, he proposed minzokugaku as a synthesizing science that directly responds to the neglected social and political needs of the silent majority in his own nation and the world.

My study, therefore, offers an intellectual biography of Yanagita, reconstructed on the basis of an unconventional interpretation of his texts against the backdrop of the political and intellectual contexts in which they were written, with an emphasis on his conception of space and time. My purpose here is not to present Yanagita as an

their association minzokugakkai in the mid-1930s. His reluctance was partly explained by the fact that ethnology was also translated into minzokugaku (民族学) with another Chinese ideograph $z o k u$ (族), standing for tribe or clan, and he feared that the general public might confound them. He tried to distance his minzokugaku from ethnology partly because he was aware of ethnology's association with colonialism. In this study, I decided to use minzokugaku to emphasize the unique nature of Yanagita's intellectual project. 
intellectual gem hidden in the obscure corner of the Far East, but to rehabilitate him as a contemporary participant in global debates on world order by situating his intellectual project in a larger historical context, whereby the following three questions have become important for any theory of human society. The first question is, "What is the basis of cultural diversity?" The question is not new and various answers have been proposed, such as race, ethnicity, economic structures, relative moral and intellectual maturity of different peoples, and so on. The second question is, "Is diversity worth preserving or even promoting?" There can be two extreme positions with respect to the question. On the one hand, universalism posits that common human history is that of emancipation from particularistic cultures that has long divided humanity and the world is treading on a common path toward universal civilization. From the universalist point of view, therefore, the decline of diversity is a welcome sign indicating the progress of humanity. On the other, particularism claims that humanity actually consists of essentially distinct peoples and that any existing culture is complete on its own right. Diversity, in the particularist view, is good and worth preserving for its own sake. Because answers to those questions have implications for what we think and do, the third question is, "How are we doing in dealing with diversity?" Especially, the study focuses on how the idea and institution of international society and the sovereign state deal with the question of diversity.

Even though Yanagita did not directly address those questions, it is possible to reconstruct his possible answers to them from his texts, and not only the answers themselves but also how he arrived at them are interesting and significant to students of contemporary world politics. The interpretation offered in this study not only sheds light on an aspect of Yanagita's thought that has not received enough attention, but also 
illuminates possible blind spots in the modern mode of knowledge production concerning the question of diversity. Even though the intellectual biography itself does not necessarily provide a definitive answer to the question of global diversity, it surely provides an occasion for self-reflection on the part of intellectual heirs, either conscious or unconscious, to the unfulfilled promise of the Enlightenment project. That is the raison d'être of my study.

\section{Theses and Methods of the Study}

Although Yanagita repeatedly claims that his intellectual project has enormous relevance to contemporary politics and many scholars and intellectuals recognize such relevance, precisely how it is relevant is a matter of substantial controversy. The difficulty in pinning down the political relevance of his project is not least because most his writings are neither political nor theoretical in any conventional sense. They are typically written in the form of essays, consisting of not so much expository presentations of clear thesis and supporting arguments as meandering narratives that thread together seemingly unrelated anecdotes by dint of his literary intuition. ${ }^{3}$ The contents of his texts largely concern the history of the everyday life of the ordinary Japanese, which seems to have no relations to contemporary world politics. To make matters worse, he is characteristically reticent about many crucial political issues of his time, such as the Emperor system, the annexation of Korea, or war against China and the United States,

3 Yoshimoto Takaaki, who calls Yanagita's style "methodless methods (muhōhō no hōhō 無方法の方法)," describes it in the following terms: "No matter how far we follow Yanagita Kunio's methods, we never get to the essential meaning of the term 'abstract.' It is a infinite space of beads threaded by "intuition"' (Yoshimoto 1973: 192). 
and his remarks on issues of public concern often come in an extremely roundabout form.

As a result, it is difficult to pin down his positions vis-à-vis specific political issues, let alone theoretical underpinning of his positions, from texts. Therefore, any attempt to read Yanagita's texts in search of a political or social theory is destined to be frustrating. If there is any theoretical engagement behind his writings, it is hidden in literary plots underlying his historical narratives. ${ }^{4}$ Inevitably, those who seek a theory in Yanagita's

${ }^{4}$ As Hashikawa Bunzō (1985b) points out, selective reticence on his life and contemporary political issues is one of the major characteristics of Yanagita. Although Hashikawa does not elaborate, there are several possible reasons for his reticence. First, as an elite government official, he acquired a keen sense to protect himself from unnecessary troubles. After resigning from the government in 1919, he became more openly critical of the foreign policy of the government and the delay in domestic reforms. Nevertheless, he generally wrapped his criticism with nuanced or sometimes obfuscating language, possibly to avoid provoking the government and increasingly nationalistic public opinion. Especially, as official censorship made it increasingly risky to openly challenge certain political institutions or government policies, he seemed to prefer silence to lying. It is even arguable that his oblique engagement with contemporary politics through the apparently politically innocuous historiography of rural society is partly explained by his disinclination toward direct confrontation. Second, however, he also self-censored his own writings out of concern that the publication of sensitive facts might have undesirable political repercussions. An example of his self-censorship is his refusal to republish some early writings on wandering priests and priestesses because, according to him, those writings had implications for the Imperial Household. Yanagita did not elaborate on the reason, but, as Akasaka (1994: 134-135) speculates, Yanagita possibly feared that his thesis that the established clergy of Shintō and wandering priests and priestesses shared the same origin might reveal a historical connection between the Imperial House and much denigrated wandering and discriminated peoples. These examples indicate his readiness to turn a blind eye to inconvenient truth. However, his selective reticence on his own political views also reveals the political side of his intellectual project. As will be discussed in the second chapter, he had an instrumentalist notion of knowledge and repeatedly criticized the production knowledge for the sake of knowledge. In Kokushi to minzokugaku (国史と民俗学 National History and Minzokugaku, 1944) (Teihon 24: 11-14), he claims that historiography always had important political functions and historical knowledge has always been a source of political authority. In this context, his selective reticence can be interpreted as his readiness to privilege political objectives over historical truth, and for him, the ultimate objective of politics is the preservation of spatial order to prevent the reversal of human progress. Arguably, selective memory—i.e., remembering something while forgetting 
writings are forced to comb his voluminous and diverse texts, biographical information, and intellectual and political contexts in which they are written for relevant clues and to assemble them into what would be Yanagita's theoretical perspective he himself never fully articulated. Any study of his political thought requires a positive interpretive device to distill theoretical contents from his non-theoretical texts, with all the risk of reading too much from too little.

The strategy this study adopts is to read his texts through three interpretive hypotheses, which serve as a sort of conscious prejudice. The first hypothesis is that his intellectual project can be described as a critical engagement with John Stuart Mill's philosophy of history, especially the one expressed in his influential essay On Liberty. While Mill's text is the quintessential defense of diversity as a basis for social progress, it refuses to extend the same logic to less developed societies on the ground that diversity outside Western civilization is a sign of immaturity and not conducive to progress. I will argue that Yanagita embraces Mill's defense of diversity as the basis for social progress but turns it against the latter's justification for enlightened despotism in less developed societies. The second hypothesis is that, in order to counter Mill's individualistic notion of progressive agency, he turns to a Marxian notion of anthropological space underneath the superstructure of civilization as a true site of progress, where human life is reproduced by incessant labor to subordinate nature to human will. He identifies rural folks who directly work in and on nature, instead of the urban literate class specializing in mental labor, as primary progressive agents. However, he rejects Marxian universalism

others-is at the heart of his minzokugaku project. 
by allowing natural conditions, human choice, and memory to play a greater role in producing diversity and claims that each civilization has its own path to modernity.

A few caveats are necessary before we proceed to the third hypothesis. My claim is not that Yanagita consciously engaged with Marx and Mill's texts in the course of establishing minzokugaku. Both Mill and Marx were widely read in Japan during his lifetime, and judging from his educational background and occasional references to their names in texts, he was most certainly familiar with some of their texts. However, there is little direct evidence that indicates the influence of On Liberty and Marx's historical materialism on Yanagita's intellectual project. Yanagita's direct contacts with Mill's texts seem to be limited to his formative years and all the reference to Mill in his earlier texts concerns a Mill the economist, not the political theorist. Although his engagement with Marx may have been extended well into the1930s or later through his Marxist disciples and friends, he discussed neither Marx nor Marxism in his texts. Neither do I claim that Mill and Marx are the only, or even primary, source of theoretical inspiration for his intellectual project that culminates in the establishment of minzokugaku. As an academic discipline, it was more directly inspired by European ethnology and folklore and, probably, the sociology of Durkheim. Yet his turn from political economy into ethnology and folklore seemed to be motivated by deeper theoretical concern. In fact, it is not difficult to detect the influence, either direct or indirect, of British and French Enlightenment thinkers in his texts, such as Montesquieu, Rousseau, and Adam Smith, just to name a few. However, as Tsurumi Kazuko points out, Yanagita weaves an assortment of thoughts, from European literary works, folklore, and ethnography to Japanese classics such as works of Motoori Norinaga (本居宣長 1730-1801) and Hirata 
Atsutane (平田篤消 1776 -1843) into “a seamless patchwork” with “fuzzy boundaries" (Tsurumi 1998: 35). It is, therefore, risky, if not utterly preposterous, to assert Mill and Marx's direct influence on Yanagita's thought.

In light of comparison between Mill's and Yanagita's texts, I am inclined to think that the influence of Mill on Yanagita's thought is vastly underappreciated with respect not only to the question of diversity but also to reformism in his political economy, the rejection of paternalism and the ideal of self-reliance, the importance attached to public debates, ambivalence toward civilization, the commitment to "inductive" methods, and possibly attention to the plight of women. However, I doubt that Yanagita himself understood his project as a lifelong engagement with Mill's philosophy of history. It is more probable that Mill's defense of liberty and diversity left an indelible impression on the sensitive and absorbent mind of young Yanagita and the Millian spirit became internalized through his subsequent struggles against the paternalistic state. As for Marx, the direct influence is even less obvious and probably one can make a stronger case for the affinity between Yanagita and Adam Smith—not so much a Smith the father of liberal economics as a Smith the moral philosopher who was concerned with the moral and political implications of the transition from agrarian to commercial society—as long as the ideological orientation is concerned. Again, my educated guess is that Marx's influence on Yanagita is substantial, but I do not insist that the influence is direct and unmistakable.

My study concentrates on Mill and Marx, not because their influence is obvious or greater, but because the focus is useful for the purpose of this study: i.e., shedding light on Yanagita's unique but by no means idiosyncratic conception of space and time and its 
epistemological and political implications. The claim of this study does not necessarily depend on whether his intellectual project is a conscious theoretical engagement with those thinkers. As a matter of fact, Yanagita was never a theorist and was not interested in theoretical debates at all. The major target audience of his writings and speeches, especially in later years, were not professional scholars or ideologues but the general public. However, because his original understanding of space and time, on the one hand, and history and political community, on the other, was largely shaped by the absorption of the Enlightenment thought, his revisionist historiography by means of minzokugaku inevitably carries critical potential vis-à-vis the Enlightenment thought. Even if Yanagita himself did not recognize the influence of Mill and Marx on his project, comparison between Mill and Marx, arguably two greatest heirs to and critics of the Enlightenment tradition in the nineteenth century, and Yanagita still makes sense in this broader intellectual context.

As for the third hypothesis, I will argue that Yanagita complement the history of the common people with that of wandering people. The implicit grand narrative of his hypothetical world history is underscored by Malthusian wariness, which has two important ramifications for his conception of space and time. First, his concern with spatial limits to the possibility of progress moves him away from a linear to a cyclical notion of time, on the one hand, and from progressivism to conservatism, on the other. Second, it also directs his eyes to the existence of landless people who have lived on the margin of agrarian civilization. In his minzokugaku, he transcends his initial Romantic inclination by combining his wanderlust and Malthusian wariness into a theory of cultural transmission across spatial divisions. In this theory, the presence of wandering people are 
no longer an object of Romantic yearning, as their status as the internal other of civilization is explicitly recognized and their role in history as the countervailing force to the innate parochialism and conservatism of civilization is incorporated into his theory of civilization. In a parallel move, travel, or temporary wandering, is no longer an act of rebellion against civilization or escapism, and is redefined as a method of knowledge production and a means of political education.

Combined, the three hypotheses make it possible to reconstruct a more or less coherent theoretical core from Yanagita's writings, whose implications easily transcend various disciplinary and ideological boundaries, including the one between Political Theory and International Relations. ${ }^{5}$

\section{Significance of the Study}

A folklorist, little known outside his native country and whose writings do not directly deal with either political theory or international relations, is certainly an odd choice for a study of world politics. Nevertheless, there are several reasons Yanagita's thought ought to interest students of politics outside Japan. The significance of this study is two-fold. First, it sheds new light on the thought of an important non-Western thinker in a way that rehabilitates him as a relevant participant, different from but coeval with

${ }^{5}$ Throughout this study, Political Theory and International Relations refers to the current division of labor in knowledge production based on the allegedly qualitative difference between politics within each political community and relations between them. As such, Political Theory includes theoretical activities in the subfields of Comparative Politics and American Politics as well as Political Theory narrowly defined. Furthermore, as Walker (1993) suggests, International Relations itself is built upon Political Theory broadly defined, and one cannot stand independently from the other. 
Western critics of modernity, in the formation of discourses on world order. Second, his critique of the modern spatiotemporal order and the methods of knowledge production predicated on it provide new materials for self-reflection on the part of those of us who works within the conventional frameworks of Political Theory and International Relations. For the remainder of this section, I elaborate on each of these two points.

\section{Non-Western Thinker as Coeval Contestant}

Yanagita is a complex thinker. His ambivalent attitude toward modernity haunts both his career and writings, which verge precariously upon the boundaries between literature and science, Romanticism and rationalism, aesthetics and politics, obscurantism and enlightenment, and poetic imagination and scientific rigor. Therefore, it is difficult to classify his thought into any preexisting category. The complexity, much appreciated by admirers of Yanagita, becomes a liability when it is necessary to represent his thought to those who are not familiar with his writings. For not only international audiences but also many Japanese contemporaries, the historical significance of his writings is far from self-evident.

The major claim of this study is that Yanagita's intellectual project can be understood as a critical engagement with the modern spatiotemporal order that informed the dominant understanding of what was happening in the world in the early twentieth century. As discussed in the previous section, he, on the one hand, heavily draws on the Western political and economic thought. On the other, that does not mean that he blindly accepts Western theoretical knowledge and uncritically applies it to the case of Japan. Instead, in engaging critically with Western conceptions of space and time, he radically 
transforms the conception of political community and progress. A result is a more conservative and nationalist theory of world politics with ingrained wariness toward industrialization and urbanization, but in line with the Enlightenment tradition and more sensitive to the question of diversity. The advantage of the approach of this study can be illustrated by contrasting it to two conventional understanding of the meaning of Yanagita's work in intellectual history.

First, a most popular narrative of Yanagita's legacy is that of a nationalist thinker who tried to preserve Japanese cultural distinctiveness against the tide of modernization-cum-Westernization. Both admirers and critics often characterize him as a spokesperson of a distinctive Japanese perspective, genuine or false, and a defender of Japanese traditions. In this narrative, his intellectual project is understood as an attempt to counter Western influences with allegedly Japanese indigenous culture and the goal of his minzokugaku is the self-affirmation of cultural distinctiveness. Thus, his writings themselves become expressions of this distinct cultural ethos, almost impenetrable to those who do not share it. Although there is a grain of truth to this interpretation, it has an unintended effect of severing Yanagita's thought from the global public sphere and contributing to the idolization of him as a national intellectual hero. The major dilemma of this interpretation is that the more one emphasizes his role as a representative of the Japanese unique perspective, the less relevant his thought becomes to international audiences.

In a sense, an enormous gap between Japanese and Western reception of Yanagita's writings illustrates the problem. He is not only an enormously popular figure in Japan, almost a cultural icon himself, but also has been touted by many Japanese intellectuals 
and scholars as a "world-class intellectual," or one of the few "exportable" thinkers Japan has ever produced (e.g. Hashikawa 1985a; Umesao 1973). Yet, international audiences remain unimpressed. The scholarly interest in him abroad has been largely limited to folklorists and cultural anthropologists who simply see his minzokugaku as the Japanese counterpart of their own disciplines. For many others, he is simply a "very Japanese" (Ōiwa 1985: vii) writer, to the effect that his texts may be enjoyed and evaluated as Japanese literary works, but not treatises with theoretical values. It is arguable that the varying reception of Yanagita in Japanese and international audiences itself is an extension of the problem he grappled with one century ago: the privileged position of "universal" knowledge as the standard for relevance. Although there is no indication that Yanagita considered his own writings impenetrable to non-Japanese readers, some Japanese scholars suggest that this is precisely what happens when Western scholars are too quick to dismiss him as a literary genius fraying into the field of positivist science, at best, or an nationalist ideologue in guise of a positivist scientists or historian, at worst. ${ }^{6}$

Without any doubt, a problem is the notorious difficulty of translating his writings into foreign languages, and, not surprisingly, his writings largely remain to be translated. ${ }^{7}$

${ }^{6}$ Compare, for example, essays, written by both Japanese supporters and Western critics, in the volume edited by Koschmann et al (1985).

${ }^{7}$ Yanagita published more than ninety books and countless articles throughout his life, but, according to Morse's (1990: 208-209) bibliography, only ten articles and seven books have been translated into English. Of the seven translated books, one is a dictionary of Japanese folklore and other two are the reports of major fieldwork that his disciples conducted in Japanese mountain and seaside villages and cannot be properly called his own works. Other two is a collection of Japanese folktales and its revised edition. None of translated books and articles directly concerns theoretical and the methodological aspects of his minzokugaku. 
Yet the issue goes deeper than the problem of translatability. One of the editors of the volume titled International Perspectives on Yanagita Kunio and Japanese Folklore Studies frames the question of the limited international appeal of Yanagita as follows: [The limited appeal of Yanagita to the international audience] might have been because the great bulk of Yanagita's writings remain to be translated, and hardly mentioned in foreign languages. It thus has remained unknown even to those who often hear Japanese reference to it. At the same time, one could not help wondering if it would be worthwhile to spend the great time and effort translating Yanagita's work when many seemed already to have passed judgment on it: "it's very Japanese," they would say with a smile. Could Yanagita be at all meaningful when detached from the Japanese context? (Ōiwa 1985: vi-vii).

By giving a vehement "no" to the question above, some Japanese admirers of Yanagita have unwarrantedly contributed to the exoticization of his voice and have deprived his thought of global relevance.

A more sensible and fruitful approach is to reckon him as a thinker who reacted to the advent of modernity like many others in modernizing societies. As industrialization, urbanization, administrative centralization, democratization, or other forms of social changes engulfed the Japanese society, there emerged the intellectual challenge of how to interpret these developments. In this sense, Yanagita is no different from modern Western thinkers who grappled with the same kind of questions. Thus, it is not nationality but the ideological orientation of Yanagita that should be emphasized. According to this view, Yanagita can be most plausibly characterized as a Burkean conservative who viewed rapid social changes with skeptical eyes and favored gradual and moderate reform over 
radical and revolutionary paths to progress (Nakamura 1974; Hashikawa 1985a;

Koschmann 1985; Satō 2004). An alternative view, represented by recent critical scholarship on Yanagita, suggests that his intellectual project was a misplaced effort to resist modernity_-"misplaced" because it actually takes part of it by concealing the reality of capitalist modernity underneath the false sense of cultural permanence (e.g., Ivy 1995; Figal 1999; Harootunian 2000).

The second approach is more amenable to the fact that Yanagita's thought was in fact nurtured in close conversations with the Western intellectual tradition. As discussed in the previous section, although his reticence about intellectual debt makes it difficult to gauge the precise form in and the extent to which his intellectual project was shaped by Western thought, one cannot help noticing the shadows of various Western thought in his writings. With or without any direct influence from these thinkers, his unarticulated political theory seems to belong to the same discursive space of modernity. As such, his intellectual relevance can be evaluated with the same standards as those used in the Western intellectual history.

However, I find the second approach wanting as well. According to the view, Yanagita, or any other non-Western thinker for that matter, is placed on the receiving end of knowledge production and dissemination. Commonalities or affinities found between Yanagita and various Western thinkers are usually interpreted as either direct or indirect influences from them or interesting parallels attributable to comparable structural conditions between nineteenth-century Western societies and twentieth-century Japan. Accordingly, his thought may be considered a variation of the conservative ideology and its commonalities with and differences from the paradigmatic models may become 
worthy objects of historical inquiry. What is missing in this view, however, is that the major object of Yanagita's criticism is precisely the one-way flow of knowledge across boundaries that divide humanity into the subjects and objects of knowledge, depending on where they are located in the global spatiotemporal order. True, Yanagita's thought is substantially shaped by Western discourses he absorbed during his formative years, but he is far from being a passive and unconscious taker of received knowledge.

The novelty of the approach adopted in this study lies in the characterization of Yanagita's intellectual project as an attempt to bring down the spatiotemporal boundary between the subjects and objects of knowledge. As such, it has the advantage of rehabilitating Yanagita as a serious critic of modern theoretical knowledge without compartmentalizing his thought into a particular cultural matrix. On the one hand, it argues that his political thought is by no means incommensurable with the tradition of Western political thought. Instead of claiming that he is a cultural essentialist and a proponent of Japanese exceptionalism, it suggests that his ultimate objective is not to divide the world into mutually incommensurable cultural spaces but to reground universal knowledge on the empirical fact of global diversity. On the other hand, his thought is unmistakably shaped by his own personal experience as a Japanese urban intellectual whose ambivalence toward modernity is rooted in a particular historical context of Japanese modernization. That does not mean that the experience of Japan is idiosyncratic or that his thought is representative or paradigmatic of Japanese nationalism. ${ }^{8}$ What distinguishes him from many other Western theorists and Japanese

${ }^{8}$ By the 1930s, he was a prominent public intellectual, but was perhaps considered a "dilettante" historian with encyclopedic knowledge of traditional rural life, not a serious 
nationalists is the fact that he consciously took advantage of the position to view the world from the standpoint of the culturally denigrated.

In this context, it is worth emphasizing the fact that Yanagita was a traveler, in both the literal and metaphorical senses, who went back and forth between different cultural spaces - between rural and urban on the one hand, and national and global space on the other. Roxanne Euben (1999: 10-11) points out that there is an etymological and methodological connection between theory and journey. One of the etymological origins of the term "theory" is theoros, a Greek word that referred to "a public emissary dispatched by his city to attend the religious festivals of other Greek cities" (Wolin 1968: 319). In the passage of time, theoria "acquired the connotation of a long journey undertaken to see (theorein) different lands and to observe their diverse institutions and values" (Wolin 1968: 319). Traveling means stepping outside of a familiar place and meeting an unfamiliar world. An encounter with others produces an opportunity to learn not only about them but also about the self. Euben suggests that political theory was and still is an inherently comparative enterprise, at least in part because it is through comparisons that we are led to question the 'naturalness' of our own perspective (Euben 1999: 11).

In spite of his apparent atheoretical or even anti-theoretical inclinations, Yanagita's disposition closely parallels that of the traveling theorist. He was a legendary traveler who is said to have walked the length of the Japanese archipelago, not only the densely

nationalist thinker or ideologue. His nationalist thought is more resonant with postwar pacifist nationalism, but it can hardly be said that the complexity of his thought is widely understood and appreciated even in the postwar period. 
populated coastal regions but also remote areas deep in mountains and in isolated islands, which newly constructed railways, modern highways, or steamship lines did not reach. His physical travel abroad is relatively limited, but he was always in the privileged position to absorb Western knowledge and played a significant role in introducing the Western literature into Japan. His minzokugaku was built upon what he observed in person during his innumerable journeys as much as it was by what he read. Metaphorically, it is arguable that his life itself is a sort of a long journey. Unlike the theoros who belonged to particular poleis, Yanagita's spatiotemporal affiliation is always ambiguous, neither completely urban or rural, modern or traditional, nor completely Japanese or Western, making him an outsider wherever he went.

Yanagita's Romanticism partly derives from this rootlessness, but at the same time he was well aware of the advantage that the status of being outsider accords to him in the production of theoretical knowledge. In the preface to Kainan shōki (海南小記 Brief Writings on the South Sea), a collection of essays about a journey to Southern Japan he made in the winter of $1920 / 1921$, he wrote:

Because I was a traveler, I did not observe the way of life in this archipelago [of southern Japan] exclusively from the standpoint of a particular island. Without using as the standards the historical distinctions created during the last few centuries [that divided the archipelago into centers and peripheries], I sought to clarify a law of life that is universal to both large and small islands of southern Japan. I believe that good scholars in the future, adopting this attitude, will repent of unnecessary human conflicts [in the past] and, following this path, will not fail to 
move gradually toward a bright future, a world of racial equality. ${ }^{9}$ (Teihon Yanagita Kunio shū [Teihon, hereafter] 1:221)

With this advantage in mind, he self-consciously assumes the role of mediator between different spatial divisions, first between rural and urban within Japan and later between the global East/West and the North/South. What is more, he further claims that the effectiveness of his mediation rests on the fact that in-betweenness is the common experience of the silent majority of humanity underneath conceptual spatial divisions. For example, he writes in the preface to Toshi to nōson (都市之農村 City and Village, 1929):

Quite fortunately, however, here is a person like me, a most typical city dweller, who, having long lived in a city without being completely urbanized, still cherishing villages as much as he did when he was a boy, and, what is more, standing apart from any special [urban or rural] interest at the present time, happens to be in a position of observing discords between city and village. My common sense probably represents [the sentiment of] the majority. Even those who happen to be indifferent [to the plight of peasants] shall eventually come to share this same feeling if they give the matter continual thought. ("Toshi to nōson." Teihon 16: 240) Yanagita believes that the act of travelling is indispensable to share the common sentiment of the silent majority that runs deeper beneath the conceptual spatial divisions on the surface and to make knowledge more universal.

${ }^{9}$ All the translations quoted in this study are mine, except indicated otherwise. Yanagita's writings are notoriously difficult to translate, not least because of their literary quality. I try to strike a balance between clarity and literary quality, but, given the objective of the study, prioritize clarity over literary authenticity whenever I have to choose one. 
If the notion of travel as part of theoretical activity in its own right is accepted, the experience of many modern non-Western thinkers must be appreciated as that of theoros who travels back and forth between the West and their own native places. Of course, the experience of such theoros does not necessarily lend itself to a common conclusion and it is debatable whether they did better than their Western counterpart in navigating between the Scylla of universalism and the Charybdis of particularism. However, dismissing them outright as either imitators/followers of secondary importance or absolute others, Western theorists may have missed important opportunities to cross-examine their own findings from forays into unfamiliar places. The experience of Yanagita, who self-consciously tries to exploit his epistemological advantage of being an in-between, is a good starting point for redeeming the possibility.

\section{Critique of Political Theory and International Relations}

Interpreted as a critique of the modern spatiotemporal order, Yanagita's thought directly cuts into a deeper layer of Political Theory and International Relations. In other words, in spite of the oblique way in which he approaches the question of world political order, his intellectual project is political in a more than trivial sense, because it penetrates into philosophical issues concerning the meaning of political community, on the one hand, and history and human agency, on the other. What motivates his intellectual project is the desire to explore the possibility of political community other than the impersonal modern state and progress other than the history of Western civilization, which possibility cotemporary Political Theory and International Relations are often unable or unwilling to recognize. In light of his critique of the modern spatiotemporal order, the major flaw of 
Political Theory and International Relations can be said to be its failure to bear the full weight of empirical global diversity upon their own theories. The division of humanity into the subjects and objects of knowledge production filters out the most radical otherness as irrelevant and immaterial to theoretical knowledge, and as a result what is potentially a mutually enriching learning process was perverted into a dogmatic imposition of particular standards of civilization over the world population. The act of exclusion in guise of scientific objectivity not only is unjust to the excluded, but also vitiates Political Theory and International Relations, as it undercuts their ability to understand the persistence of radical difference in the midst of modernity.

For Yanagita, the failure of Western "universal" knowledge to embrace diversity is far from accidental. His awareness that knowledge and power are inseparably wedded to each other through the spatiotemporal order leads him to conclude that in order to change political order, first it is necessary to develop a alternative method of knowledge production, predicated on a different conception of space and time. By passively accepting imported knowledge, political and intellectual leaders of non-Western societies inevitably reproduce international hierarchy at the national level, by dividing the national space into progressive and stagnant spheres. Then, domestic diversity is redefined as a deviation from the universal course of political and economic development and thus is confined to the supposedly time-resistant cultural realm. Thus, diversity is doubly removed from world politics: first, it is removed from international politics, which is conceived as cultureless or only thinly cultural; and second, internally, it is removed from the public sphere and is confined to the private realm. Western civilization now can rely on modernizing elites in non-Western societies as the first guards against the dangerous 
intrusion of diversity into world politics. At the same time, modernizing elites in non-Western societies depends on the superiority of the Western model for the legitimation of their internal authority. As a result, the international and domestic hierarchies reinforce each other, and oppositions to domestic hierarchy inevitably carry international implications. This mutual penetration of international and domestic politics is the basis for Yanagita's claim that minzokugaku, in spite of its exclusive focus on national culture, has global political significance.

The domestic opposition to the paternalistic and authoritarian state inevitably challenges the monopolization of knowledge by the latter on the ground that the West represents a common destiny for entire humanity. That is why he believes that intellectual autonomy must come first before genuine political autonomy. In minzokugaku, both subjects and objects of knowledge is the common people and its purpose is to "know the self "(Teihon 25: 327-328, 337). In other words, minzokugaku is designed for culturally denigrated peoples to acquire self-knowledge, in opposition to imposed knowledge by professional scholars and bureaucrats who are more familiar with the theoretical knowledge of and from the West than with the historical experience of their own country. In this sense, his minzokugaku is not merely the Japanese counterpart of the European disciplines of ethnology and folklore, but also deemed to be a national intellectual movement aimed at nation-building from below.

Although Yanagita himself never directly engaged with Political Theory and International Relations, his intellectual biography offers a promising site in which the way contemporary world politics is perceived and studied is critically reexamined. Particularly, his views of global diversity and progress raise the question whether it is 
possible for Political Theory and International Relations to make contribution to the creation of a more inclusive and democratic progressive world order without fundamentally rethinking the current practice of knowledge production.

\section{Space, Time, and Political Order}

For the past two decades, the question of space and time has become one of the focal point in debates on world politics and global order. The renewed interest in space and time is partly because the link between two important and interrelated coordinates of the global spatiotemporal order - the nation-state and progress — has been brought into question on both empirical and normative grounds. On the one hand, the nation-state, which used to be regarded as a site of economic, political, and cultural development, can no longer contain, if it ever did, either politics, economy, or culture within it. Thus, once seen as the endpoint of human progress, it is today more likely to be regarded as an obsolete artifice impeding the further advancement of humanity. Instead, progressive time, often perceived as a force of political, economic, and cultural convergence into a preordained destiny, seems to be spilling out of the container of the nation-state and threatening to sweep it away. On the other hand, there is a persistent fear that uncontrolled time is a threat to order and the ascendance of time over space does not go unchecked, as many attempts have been made, in both theoretical and practical fields, to freeze the flow of time into space. Especially, as will be discussed below, essentialist notions of culture are often invoked to justify those attempts. In those attempts, it is the idea of universal progress that is put aside, if temporarily, in favor of some other spatial 
order. Either way, the marriage between the nation-state and human progress is no longer taken for granted.

The dissolution of the link between the nation-state and progress has profound implications for political and social theories, because the latter is, to a substantial degree, predicated on the former. And Political Theory and International Relations are not exceptions to this trend. In fact, it is arguable that the crisis should be particularly acute in these academic fields because the ideas of the nation-state and progress have been the major focuses of these disciplines, either as implicit theoretical assumptions or explicit goals. Moreover, it has been asked whether the practical objective for which these disciplines are put in use is often the advancement and defense of "Western" civilization that privileges the nation-state and progress. ${ }^{10}$ In other words, those disciplines are a part and expression of the political project to make the world safe and, if possible, exploitable for a particular form of civilization, either by the assimilation or exclusion of potentially threatening others.

The ideas of the nation-state and progress have constituted the main grids of the modern world order that emerged from a historically specific experience of the West. Not surprisingly, such order is repeatedly challenged, both politically or intellectually, by repeated encounters with unknown others whose existence cannot be easily located

\footnotetext{
${ }^{10}$ I should have desisted from using such a spatiotemporal category as "Western" or "non-Western" because there is a risk of reifying the spatial opposition of West/non-West. Needless to say, the West or any other spatiotemporal categories are neither uniform nor closed ones. However, I found it impossible to avoid them entirely to make my sentences less cumbersome and awkward. For the remainder of the study, the spatiotemporal categories, such as the West, the non-West, or the East, should be read as "what is conventionally considered as the West," etc.
} 
within it. Instead of revising ethnocentric knowledge, however, the challenge posed by the existence of others has repeatedly been handled by distancing them away from the present time as well as confining them to safely remote spaces, so that Western civilization can continue to occupy a privileged place in human history with minimum efforts for self-reflection and accommodation.

Although the postwar global spatiotemporal order largely eschewed overt racist categories such as "barbarian" or "savage," the main structure of the order survived almost intact with apparently race-neutral but similarly hierarchical spatiotemporal categories—-the North/South, the East/West, the modern/traditional, the advanced/developing, etc. Furthermore, even attempts to revise the spatiotemporal order that privileges the nation-state and progress are often dominated by the same reflexes. Two of the most popular books written about the post-Cold War world order-Francis Fukuyama's The End of History and the Last Man and Samuel Huntington's The Clash of Civilizations - offer an illustrative example of such reflexes. Fukuyama resurrects the Hegelian history of universal human progress and notes that Kantian peace is attained at least among consolidated liberal democracies. On the basis of this assessment, he suggests that as progressive time in domestic space spills over into the international arena, the relations among democratic states is fundamentally transformed from anarchy into a community. As democracy overtakes the last citadel of false ideologies, as it seemed at the time he was writing, the world will be more homogeneous and peaceful (Fukuyama 1992: 245-284). Although he retains the nation-state as the end-point of history, not least because he inherits the Hegelian notion of the modern state as the culmination of human progress, he subordinates them to the inexorable force of convergence exercised by the 
flow of time over spatial diversity. Partially in response to Fukuyama's optimism, Huntington suggests that Fukuyama's history of universal civilization is actually the history of Western civilization proper. According to the former, there is more than one civilization and what matters to the post-Cold War world order are not civilization in the singular but civilizations in the plural (Huntington 1997: 40-41). For him, "a civilization is a culture writ large" (p. 41), and the cultural is much more resistant, if not immune, to change than the political or the economic. Thus, he contends that nine civilizations are replacing nation-states as major units in the post-Cold War world order (pp. 33-35). In this way, Huntington counters Fukuyama's theory of temporal transcendence with a new theory of spatial segmentation on the basis of allegedly essential cultural differences. Fukuyama and Huntington's provocative theses, although far from exhausting the possible alternatives available, represent two influential spatiotemporal frameworks that have been recycled in both popular speech and scholarly texts. Instead of being mutually exclusive, they often work together to enhance the either/or notion of human progress - that is, either Western civilization survives intact or progress perishes with it. What is missing from this limited framing of the debate is the possibility of a cross-cultural dialogue that is mutually enriching for the West and the Rest. Therefore, the alternatives offered by Fukuyama and Huntington turn out to be not so much alternatives as the recycled discourses emanating from the persistent desire and fear of Western civilization.

One of the major intellectual tasks today, therefore, is to navigate between spurious universalism and reactionary particularism by rethinking obscure but consequential 
connections among spatiotemporal order, world politics, and knowledge as an active instrument of politics.

The question of space and time is not new for political theory. Rather, it has been an essential, if often implicit, component of political theory in the Western intellectual tradition. Gunnell (1968) traces back the birth of political philosophy in ancient Greece to the collapse of a cosmological order that completely assimilated human existence into the universe. Cosmological time is ever recurrent and in spite of the coming and going of particular elements therein, the cosmos itself is permanent, just as a river remains even if water flowing in it never stays still. It was understood that human beings partook in this recurrent order, and cosmic and human space/times were not differentiated. As a result, there was no need for a separate body of knowledge about human history and space, simply because such things did not existed. Instead, an "integral myth" representing the atemporal working of the entire cosmos was the symbolic system representing the cosmological order (Gunnell 1968: 25-28).

However, the realization that cosmic and human times were not necessarily aligned with each other led to the alienation of humanity from nature and, with it, a challenge of making sense of human existence. Gunnell identifies two answers to such a challenge: Hebrew teleological history and Greek political philosophy. On the one hand, the Hebrews' experience of displacement from their native land produced a theology that understood human historical existence as a temporal journey from the beginning to a destined end. As a result, Hebrew thought rejects confinement into a fixed spatial order and sought the meaning of human historical existence in preordained history (Gunnell 1968: 54-71). On the other hand, the sudden collapse of the Mycenaean civilization 
resulted in the similar estrangement of human society from the cosmological order. Greek myth contrasted the transitoriness of the mortal humans with the permanence of the immortal gods, but unlike the Hebrews, the Greek philosophers developed "the notion of an imperishable space as a victory over time" (Gunnell 1968: 115). In the wake of the Peloponnesian War that devastated Hellenic civilization and led to the breakdown of the Athenian empire, Plato attempted to replace the Homeric myth, in which the hubristic attempts by mortal heroes to approximate to the immortal was met with tragic ends, with political philosophy that could reorder polis as a microcosm, a conscious recreation of the lost cosmological order (Gunnell 1968: 125ff.).

It is arguable that the two answers to the problem of human estrangement from the cosmic order are precursors to the notions of history and political space in modern political thought. Scholars disagree as to whether modernity should be characterized as the supremacy of time over space or space over time (Walker 1993: 9-11). Yet, as Henri Lefebvre puts it (1991: 175), “[p]henomena which an analytical intelligence associates solely with 'temporality', such as growth, maturation and aging, cannot in fact be dissociated from "spatiality"' because time can be experienced only through movements registered in space. We know that time has passed when something that was not there is there now, or when something that was there is no longer there. That means that any human agency in history entails the conscious creation and maintenance of spatial order, and progress, a secular version of teleological history, demands a particular type of spatial order - the sovereign state. Therefore, modernity, from the very beginning, has been characterized by a duality: the acceptance of the temporality of human existence and the search for a permanent spatial order on the basis of eternal and immutable principles. 
Baudelaire's formulation, quoted by Harvey (1989: 10), nicely captures this duality:

"Modernity is the transient, the fleeting, the contingent; it is the one half of art, the other being the eternal and the immutable."

It was Machiavelli who reintroduced the flux of time, personified in Fortuna, as a crucial problem for political order. His new science of politics was an attempt to find a way to subdue contingent time by means of the maintenance of political order, the state. In Hobbes' Leviathan, human history was radically reduced to the transition between two starkly contrasting spatial orders - the state of nature and the state presided by the absolute sovereign. Although neither Machiavelli nor Hobbes conceptualized history in terms of teleological progress, it is arguable that, in both cases, the accumulation of time in well-maintained political space was defended as a necessary precondition for good life. Yet, the search for eternal and immutable principles upon which political order should be built culminated in Hegel's theory of the modern state in which, according to Lefebvre, the subordination of time to space was complete:

According to Hegelianism, historical time gives birth to that space which the state occupies and rules over. History does not realize the archetype of the reasonable being in the individual, but rather in a coherent ensemble comprised of partial institutions, groups and systems (law, morality, family, city, trade, etc.). Time is thus solidified and fixed within the rationality immanent to space. The Hegelian end of history does not imply the disappearance of the product of historicity. On the contrary, this product of a process of production which is animated by knowledge (the concept) and oriented by consciousness (language, the Logos) — this necessary product — asserts its own self-sufficiency. It persists in being through its own 
strength. What disappears is history, which is transformed from action to memory, from production to contemplation. As for time, dominated by repetition and circularity, overwhelmed by the establishment of an immobile space which is the locus and environment of realized Reason, it loses all meaning. (Lefebvre 1991: 21) Post-Hegelian thinkers-Marx among others — responded critically to the "fetishization of space in the service of the state" (Lefebvre 1992: 21) and tried to shift the emphasis from the space of the modern state to historical time. Yet, Hegelian statism somehow survived the demise of his metaphysics and continues to be influential to this day. The notion that the modern state is simultaneously the precondition for, the container of, and the result of human progressive history has persisted until today.

Even today, political order is understood as a conscious arrangement of different elements in space so that fleeting time can be frozen and accumulated into a particular place. It aims to identify distinctive elements in society and organize them into a harmonious and self-sustaining whole, a microcosm of the universe insulated from the force of contingent time. Political order thus organized is expected to defy temporal transitoriness, associated with decay, corruption, degeneration, and, ultimately, death. As a result of the separation of the political as an autonomous sphere, time is now associated with the social realm, which can be both the driving force of history and the major spring of chaos, while the political is considered a question of order, stability, and uniformity. Gunnell describes the common thread that runs through ancient and modern political theories as follows:

For much of political philosophy from Plato to Rousseau society or the subpolitical realm appeared as the great beast to be tamed by the imposition of political order. 
Society was the realm of anxiety, instability, uniqueness, and temporality; it was the scene of necessity, the arena of the passions, and the root of human disorder.

Despite the intellectual gulf which separates Plato and Rousseau, both ultimately understood the political as a means of containing society and abolishing history. (Gunnell 1968: 249)

The original mission of political philosophy to subdue time by means of political order, for the purpose of securing human existence, can be easily extended to contemporary political scientists, as attested by the title and contents of Samuel Huntington's modern classic, Political Order in Changing Societies (1968). Perhaps, Gunnell overstates his case by citing the names of Plato and Rousseau, two manifestly unprogressive theorists of political space, as representative of political philosophy, but even if all modern political theorists do not intend to entirely abolish history, their wariness of the social and desire to tame it by means of political order are discernible even in the thought of progressive thinkers such as John Stuart Mill. Generally, in modern political theory, the task of politics is understood as channeling the dynamics of the social into a desirable direction by actively rearranging spatial order in a way that is conducive to the accumulation of time in a particular space. Political Theory and International Relations are expected to provide the administrators of political order with a practical conceptual map according to which the social is domesticated under political order.

The interpretation of Yanagita's texts offered in this study allows us to connect his minzokugaku to Political Theory and International Relations by pointing to the fact that the question of political space and history occupies a central place in his thought. The connection between Yanagita and Political Theory/International Relations is not a mere 
coincidence. His lifetime coincided with the period when Japan was undergoing the radical transformation of its spatial and temporal consciousness. ${ }^{11}$ As Ronald Morse aptly puts it, "[t]he changes that occurred during those eighty-eight years [of Yanagita's lifetime] were so profound and the results so far reaching that it is hard to imagine that one man's life could have spanned them all. Born in an era of the rickshaw, he lived to see the use of jet airplanes. During his youth he witnessed famine and infanticide, yet before he died Japan was the most advanced nation in Asia" (Morse 1990: xvi). Those visible technological and socioeconomic changes are only part of a larger process known by the name of "modernization," or a movement from the "traditional" to the "modern" era. It demanded no less than a radical redrawing of the country's political, economic, and cultural maps and the makeover of people's spatial and temporal consciousness. The new Japanese political and intellectual leaders understood too well that modernization and Westernization were interrelated, as suggested by an official slogan of modernization efforts during the Meiji period: “Exit Asia, Enter Europe (datsu-a nyū-ō 脱亜入欧).” That is, Japan would become "modern" only by reordering national space after the Western model and inserting itself into the Eurocentric international society. As a result, the organization of spatiotemporal categories in Japanese was radically changed, as the Western/Japanese opposition was added to the existing spatial divides between the rural

11 In spite of Gunnell's somewhat evolutionary history of human consciousness from cosmological to political and teleologico-historical orders, cosmological order is not necessarily limited to ancient times or entirely lacking the consciousness of human historical existence. At least, in light of Yanagita's historiography, myth has been the major mode of understanding the world for the Japanese rural population well into the late-nineteenth and early-twentieth century. Moreover, he reinterprets the cosmological order in the Japanese countryside by claiming that it is a product of the more or less conscious collective will to maintain spatial order in the midst of temporal change. 
and the urban. Needless to say, the urban and the Western was now equated with the new and the better, whereas the rural and the Japanese or Eastern with the old and the worse. In the course of the transformation, the cosmological order that had underpinned the preexisting spatial order in the countryside was relegated to the category of superstitious beliefs.

Yanagita belonged to the generation who experienced the acute sense of disorientation because of the breakdown of the prior cosmological order with no clear alternative in sight. It is not surprising, therefore, that the question of space and time occupies a central place in his thought. In this sense, his experience is not radically different from those of many Western modern thinkers. Hope and enthusiasm for a better future, on one hand, and a sense of loss and nostalgia, on the other, is the hallmark of his ambivalence toward modernity as well. He shared with progressive nationalists the notion that the creation of national political order was the precondition for and the immediate goal of progress. However, his ambiguous spatial affiliations-being born in a agricultural community but not part of it, being an urban elite from a semi-peripheral nation, being both at the center and the periphery - made him keenly aware of the arbitrariness of the existing boundaries, internal or international. In consequence, he refuses to assimilate himself into any of the existing spatiotemporal categories - neither modern nor traditional, neither rural nor urban, or neither Western nor Eastern.

The ambiguity of Yanagita's spatial affiliation allows him to approach the problem of the modern spatiotemporal order from the perspective of not only those at the center but also those whose voice is systematically suppressed and misrepresented - that is, the other of the modern, the urban, and the Western. The characteristic makes his critical 
engagement with the question of space and time somewhat inaccessible, but on closer inspection, enormously insightful to the modern, urban, and Western/Westernized students of world politics.

\section{Spatiotemporal Order and the Question of Others}

With the global expansion of the West, the idea of the nation-state as the precondition for as well as the culmination of human progress has become the central grid of the modern spatiotemporal order. By the modern spatiotemporal order, I mean an order that, in the most basic form, divides global space into "progressive" and "stagnant" spheres. It is a product of the West's efforts to organize, both in theory and in practice, the global space, and it has both material and ideational aspects: the organization of institutionalized practices and symbolic representation of such a organization. Without doubt, the modern spatiotemporal order reflects the interests of powerful social classes or states. However, it is a hegemonic order in the sense that it aspires to be a complete and universal order, but falls short of being so. It has had a far-reaching influence on how people think and act by legitimating certain ideas and practices in exclusion of others. Like any other order, it is also self-reproductive to some degree in the sense that it simultaneously legitimates and is legitimated by the imposition of itself upon different spatiotemporal orders. That is not to say that the inscription of a uniform global space over diverse local ones completely annihilated the latter, but tensions between new and old orders remain and have given impetus to the dynamics of modern world politics. What Anthony Giddens calls "disembedding" - " "the lifting out' of social relations from local contexts of interaction and their restructuring across indefinite spans of time-space 
(Giddens 1990: 21)"- -is countered by various attempts to rein in its fleeting process of "lifting out." 12

The full exposition of the modern spatiotemporal order is a formidable task by itself, because there have been various conceptual expressions and has been in a state of constant flux. Although a complex process through which this spatiotemporal order has evolved is beyond the scope of this study, it is important to note that its origin can be traced to two parallel but interrelated events at the roots of modern international relations, in which the question of cultural diversity became an explicit concern for European theorists. The first was an intra-European process in which sovereign states gradually emerged out of the disintegrating feudal order. The Peace of Westphalia of 1648, where the concept of territorial sovereignty was officially accepted as the organizing principle of the European political system, is conventionally deemed to be a milestone for modern international relations. The space of the sovereign state was originally conceptualized as a

${ }^{12}$ In this regard, Henri Lefebvre's distinction of three aspects of space seems relevant. He argues that social space has three dimensions: social practice, representation of space, and representational space, corresponding, respectively, to the perceived, the conceived, and the lived experiences (Lefebvre 1991: 38-42). It is worth emphasizing why Lefebvre makes it a triad, not a dyad of mental representation and social practice. The triad is intended to go beyond the conventional binary opposition between idea and matter, the mind and the body. (Lefebvre 1991: 40). What differentiates "representational space" from "representations of space" is that the latter is conceived space, that is, conceived by the minds of intellectuals, scientists, or artists who stands outside of the space they are creating. The latter is space sensed not only mentally but also as a bodily experience of those who live there. In other words, the former is the abstract, the latter the concrete. Lefebvre argues that representational spaces survive the superscription of representations of space, often in the form of "more or less coherent system of non-verbal symbols and signs" (Lefebvre 1991: 39). It can be argued that a major object of Yanagita's minzokugaku is to verbalize such systems of symbols and signs that persisted in rural communities in order to use it as a mirror upon which the modern conceptual representation of space is reflected. 
realm of order insulated from a chaotic or decaying world. As Inayatullah and Blaney (2004: 21-45) argue, however, it was partly because of the problem of cultural difference, in the form of religious conflicts between Roman Catholics and Protestants descending into the devastating Thirty Years' War, that the principle of state sovereignty was accepted. Nevertheless, Inayatullah and Blaney suggest, it is just a "deferral," not a solution, of the problem of difference because whereas the principle of sovereignty allows mutual toleration of cultural others beyond state borders, it externalized difference in the form of foreign threats and justified the assimilation of internal others.

The second origin, which has long been neglected in International Relations theory, is the Europeans' encounter with and subsequent subjugation of others, especially the conquest of America (Todorov 1999; Jahn 2000; Inayatullah and Blaney 2004: 47-91). The "discovery" and subjugation by the Spaniards of the Amerindians, whose existence had been completely unknown to the European and therefore had no place in European theoretical knowledge, posed a formidable intellectual challenge. The Spaniards' response to this challenge would later become a template with which they incorporated otherness into their own knowledge in the course of the further global expansion (Inayatullah and Blaney 2004: 47-91).

According to Tzvetan Todorov, contacts between two different cultures tend to produce two apparently conflicting but mutually reinforcing movements: equalization through assimilation and establishment of hierarchical relations on the basis of difference. This "double movement" (Todorov 1999: 50) was present in the fateful first encounter between the European and the Amerindian: 
Either [Columbus] conceives the Indians (though without using these words) as human beings altogether, having the same rights as himself; but then he sees them not only as equals but also as identical, and this behavior leads to assimilationism, the projection of his own values on the others. Or else he starts from the difference, but the latter is immediately translated into terms of superiority and inferiority (in his case, obviously, it is the Indians who are inferior). What is denied is the existence of a human substance truly other, something capable of being not merely an imperfect state of oneself. These two elementary figures of the experience of alterity are both grounded in egocentrism, in the identification of our own values with values in general, of our $I$ with the universe - in the conviction that the world is one. (Todorov 1999: 42-43)

From the standpoint of the conquered, the double movement presents itself as a choice between two bleak options: Either to seek equality at the price of assimilation, or to be stigmatized as inferior and subjected to the conqueror's paternalistic protection.

The Peace of Westphalia and the Conquest of America were connected events, because the latter gave rise to the notion of the state of nature, which, in turn, modern political theorists used to justify the sovereign state (Jahn 2000). The association of the Native Americans with the state of nature led to the temporalization of spatial difference, whereby cultural others the European encountered in the course of their global expansion were ranked according to their location in a linear developmental sequence from the state of nature to the establishment of the nation-state. At the top of the hierarchy are the European nation-states, and at the bottom "stateless" or "nationless" peoples—-that is, 
"primitive tribes" living in the state of nature - and each stage is associated with a distinct spatial order or the absence of it.

Such an understanding of world space and time has far-reaching ramifications for the development of Western social sciences and political theory. According to Ronald Meek (1976), the encounter with the American Indians gave inspirations and materials to what he calls "four stages theory." The theory, perfected by Adam Smith and Anne-Robert-Jacques Turgot around 1750s, formulated social progress in terms of the succession of four modes of subsistence-hunting, pasturage, agriculture, and commerce — with each stage having its corresponding institutions and ideas. The idea that the mode of subsistence is the base upon which a particular mode of politics and culture is built laid the groundwork for the development of modern anthropology and sociology and became a direct precursor of Marx's historical materialism (Meek 1976: 229). Equally, Uday Singh Mehta (1999) emphasizes the influence of British India on the development of liberal thought. In his assessment, the self-understanding of liberalism is substantially shaped by its engagement with the question of India. Liberal thinkers thought India to be "the promised land of liberal ideas—a kind of test case laboratory" (p. 9), and, in contrast to Edmund Burke, eagerly took part in the civilizing project.

The impact of the modern spatiotemporal order is widely recognized in the case of international colonialism, but even those countries that maintained its nominal independence did not escape it. The new Japanese leadership understood the logic of the modern spatiotemporal order too well and embarked on the mission of "civilizing" the inhabitants of the Japanese archipelago by nation-building from above. In Bunmeiron no gairyaku (文明論の概略 An Outline of a Theory of Civilization, 1875), for example, 
Fukuzawa Yukichi (福沢諭吉), a leading intellectual in the early Meiji period, accepts the tripartite division of the world into civilization (bunmei 文明), barbarism (hankai 半 開, literally half-enlightened), and savagery (yaban 野蛮), which was in wide use in Western discourses at the time, and characterizes it as the three stages of human progress. (Fukuzawa 1995: 26-27). According to him, Japan, along with China, Turkey, and other Asian countries, is in the stage of hankai (p. 25). Based on this assessment, Fukuzawa, to whom the coining of the slogan "Exist Asia, Enter Europe" is attributed wrongly but not unreasonably, exhorts the Japanese people to emulate not only the material but also the spiritual aspects of Western civilization. ${ }^{13}$

The superimposition of the abstract space of the sovereign state upon preexisting social space, however, had much more extensive and profound political ramifications than is usually recognized. Ironically, to the extent that national space was successfully reorganized according to the modern spatiotemporal order, the nation found itself more split between the urban, Westernized elite and rural people who continued to live in their own respective space and time. However, the urban elite tended to react to the problem of internal others with the reflexes of a "double movement," thus reproducing the global cultural hierarchy at the national level. As a result, the bulk of the national population

13 It is known that Bunmeiron no gairyaku draws heavily on François Guizot's General History of Civilization in Europe and Henry Thomas Buckle's History of Civilization in England, along with John Stuart Mill's Consideration on Representative Government, On Liberty, and Principles of Political Economy (Matsuzawa 1995: 368-369). In previous works, such as Shōchū bankoku ichiran (掌中万国一覧) or Sekai kunizukushi (世界国 尽), Fukuzawa used the four-stage theory, placing konton (混沌 chaos or anarchy) before the three stages of yaban, hankai, and bunmei. See the endnote to the page 25 by the editor of the Iwanami edition of the text (Fukuzawa 1995: 311) 
was denigrated as "traditional" or "backward" other, in spite of formal equality granted to all Japanese nationals, and became the object, rather than the subject, of knowledge production and the politics of nation-building.

\section{Yanagita and Minzokugaku}

Although Yanagita was interested in folklore and ethnology from early on, the institutionalization of minzokugaku as an academic discipline came late in his lifetime and perhaps not in a completely satisfying form for him. It is difficult to pinpoint the specific date of the establishment of minzokugaku, but the history of the Folklore Society of Japan traces its origin to minkan denshō no kai (民間伝承の会) established at a seminar commemorating his sixtieth birthday in the summer of $1935 .{ }^{14}$ The object of this study is not to examine the discipline of minzokugaku per se, but the evolution of Yanagita's thought that culminated in minzokugaku and mainly covers the period spanning from 1900 to 1935 . The section offers a brief biography of Yanagita up to the point of the establishment of minzokugaku. ${ }^{15}$

\footnotetext{
${ }^{14}$ Nihon Minzokugakkai, Gakkai ni tsuite, http://www.fsjnet.jp/about_us/about_us.html (accessed September 21, 2011).

15 The information offered here draws on the chronological record of Yanagita's career in Teihon (sup. 5: 619-661), his autobiography, Furusato nanajūnen (故郷七十年 Teihon sup. 3), and several other biographical works by others, including Yanagita Kunio Kenkyū Kai (1988), Okaya (1985; 1991; 1996), and Fujii (1995). For the reader who is not familiar with Japanese, the best biographical information of Yanagita's life can be found in Morse (1990).
} 
Yanagita was born on July 31, 1875, as the sixth son of Matsuoka Misao (松岡操) and Take (たけ). ${ }^{16}$ Tsujikawa, Hyōgo Prefecture, where Yanagita was born and spent his early childhood, was a small agrarian community, a kind that he himself would later make the object of his study. However, the household of Matsuoka had abandoned agriculture several generations ago and his father was a village intellectual steeped in Confucianism and nativist thought (kokugaku). The fact that the Matsuoka family was non-farmer seems to have kept the relations of the Matsuoka family with other villagers somewhat at arm's length. At age eleven, because of the financial hardship of the family and his own health problem, he left Tsujikawa to live in Fukawa village, Ibaraki Prefecture, where his eldest brother had opened a clinic. Later, his parents and younger brothers followed him, and the Matsuoka family was completely uprooted from their native place. In 1890, Yanagita moved to Tokyo to prepare for the university entrance exam, and, from then on, Tokyo became his permanent base.

During his youth, he put his heart into literature, both Japanese and Western. In 1890, with the introduction of Inoue Michiyasu (井上通泰), his biological brother and a politically well-connected ophthalmologist, he became a pupil of Matsuura Tatsuo (松浦 辰男), the master of the Keien School (桂園派) of waka, or the 31-syllable Japanese poem. Also under his tutelage was Tayama Katai (田山花袋), who would later become a

\footnotetext{
${ }^{16}$ Yanagita was born as Matsuoka Kunio (松岡國男) and became Yanagita Kunio when he was adopted by the Yanagita family as heir successor to the headship of the household in 1901, to marry one of the Yanagita daughters three years later. The practice was not uncommon in prewar Japan as a means to preserve family lineage when a household had no male child. To avoid confusion, the subject of this inquiry is referred to as Yanagita, regardless of the period in question, unless explicitly indicated.
} 
leading figure of the so-called naturalist novel. Yanagita and Tayama became lifetime friends, although their relations became strained later because of Yanagita's critical attitude toward Tayama's self-confessional novels, in which characters modeled after Yanagita made frequent appearances. Also, he acquainted himself with Mori Ōgai (森鴎 外), a military doctor educated in Germany and a pioneer of the Japanese modern literature. Even after entering the Department of Law of Tokyo Imperial University, a training ground for future high-ranking government officials, in 1897 and majoring in agricultural policy science, his passion continued to be literature, and especially non-Anglo-American Western literature grew on him. Yanagita, Tayama, and other young writers published a collection of prose poems, Jojōshi (抒情詩 Lyric Poetry), in 1897. It was the first kind of a free-style poetry, called shintaishi (新体詩 new-style poetry) in opposition to the Chinese and Japanese style poetries with rigid rules of syllables. Yanagita's poems, which showed the influence of the Keien school and European Romanticism, were acclaimed as a best representative of the new form.

However, Yanagita suddenly lost interest in poetry and abandoned it for good in 1900. Instead, he turned his passion to agricultural policy science. After graduating, he entered the Ministry of Commerce and Agriculture and started a professional career as an elite bureaucrat. In 1901, to the surprise of his friends in the literary circle, he accepted an offer of being adopted into the household of Yanagita Naohira (柳田直平), a Supreme Court Justice, as his heir successor. Some old friends of his, who once admired him as a handsome Romantic poet, regarded the adoptive marriage as a sellout to careerism. ${ }^{17}$ Yet,

${ }^{17}$ Throughout his life, Yanagita kept reticent on the reason for his abandonment of 
he continued to play a leading role in the development of the modern Japanese literature, hosting various literary societies into which many promising young writers were attracted. Although he himself did not produce any novel, he provided Tayama Katai with inspirations and ideas, until he became upset with the latter's naturalist novels. Yanagita's classic, Tōno monogatari (遠野物語 The Tales of Tōno, 1910), a collection of folktales from northern Japan, was written partly as an implicit criticism of the triviality and lack of social contents of naturalist self-confessional novels in which the interiority of urban individuals were obsessive concerns.

Yanagita's intellectual career covered in this study can be divided into four periods, some of which are partially overlapping. The first period spans the years 1900 to 1910 , when he started a promising professional career as an elite bureaucrat-intellectual specializing in agricultural policy and was actively involved in policy debates on agrarian problems. Under the heavy influence of the German Young Historical School of Economics, his political and economic vision during this period was largely progressive and reformist with a strongly statist proclivity. Well acquainted with the experience of Western societies, he believed that appropriate government policies could rationalize

poetry and the adoptive marriage, but it seems that the death of loved ones loomed large in the mind of the sensitive youth at this period. He had lost his mother and father successively in the summer of 1896. And, the deterioration of his own health forced him to spend some time in a sanatorium. Yet, Tayama Katai's self-confessional novels indicate that a love affair with a girl from Fukawa, which seems to have ended tragically with her death from tuberculosis, was the major factor for his ultimate disillusionment with Romantic poetry. From that point on, his early Romanticist infatuation with death gave way to the pragmatic study of the real life of the common people. However, the question of death continued to follow him in the form of his interest in the strange and unfamiliar from the invisible world and, then, the role of religion in rural life. Okaya $(1991 ; 1996)$, who documented the biographies of poet Matsuoka Kunio (i.e. young Yanagita), emphasizes the lifelong impact of the tragic love affair on his thought. 
Japanese national economic space better than the free market system. He seemed to accept the elitist claim that in determining the public good, the intellectual elite, who was deemed the possessor of impartial knowledge, rather than self-interested private actors in the market, should be accorded a privileged position. Based on this confidence, Yanagita did not shy away from proposing various measures that aimed to rationalize, both at the macro- and micro-level, the use of national space, even at the cost of antagonizing powerful rural and urban interests. It was partly because of his aloofness from powerful special interests that his proposals largely fell on deaf ears. However, what troubled him even more, his vision was equally rejected by small farmers, whose interests he was trying to protect. He partly attributed this reaction to the ignorance of rural folks, as many other progressive intellectuals had done. However, he was humble enough to admit the inadequacy of his own knowledge, and knowledge possessed by state bureaucracy and academia in general. Accepting the partiality of modern knowledge, in both senses of the word, opened a possibility that those rural folks were possessors of partial knowledge as well.

In the second intellectual period between 1910 and 1919, Yanagita's growing dissatisfaction with the bureaucracy-academia complex led him away from agricultural policy science to an unrecorded history of rural life and the shadowy presence of wandering peoples behind it. During this period, Yanagita's understanding of space and time took an anthropological turn. As he became disillusioned with partisan politics and a bureaucratic career, his public engagement with agricultural political economy became sporadic. Instead, he was increasingly absorbed into his "hobby," that is, the study of folktales and traditional customs, especially those related with religious beliefs, in rural 
Japan. As a result, his attention was diverted from the contemporary condition of rural life to those who have lived on the margin of agrarian society, such as yamabito (山人 mountain people), wandering priest and priestesses, hunters, entertainers, prostitutes, and crafters of wood tableware. Even after being appointed fourth Secretary General of the House of Peers in 1914, he continued to travel extensively to the interior of Japan and was surprised by the fact that the "barbarous" elements stubbornly remained in the midst of civilization. As a result, he became increasingly critical of the notion of the Japanese national space as a homogeneous container where time simply flowed from the past to the future. In contrast to the notion of empty space implicit in Western theoretical knowledge and flat urban social landscapes depicted in highly individualistic "modern" novels of his friends, he found that the life and death of rural folks were embedded in rich textures of ecological, cultural, and even a hint of ethnic diversity. During this period, he started to explore anthropological space as the true basis for cultural differences.

The third period was brief but was an important turning point in Yanagita's thought. The shift was catalyzed by a series of journeys he undertook after resigning from the bureaucracy in December 1919 as a result of a personal feud with Tokugawa Iesato (徳川 家達), a scion of Tokugawa family and then President of the House of Peers. The first leg of journey consisted of journeys to the Northeast, which was popularly considered the most backward and barbarous region in the mainland. The second leg is a journey to Okinawa and other southern islands, another periphery within Japan. The third is his voyage to Europe and stay in Geneva, where he served the League of Nations Permanent Mandate Commission from 1921 to 1923 . His excursion into the internal and global 
centers and peripheries expanded Yanagita's spatial horizon. Subsequently, he came to perceive the world order as a set of multiple layers of hierarchical relations. As a result, he situated the predicament of the Japanese people in a global context, in which urban centers, with the help of foreign technology and knowledge, established political, economic, and cultural hegemony over the rural population. In a surprising move, he identified Japan with the South Pacific islands, rather than Western nation-states, on the basis that both were islands susceptible to internal strife and external intervention.

The fourth intellectual period began in 1923, when, on the news of the Great Kantō Earthquake, Yanagita hastily resigned his post on the Permanent Mandate Commission and returned from Europe. He had been invited to join the editorial board of Tokyo Asahi (東京朝日), a liberal newspaper, and became one of its editorial writers until 1929, when he quit the board. As a journalist, he was an unwavering supporter of universal suffrage and other democratic reforms introduced during the last stage of the period known as Taishō democracy (approximately 1905-1925). At the same time, he vigorously worked for the establishment of minzokugaku. During this period, he shifted his attention back from wandering peoples on the margin of agrarian society to the inhabitants of agricultural communities. The concept of jomin (常民 the common people) gained prominence during this period, as minzokugaku could be defined as the study of jōmin, by jōmin, for jōmin. Jōmin, one of the rare abstract concepts Yanagita used in his writings, refers to denizens of anthropological space, where history is made through culturally distinct social institutions and practices. The purpose of minzokugaku was to excavate the history of anthropological space, the world of jomin, in the service of nation-building from below. 


\section{Plan of the Dissertation}

The main body of the dissertation consists of three chapters, each of which addresses one of the three hypotheses presented in this chapter. Organizing the study in this way allows us to follow the evolution of Yanagita's thought in a more or less chronological order. The second chapter examines the intellectual and political contexts in which Yanagita confronted with John Stuart Mill's philosophy of history, and interprets his texts against the backdrop of those contexts. The third chapter focuses on his turn to a Marxian notion of anthropological space in an attempt to offset Mill's individualistic notion of progressive agency and explores the theoretical connections and major differences between Yanagita and Marx's thought. The philosophical foundation of his agrarianism and concept of jomin are the major topics of this chapter. The fourth chapter examines the notion of travel as a method of knowledge production by tracing it back to his Malthusian wariness toward the possibility of progress and his interest in wandering people during the second intellectual period. The concluding chapter recaps the major points of previous chapters and explores its implications for contemporary debates on diversity and world politics and the theoretical framework and methods of Political Theory and International Relations. 


\section{CHAPTER II}

\section{DIVERSITY AND ENLIGHTENED DESPOTISM}

One of the interpretive hypotheses of the study is that Yanagita's intellectual project can partly be understood as a critical engagement with John Stuart Mill's philosophy of history, especially the one expressed in his most primed text, On Liberty. This interpretation runs counter to the conventional understanding of his ideological orientation, which depicts him as a Burkean conservative (Hashikawa 1985; Nakamura 1974; Satō 2004) or a representative of "conservatism always willing to converse with progressivism" (Tsurumi 1973: 154). Although this characterization is not totally off the mark, as Yanagita sometimes characterizes himself as conservative, it does not capture the entire picture of his intellectual project. Rather, it is more plausible to think that it is through a critical engagement with Mill's philosophy of history that he became appreciative of Burkean conservatism.

Mill's influence is of special importance for this study because it seems to have been through his On Liberty that Yanagita confronted the problem of the global spatiotemporal order and the question of diversity. The relationship between the text and his thought is far from straightforward, however, partly because On Liberty is a text with an equivocal meaning for any non-Western progressive. On the one hand, the text justifies non-democratic governments in less developed societies. On the other, Mill's defense of diversity as a necessary condition for knowledge production and social progress has a critical potential to challenge the political and intellectual hegemony of the 
West and the Westernized. While troubled by Mill's ethnocentrism, Yanagita must have taken the following passage from On Liberty to heart:

What is it that has hitherto preserved Europe from this lot [of stagnation]? What has made the European family of nations an improving, instead of a stationary portion of mankind? Not any superior excellence in them, which, when it exists, exists as the effect, not as the cause; but their remarkable diversity of character and culture. Individuals, classes, nations, [and, Yanagita would have added, regions within a nation] have been extremely unlike one another: they have struck out a great variety of paths, each leading to something valuable; and although at every period those who traveled in different paths have been intolerant of one another, and each would have thought it an excellent thing if all the rest could have been compelled to travel his road, their attempts to thwart each other's development have rarely had any permanent success, and each has in time endured to receive the good which the others have offered. Europe is, in my judgment, wholly indebted to this plurality of paths for its progressive and many-sided development. (Mill 1991: 80)

However, in this passage Mill is explaining the secret of European superiority, and his tolerance toward diversity stops at the border of Western civilization. Beyond that border, differences or deviance from the standards set by the Western example are translated into the sign of immaturity caused by either infantile impulsiveness or submissiveness of people. ${ }^{18}$ Such kind of diversity is not conducive to progress and must be reduced to a

${ }^{18}$ Mill uses the term barbarian at least in two senses in his texts. The term is simply used as a synonym of savage - that is, the pre-agricultural and pre-political state of society composed of highly independent individuals or groups of individuals, conventionally associated with the American Indians. He also calls barbarian those old, 
tolerable level. In other words, diversity should be tolerated and encouraged in domestic and international relations within Europe, but in non-Western societies, governments should be granted the despotic power to bring people into line.

The apparent contradiction - diversity and pluralism for Western societies and homogeneity and hierarchy for non-Western societies - turns out to be no contradiction if one takes Mill's analogy between children and "immature races" seriously. In fact, the analogy is not Mill's invention. The idea that human race, just like an individual, has its own age and the existing differences among the world population actually reflects the stages of development through which human race matures was widely accepted in Western discourse when Mill wrote the passage. Two types of diversity—one expressed by mature Western individuals and nations and the other expressed by immature non-Western peoples—characterize Mill's distinction. The limited tolerance toward diversity, made contingent on the spatial location in which diversity has manifested itself,

agricultural civilizations of the East, such as India and China, where, according to his assessment, paternalistic government suppressed individuality and stifled social progress. Therefore, there are at least two kinds of barbarians in Mill's thought, one with excessive individuality and the other with little or no individuality. Although Mill was more interested in the contrast between the civilized and the barbarian (i.e. non-civilized) than in variance among barbarians, Beate Jahn (2005: 615) identifies four stages of social development in Mill's philosophy of history: savagism, slavery, barbarism, and civilization. Mill suggests in Considerations on Representative Government that slavery is a necessary stage to raise the savages out of savagism by disciplining them for collective life (Mill 1991: 232). It is possible that Mill thought the prolonged state of slavery under excessively paternalistic government perpetuates the state of dependence, resulting in barbarism. If this interpretation is correct, civilization and barbarianism are two alternative outcomes as well as two consecutive stages of social development. According to Mill, only Europe managed to transit from barbarism to civilization because of pluralist and decentralized social organizations. This interpretation is partially corroborated by Mill's belief that civilization can be reverted to barbarism (e.g. Mill 1991: 103) and his fear that Western civilization is confronting such a prospect with the advent of mass democracy. 
places a severe limit on the possibility of democracy in non-Western societies. In so far as non-Western people exhibit immaturity, or, to put it more blatantly, in so far as non-Western people remains non-Westernized morally and politically, the government is justly granted the wider discretion to intervene society and individual life, though the purpose of such intervention is limited to lifting them out of immaturity.

Although Japan escaped the fate of being directly colonized by foreigners throughout its known history, the political and intellectual elites influenced by foreign cultures often looked down on the internal diversity of their own country with the same kind of arrogance, apprehension, and intolerance as those harbored by foreign rulers. They had limited knowledge about the space outside urban areas, but that did not deter them from claiming that they knew better about Japan than anybody else. The division of society into the knowing subjects and known objects of knowledge/politics had happened in the sixth century, if not before, when the Yamato Dynasty tried to reorganize society according to conceptual space imported from China. Then, in the wake of the Meiji Restoration of 1868 , new political leaders, using abstract spatiotemporal categories imported from the West, tried to give forms to the opaque and seemingly disorderly space by drawing and redrawing boundaries, giving a name to each spatial unit, and assigning each of them a proper place and function in the national political, economic, and cultural system. Whatever escaped from this new political, economic, and cultural map was deemed irrelevant to knowledge production and undesirable for the integrity of the nation. Internal differences might be accepted and even appreciated as folk "traditions" and "customs," as long as they did not threaten the legitimacy of the central government, but beyond that point, they had to be neutralized. 
The gaze of those political and intellectual elites was that of the modern state. As James Scott's (1998) examination of various devastating development projects indicates, the state, in an "attempt to make a society legible, to arrange the population in ways that simplified the classic state functions of taxation, conscription, and prevention of rebellion" (Scott 1998: 2), ignores local perspectives and has given rise to hubristic interventions in nature and society. Particularly, agriculture emerged as a main target of bureaucratic intervention, because "[a]griculture is, after all, a radical reorganization and simplification of flora to suit man's goals. Whatever their other purposes, the designs of scientific forestry and agriculture and the layouts of plantations, collective farms, ujamaa villages, and strategic hamlets all seemed calculated to make the terrain, its products, and its working force more legible — and hence manipulable—from above and from the center" (Scott 1998: 2). The bureaucratic state that was emerging in Japan in the early twentieth century shared a similar penchant for hubristic intervention, and, in spite of his sympathy with the plight of farmers, it is not difficult to recognize in Yanagita's early writings an expression of the state's desire to make complex and opaque nature and society transparent, intelligible, and manipulable.

Yanagita, however, soon became an internal critic of this "progressive" alliance of administrative power and academic knowledge. In so doing, he turned the Millian defense of diversity against the Millian justification of enlightened despotism. Enlightened bureaucrats and scholars, instead of lifting immature peoples from the despotism of custom, were leading them into another kind of despotism —namely, that of authoritative knowledge imported from abroad. His subsequent intellectual project culminating in the establishment of minzokugaku can be interpreted as efforts to extend a 
democratic potential in Mill's defense of diversity to non-Western space. Thus, his minzokugaku is a Millian project only in a paradoxical sense - paradoxical because in an attempt to carry Mill's defense of diversity to a logical conclusion, he turned Mill's political theory into a very different thing.

The remainder of this chapter examines how and why Yanagita became critical of enlightened despotism that emerged in Japan, of which he was once part, by examining his early writings on agricultural policy science and the intellectual and political contexts in which they were written.

\section{Two Faces of On Liberty}

John Stuart Mill's On Liberty has two faces. It offers at once a sweeping defense of freedom in Western societies and an equally sweeping justification for non-democratic governments in non-Western societies. It is easy to dismiss Mill's discrimination against "immature races" as an unfortunate but ultimately dispensable expression of ethnocentrism common in his time and to read his defense of liberty separately from his defense of colonialism. By doing so, however, we risk overlooking the fact that his defense of liberal democracy and his theory of international relations are internally connected through a philosophy of history based on the global spatiotemporal order. Although blatant racism exhibited by Mill is certainly discredited as a public discourse today, the same cannot be said about his philosophy of history because the contemporary world order is still informed by the same spatiotemporal order that informed Mill's philosophy of history (Jahn 2005). 
In On Liberty, Mill attempts to defend freedom of speech and action on a ground other than natural rights theory. He offers a utilitarian defense of liberty by linking free and open discussion with social progress. His defense of diversity is in turn based on the epistemological claim that absolute truth is unreachable to the fallible human intellect and the best humans can do is to subject any received opinion to constant public scrutiny. Only those opinions that survive such scrutiny gain the temporary status of true knowledge or knowledge of truth until a new challenge is posed against them. A passage from On Liberty reads:

There is the greatest difference between presuming an opinion to be true, because, with every opportunity for contesting it, it has not been refuted, and assuming its truth for the purpose of not permitting its refutation. Complete liberty of contradicting and disproving our opinion, is the very condition which justifies us in assuming its truth for purposes of action; and on no other terms can a being with human faculties have any rational assurance of being right. (Mill 1991: 24)

Thus, for Mill, even a true opinion, if not repeatedly tested in free and open discussion, become "a dead dogma, not a living truth" (p. 40). If this happens, he suggests, opinions will be accepted not because they are true or just but because it is customary to do so, and the exercise of reason will be replaced by blind deference to what is already established as true or just. Resulting from this is what he calls "the despotism of custom" (p. 78).

Progress, as understood by Mill, results from the accumulation of knowledge and the decrease of false beliefs and would be jeopardized unless dissenting minorities are allowed to challenge the truthfulness of conventional wisdom as well as majority opinions. For Mill, this is not merely a hypothetical problem. His underlying concern is 
that democratization, instead of improving the intellect and tastes of the masses

constituting the majority in a democratic system, eventually drags down the better part of humanity into conformism, mediocrity, and complacency. According to Mill, there exist concrete precedents for this danger: The East. He particularly singles out China as an example of the despotism of custom. Once a great civilization, China slid into stagnation precisely because of the despotism of custom (p. 78). On the basis of this observation, Mill draws a striking parallel between Chinese civilization and burgeoning democracy in the United Kingdom: "The modern régime of public opinion is, in an unorganized form, what Chinese educational and political systems are in an organized; and unless individuality shall be assert itself against this yoke, Europe, notwithstanding its noble antecedents and its professed Christianity, will tend to become another China" (p. 80). In other words, democracy without a room for diversity is as antithetical to social progress as the rule by a paternalistic government.

At the center of Mill's defense of progress against the despotism of custom is the protection of individuality from the tyranny of the majority. He gives the Romantic ideal of the individual's unique and distinctive character as the goal of life a utilitarian justification on the ground that individuality is not only good for individuals but is also beneficial for entire society. Given the fallibility of human knowledge, the homogenization of opinion amounts to the premature foreclosing of further experiments with new ideas and practices, resulting in a stagnant social state. Like Alexis de Tocqueville in Democracy in America, Mill sees in democracy a tyrannical potential that suppresses individuality by leveling out the social landscape to the lowest common denominator. His fear is that the preponderant majority in democracy, if left unchecked, 
would not hesitate to reduce social diversity and unwarrantedly forestall further social improvement. To prevent that from happening, the diversity of opinion should be deliberately promoted. This, in turn, requires the preservation of aristocratic islands, so to speak, in the middle of the flattened landscape of democracy. Mill names two requisites for the development of individuality — “freedom" and "variety of situations" (p. 64) and suggests that such aristocratic islands can be preserved only if the private sphere of the individual is respected by the members of society. These considerations lead him to develop his famous harm principle: "[T]he sole end for which mankind are warranted, individually or collectively, in interfering with the liberty of action of any their number, is self-protection. ... [T] he only purpose for which power can be rightfully exercised over any member of a civilized community, against his will, is to prevent harm to others" ( $\mathrm{p}$. 63).

However, Mill refuses to extend the same principle to "immature races" and, instead, designates enlightened despotism to be an appropriate form of government for them - at least until they advance to the point that they can handle the responsibilities of freedom. An infamous passage from On Liberty reads:

For the same reason [that unrestricted freedom is not applicable to children], we may leave out of consideration those backward states of society in which the race itself may be considered as in its nonage. The early difficulties in the way of spontaneous progress are so great, that there is seldom any choice of means for overcoming them; and a ruler full of the spirit of improvement is warranted in the use of any expedients that will attain an end perhaps otherwise unattainable. Despotism is a legitimate mode of government in dealing with barbarians, provided 
the end be their improvement, and the means justified by actually effecting that end. Liberty, as a principle, has no application to any state of things anterior to the time when mankind have become capable of being improved by free and equal discussion. Until then, there is nothing for them but implicit obedience to an Akbar or a Charlemagne, if they are so fortunate as to find one. (Mill [1854] 1991: 14-15) Needless to say, the immature races referred to here include the Indians, the Chinese, and all those who live in the global East and the South at that time. Thus, his exception of immature races from the principle of freedom amounts to a justification of Western colonialism in non-Western societies. (Mehta 1999: 77-114).

As Uday Singh Mehta's (1999) study of the impact of India on British liberal thought demonstrates, Mill simply follows the predominant discourse of the time in justifying the colonial rule by means of the metaphor of family. Rejected by Locke in Two Treatises of Government as a basis of political authority in the domestic arena, parental authority is reintroduced into international relations, or more specifically relations between mature and immature peoples, by later liberal thinkers. In the liberal conception, therefore, the political sphere, where free and equal individuals relate to each other, is a space artificially constructed between the purely private sphere of family relations and the sphere of international relations outside civilizational boundaries, and freedom is possible only in this privileged space. The authority of colonial government, British liberals contended, is something analogous to the authority of parents, especially that of the father, over the child. The metaphor is strategically employed to skirt the question of uncertain knowledge by equating the colonizer with the knowing figure of father and the colonized with the known child. "The child/deviant," Mehta explains, 
"whose difference threatens the legitimacy of the father by placing a limit on the reach of his authority by straining his understanding, must therefore be assimilated in a power that 'knows' or offers a progressive future in which the ambivalence of 'not-being-one-of-us' and being 'one-of-us' will assuredly get resolved." Although children may serve as a mirror through which interesting insights about mature persons can be drawn, few expect from children themselves any contribution to the discovery of scientific, political, or moral truth. It is the task of mature persons to retrieve meaningful knowledge from the observed behavior of children. Likewise, diversity exhibited by immature races may be relevant for the understanding of human nature, but it is hardly expected that immature people can know something about mature persons hitherto unknown to the latter or that self-reflection by immature people produce new knowledge about themselves. Children's behavior may become an object of some scientific or moral inquiry, but they are never recognized as the subjects of knowledge production. They are little more than data whose behavioral patterns are to be classified and whose substance is to be subjected to analysis and judgment according to some standards set by the fatherly figure. In short, they can be known but can never know anything other than what mature peoples already know. Therefore, the diversity that is found outside the West is not worth preserving or promoting. Rather, it may be quite dangerous and must be reduced to the point that it no longer threatens the authority of the knowing subject.

From the vantage point of immature people, therefore, there are but two options: either the despotism of customs, which will keep them mired in a backward state, or enlightened despotism, which, supposedly, will put them on the path of progress. The first option condemns them to eternal childhood. The second option leads to the rule by 
"foreigners," unless, in rare circumstances, they have domestic despots energetic enough to embark on "a civilizade" (p. 102) of their own against the despotism of custom.

Arguably, Japan was fortunate enough, if we borrow Mill's terminology, to have its own Akbar and Charlemagne in the form of an enlightened bureaucratic state, of which Yanagita was part during his early professional life. However, he soon came to question the wisdom of Japanese enlightened bureaucracy. His major concern was that, to draws on Mill's distinction, the enlightened Meiji bureaucrat-intellectuals were "full of the spirit of improvement" (p. 78), but actively undermined "the spirit of liberty" (p. 78) among the Japanese population. They also depreciated internal diversity of the nation and tried to convert the people into a mere object of knowledge and social engineering. Instead of guiding an "immature" people into the age of reason and enlightenment, Yanagita feared, it was producing in a bureaucratic developmental state, which not only relegates the majority of the Japanese population into the status of second-class citizens, but also actively loathes diversity as a hindrance to progress.

\section{Despotism of Enlightened Bureaucracy in Japan}

The enlightened despotism that emerged in Japan around the turn of the twentieth century took a form of the bureaucratic developmental state. The principal agents for this transformation were a new generation of bureaucrats-intellectuals well immersed in the Western experience and knowledge. They were the product of the rationalization and professionalization of the civil service, which had made it possible for the best and brightest to be recruited from all over the country, regardless of their social statuses, regional origins, or political connections. The new public education system served as a 
pyramid-like monopoly network that absorbed local talents and sifted them out through a uniform competitive process (Silberman 1982: 236-238). At the top of the hierarchical network was the Department of Law of the Imperial University of Tokyo, a training ground for future high-ranking government officials. Throughout this preparatory process, they acquired new historical and spatial consciousness well ahead of the rest of the Japanese population.

Kenneth Pyle calls the new generation of well-educated government officials "bureaucrat-intellectuals" to avoid the connotation that they are little more than the executors of clerical tasks decided elsewhere (Pyle 1974: 149-150). Indeed, those bureaucrat-intellectuals and their academic mentors became the major intellectual masterminds of a wide range of social and economic reforms carried out in prewar Japan. They despised partisan politics and regarded themselves as genuine defenders of the public interest and, hence, above politics. They were generally progressive nationalist and were intent to transform Japan into a formidable economic and military machine on par with the Western nation-states. Their ideal was an autonomous state independent of parochial societal interests and equipped with universal scientific knowledge. Their prestige and power was largely owed to their privileged access to knowledge of and from the West. However, unlike the previous generation of the Westernizing elite, they were well aware that the Western experience of industrial development was neither uniform nor without internal critics. They were progressive in the sense that they were determined to eliminate any traditions and customs that stood in the way of national modernization, but at the same time were deeply concerned with the potential negative impacts of industrialization on the social fabric. The determination to take a more orderly path to 
modernity led them to advocate active state intervention in society. It is not a coincidence that their rise took place exactly when the Japanese government was abandoning laissez faire principles in favor of more proactive social policy, in which the countryside became the main target of state intervention (Waswo 1988: 569-576).

The major intellectual inspiration for bureaucrat-intellectuals was German political economy, especially the so-called Social Policy School and the Young Historical School of Economics. The Social Policy School is an intellectual movement led by German economists, such as Gustav Schmoller, Lujo Brentano, or Adolf Wagner, who challenged the orthodox economic doctrine of the Manchester School associated with the British hegemony. ${ }^{19}$ They rejected the existence of universal economic laws and the principle of laissez faire and advocated active state intervention in social issues such as poverty, labor conditions, or housing problems. ${ }^{20}$ By the 1870 s, the Social Policy School had become

19 The label of the Social Policy School derives from Verein für Sozialpolitik, an association of reform-minded scholars. Although the labels the Social Policy School (Sozialpolitiker) and the Young Historical School of Economics are vaguely defined and are often used interchangeably, it seems appropriate to distinguish two rival camps within the Social Policy Association: the state socialist camp represented by Adolf Wagner and the Young Historical School represented by Gustav Schmoller, Lujo Brentano, and others who were sympathetic with British reformist movements and were opposed to Wagner's state socialism as well as laissez faire (Grimmer-Solem 2003). Yanagita's position is closer to that of Schmoller and Brentano.

${ }^{20}$ Kenneth Pyle (1974: 135-7; 1989: 704-705) enumerates seven basic tenets of the Young Historical School of Economics: (1) the rejection of the abstract theory and deductive methods of classical economics and the need for empirical and historical research; (2) the need for interdisciplinary approaches to economic issues because of organic connections between economic and other social phenomena; (3) the conviction that economic issues should be approached from ethical points of views; (4) the belief that the modern nation-state is a moral achievement, in which social justice was guaranteed by an impartial bureaucracy; (5) the support for active state intervention in economic and social affairs; (6) skepticism toward socialism as well as laissez faire; and (7) the acceptance of the supremacy of national interest and the support for imperialist 
particularly influential in Germany, partly because its counterrevolutionary reformism and support for active state intervention in society fit well into the Bismarckean politics of preemptive social legislation. ${ }^{21}$

By the time Yanagita entered the Imperial University of Tokyo, German political economy became very influential among the Japanese bureaucracy-academia complex, and the reformist and pro-interventionist Social Policy School was gaining a foothold in various academic institutions and the government. ${ }^{22}$ The popularity was partly because of an analogy drawn between Germany and Japan in terms of their position in the modern

expansion. All these tenets of the Young Historical School can be easily detected in Yanagita's early writings on agrarian policy, with the notable exception of his reticence about the question of imperialism.

${ }^{21}$ Recent scholarship has challenged the conventional images of the Young Historical School of Economics as little more than an apologist ideology for Bismarckean conservative reformism or an expression of German economic nationalism. See, for example, Grimmer-Solem (2003).

${ }^{22}$ It is useful to situate the Germanphilia of bureaucrat-intellectuals in the general intellectual context of the time. Itō Hirobumi (伊藤博文), a leading statesman and the chief architect of the Meiji Constitution of 1889, recalls the intellectual atmosphere in the pre-Constitution period in the following terms:

We were just then in an age of transition. The opinions prevailing in the country were extremely heterogeneous, and often diametrically opposed to each other. We had survivors of former generations who were still full of theocratic ideas, and who believed that any attempt to restrict an imperial prerogative amounted to something like high treason. On the one hand there was a large and powerful body of the younger generation educated at the time when the Manchester theory was in vogue, and who in consequence were ultra-radical in their ideas of freedom. Members of the bureaucracy were prone to lend willing ears to the German doctrinaires of the reactionary period, while, on the other hand, the educated politicians among the people having not yet tasted the bitter significance of administrative responsibility, were liable to be more influenced by the dazzling words and lucid theories of Montesquieu, Rousseau, and other similar French writers. (Tsunoda et al 1954: 675) It should be pointed out that Yanagita was familiar with all of those diverse opinions, including what Itō calls "theocratic ideas" and did not completely identify himself with any of them. 
spatiotemporal order. It was believed that Japan could learn more from Germany's efforts to take advantages of its own backwardness, as late-industrializing countries could learn from both successes and failures of pioneering countries (Pyle 1974: 128-129). Specifically, for both Germany and Japan, the experience of the United Kingdom, where the cost, as well as benefit, of market-driven development and thorough industrialization/commercialization of the economy had become visible, was supposed to serve as both a successful model to be followed and a negative example to be avoided. What alarmed Japanese bureaucrat-intellectuals particularly was the negative impact of industrialization on social integration and growing class conflicts. To borrow Marx's words in the preface to the Capital, the West showed Japan the image of their future. Yet, Japanese bureaucrats and scholars did not necessarily share Marx's belief that class antagonism was an unavoidable outcome of capitalist development. They believed that the timely intervention of human agency, embodied by the rational state bureaucracy, was able to prevent social polarization and class conflicts.

In the course of the history of prewar Japan, the new class of bureaucratintellectuals came to yield immense power over politics. They accepted the claim that the Japanese people were "immature" and eagerly undertook the task of guiding them into maturity. However, their "success" in this task brought about consequences quite unexpected by Mill and other liberal thinkers. The acceptance of the modern spatiotemporal order on the part of modernizing elites in a non-Western society opened a door to a new political economy of catching-up industrialization whose implications transcended the boundary between international and domestic politics. Internationally, the division of labor between industrial and non-industrial economies was no longer 
determined by naturally endowed comparative advantage, because the latter could be altered by human intervention. Concretely, the United Kingdom's position as the industrial and commercial center and principal producer of manufactured goods in the world economy was no longer justified as part of natural order. Germany, Japan, or other followers could challenge and take over its position if they managed to take a shortcut to industrialization. As a result, the static international division of labor, justified by the Ricardian theory of international trade, gave way to much more dynamic international competition in which various nation-states compete with each other over the location of strategically important industries and access to cheap raw materials. All depended on the state's capacity to compensate or substitute the deficiency of the market system.

Internally, the new political economy endowed the state with missions and authority that the liberal theories of political economy did not. Equipped with knowledge of the predecessor's experience and projecting that image onto its own society's future, the state was believed to be capable of advancing, if not changing, the course of capitalist development in more orderly and efficient way than their predecessors. Moreover, democracy is no longer the best condition for social progress as diversity and free and open discussion are replaced by the absorption and application of authoritative knowledge of and from the pioneering West. The result was what is today known as the "developmental state," an interventionist state that rejects both laissez faire and state socialism. ${ }^{23}$ Arguably, enlighten despotism defended in On Liberty's led to the

${ }^{23}$ The concept of the developmental state was first presented by Chalmers Johnson in his historical study on the development of industrial policy in prewar Japan (Johnson 1982). It was later extended to the Northeastern states that used industrial policy effectively to promote catch-up industrialization. However, it is debatable whether the developmental 
emergence of fiercely competitive international politics in which a powerful authoritarian state, in an effort to convert a nation into an efficient economic and military machine, put competitive pressure upon democratic societies in the West. Yanagita belonged to the first generation of these bureaucrat-intellectuals, as he entered the state bureaucracy in the early days of the formation of the Japanese developmental state.

\section{Progress and Policy Science}

This and following sections examine Yanagita's early writings on agrarian policy, published between 1902 and 1910. During this period, he was a young and ambitious reformist bureaucrat-intellectual who actively engaged in the public debate on agrarian reform. The major texts written in this period include Saishin sangyō kumiai tsūkai (最新 産業組合通解 The Newest Manual of Industrial Cooperative, 1902), Nōseigaku (農政 学 Agricultural Policy Science, 1902-1905), Nōgyō seisakugaku (農業政策学 Agricultural Policy Science, 1902-1903), Nōgyō seisaku (農業政策 Agricultural Policy, exact publication date unknown), Jidai to nōsei (時代と農村 Our Age and Agricultural Policy, 1910), and several articles published in various journals. The first text is a commentary on the Industrial Cooperative Law of 1900, which explains the historical background of the idea of cooperatives and the content of the law in non-expert language. ${ }^{24}$ The next three texts are based on the lecture notes prepared for the courses

state is a phenomenon particular to East Asian countries or universally observable to some extent in the course of global capitalist development. See essays contained in Woo-Cumings (1999), especially Cumings (1999).

${ }^{24}$ In spite of the name, the Industrial Cooperative Law was also applied to agricultural 
he taught at three private universities, Waseda, Senshū, and Chūō, respectively. These texts were written by a fresh graduate for pedagogical purposes and it may be the case that its contents are a reflection of a dominant discourse in the field at that time as well as Yanagita's original insights. While occasionally revealing his burgeoning criticism of the government agricultural policy, they draw heavily on the thought of German Social Policy School and the Young Historical School of Economics. As a result, the texts are uncharacteristically theoretical and exhibit a strong statist tendency. Yanagita himself seemed to repudiate later a good part of what he wrote, as suggested by his initial refusal to the inclusion of those texts in his official anthology. At the same time, those texts are also influenced by British reformist thoughts and Millian utilitarianism. ${ }^{25}$ As will be discussed in detail in the following sections, the liberal side of Yanagita opposed the excessive paternalism of the state bureaucracy and official academia, emphasized the self-help of small, independent farmers, and favors education over coercion and subsidies.

cooperatives. Yanagita and many other experts of agrarian economy considered the promotion of farmers' cooperatives as a promising policy to prevent an agrarian crisis.

25 Fujii Takashi (1995: 140) identifies a strong influence of utilitarianism in Yanagita's agricultural policy science and contends that he was much more influenced by British liberal or socialist reform movements than the German Sozialpolitiker. Nevertheless, it is difficult to distinguish clearly one influence from the other, because the leaders of the Young Historical School, such as Gustav Schmoller, Lujo Brentano, Adolf Held, and Georg Friedrich Knapp, were admirers of British social legislation, and they had more in common with British reformers than with German state socialists such as Adolf Wagner. Yanagita's position is similar to that of Schmoller and Brentano who rejected the two extremes of laissez faire and state socialism and tried to protect a rapidly disintegrating middling class. For the importance of a middling class in the Historical School, see Grimmer-Solem (2003: 96-104, 171-186). 
The publication of Jidai to nōsei, a collection of essays previously published in various journals, marks the end of the first period of Yanagita's intellectual career, because from then on his principal interest shifted from policy science to ethnological studies of rural life. The premonition of this shift was already discernible in the essays included in Jidai to nōsei, as he came to question the universality of "scientific" knowledge and the impartiality of state bureaucracy and academia. As a result, he distanced himself from blatant statism that excessively relied on coercive means or subsidies to promote agrarian reform. Instead, the potential of local natives as agents of reform was increasingly appreciated.

Victor Koschmann points out that Yanagita's career and disposition had much in common with those who would later be known as "renovationist" (kakushin 革新) bureaucrats. They are interventionist bureaucrat-intellectuals who, impressed by the mobilizational power of Nazi Germany and the Soviet Union, aspired to establish a controlled economy after the outbreak of the Second Sino-Japanese War in 1937. Koschmann characterizes them as follows:

As a term used to describe the forward-looking application of bureaucratic rationality, ... kakushin also came to imply such qualities as nationalism, faith in central planning, commitment to rising productivity, and opposition to "feudal" social relationships. Kakushin officials sought to co-opt the left, and were critical of the hanbatsu [region-based factions] cliques based on regional loyalties, the ascriptive nobility, and also the big bourgeoisie, whose expansive enterprises and financial combines sought to distort national plans to accommodate their own "private, selfish interests." They upheld all that was "public," in the sense of 
bureaucratically impartial and technically rational. Hence, "progressivism" in this sense is typified by the so-called kakushin kanryo ("progressive bureaucrats") of the mid-to-late thirties. [a footnote omitted] (Koschmann 1985: 135-6)

Like many other kakushin bureaucrats, Yanagita studied at the Department of Law in the Imperial University of Tokyo. His major is nōseigaku (農政学 agricultural policy science), which had a long tradition in Japan, but had become a modern policy science under the heavy influence of the German Social Policy School by the time he studied it at the Imperial University. His mentor Matsuzaki Kuranosuke (松崎蔵之助) studied in France and Germany during the 1890s and was influenced by Adolf Wagner, an avowed admirer of Bismarck and an advocate of state socialism. Yanagita was a regular member of the Japanese Social Policy Association (Shakai seisaku gakkai 社会政策学会), a group of reform-minded scholars, government officials, and businessmen, which was modeled after the Verein für Sozialpolitik in Germany. ${ }^{26}$ Upon graduation in 1900, he duly entered the Ministry of Commerce and Agriculture, one of the strongholds of reform-minded bureaucrats, and became directly involved in the legislation and implementation of various economic and social policies. Although his tenure in the ministry was less than two years, he continued to be involved in agrarian issues as an expert even after climbing up the bureaucratic ladder.

${ }^{26}$ Kanai Noboru (金井昇 1865-1933), a founder of the Social Policy Association, studied in Germany from 1886 to 1890 under leading historical economists, including Schmoller, Johannes Konrad, Karl Knies, and Adolf Wagner (Pyle 1974: 139-140). On returning to Japan, he was appointed as professor of economics at the Tokyo Imperial University and became one of the most influential figures in the bureaucracy-academia complex and served as the intellectual architect of many government reforms. For a summary of Kanai's career, thought, and influence, see Pyle (1974: 139-146). 
Therefore, it is not surprising that the early writings of Yanagita show the heavy influence of the German political economy. Closely following a tenet of the Historical School of Economics, he rejects the thesis that economic disparity among nations is naturally given, as suggested by the Ricardian theory of comparative advantage. Rather, he argues, the economic prosperity of a nation is determined by the combination of natural and human agents. Natural agents include externally given conditions and events such as climate, geographical characteristics, and natural disasters. ${ }^{27}$ In contrast, human agents refer to whatever is achieved by the application of human knowledge and force to nature, ranging from individual labor and inventions to governments' policy ("Nōseigaku." Teihon 28: 189; "Nōgyō seisakugaku." Teihon 28: 291). On the basis of this distinction, Yanagita offers a definition of civilization as follows:

In the distant past, there was little difference in living conditions between animals and human beings, and natural agents constraining them were so powerful. However, as a result of cooperative life [kyōdō seikatsu 共同生活], humans alone improved their life constantly and, as time progressed, were able to conquer nature gradually. From this point of view, the so-called civilization of a country means the conquest of nature by human agents - that is, the progressive victory of human over

${ }^{27}$ In Nōseigaku, Yanagita treated race (jinshu 人種) and folk customs (minzoku 民俗) as natural agents along with climates and geographical topology on the ground that they are "permanent (jōzai 常在)" conditions. (Teihon 28: 189), but silently dropped them as examples of natural agents in a later text, Nōgyō seisakugaku (Teihon 28: 291). Although he did not offer any explanation as to why he did so, it is consistent with his later conception of racial distinctions as a product of politics. As for folk customs, one of the purposes of his minzokugaku is to recognize folk customs as the sedimentation of ancestors' practical attempts to control natural agents. In that way, Yanagita tried to rehabilitate rural folks as rational actors and rural communities as a form of civilization, coeval with the urban civilization. 
natural agents. What constitutes man-made economic phenomena, or the main parts of the so-called economic actions, are efforts not only to avoid obstructing but also actively foment what is convenient for human development out of natural phenomena that have existed since the distant past, and, at the same time, efforts to prevent and remove inconvenient natural phenomena so that they would not reappear. [emphasis added] (“Nōgyō seisakugaku.” In Teihon 28: 292)

The notion that civilization as the victory of human will over nature means that progress does not belongs to natural order but a man-made process. Therefore, human intervention in natural order is justified in the name of progress. Yanagita further divides human agents into conscious and unconscious ones and emphasizes that the possibility of promoting further civilization and progress depended on the deliberate efforts to increase the former (p. 190; pp. 291-292).

On the basis of these distinctions, Yanagita concludes that "pure" economic theory and principle - by which he means the classical economic theory of the Manchester School and the principle of laissez faire — is inadequate because it does not count on deliberate human actions in determining economic outcomes. Thus, the task of distinguishing what is desirable or not for humanity and consciously fomenting the former while forestalling the latter requires what he calls applied economics, or "a science that specializes in studying the means by which human beings bring about economic phenomena desired by them" (p. 292). Yet Yanagita further divides this practical science of applied economics into private and public branches - that is, applied private economics that aims to identify the means by which private persons bring about desired outcome in their respective lives and public policy science whose purpose is to 
identify means by which the state or local governments promote the common good for collective life. He justifies this further division on the following ground:

The life plan of an individual and that of a community never coincide with each other. True, everyone desires to live and, if possible, to live in comfort and prosperity, but there is inevitably a huge gap between the individual and the state. As a result, although both the individual and the state are the subjects of applied economics, each of them necessarily demands research in different directions. First, there is difference between the state and a private person in terms of the length of life. Whereas human life is finite, the life of the state is, ideally speaking, eternal. Whereas a individual person need not draw up a long-term plan for the next one hundred years, the state must always plan for the eternal happiness [of the nation]. Second, there is a greater difficulty of internal unity [in the case of the state]. The ears and eyes, the hands and feet of the individual are already in unity. No one feels great difficulty in uniting its own body. The state is not like this. Although the state is also a living body, it always needs far greater efforts to maintain internal unity. The national population within the state contains various kinds of social classes whose interests are mutually antagonistic. The so-called disagreement in opinions occurs in any period of history. If the state is to stand above these complex [social] interests and to judge the appropriateness of the so-called economic actions, it must have its own standards. It is only natural that the state cannot meekly follow what individuals approve or disapprove. (“Nōgyō seisakugaku.” Teihon 28: 292-293) What Yanagita implied in this passage was that the temporal and spatial horizons of the state or other public bodies were much longer than any private individual, whose 
decisions only reflect needs and desires in a relatively immediate space and time and tend to neglect long-term consequences on the spatial unity of a whole. And "long-term" means “eternal” and “a whole" is “the state (kokka 国家)."

According to Yanagita's classificatory scheme, agricultural policy science is a branch of public policy science along with industrial policy science, commercial policy science, financial policy science, labor policy science, etc. However, he is emphatic that the sectoral division of public policy science is for convenience and should not be taken as a rigid demarcation. He writes:

In private economy, those who engage in agriculture, commerce, industry, and other economic sectors are the subjects in their respective economic fields and only need to acquire knowledge about their own respective fields. In consequence, each branch [of private economics] can safely maintain its independence. In contrast, when it comes to economic policy, the actor is always the state, and even if the state has diverse aspirations, ultimately they come down to a single point. Therefore, students of economic policy cannot remain complacent with knowledge provided by any one branch [of public policy science]. For example, what agricultural policy science suggests alone cannot dictate a final judgment, but inevitably take the interests of commerce, industry, and other sectors into consideration and calculation before a final judgment is made. For this reason, this classificatory scheme is not a perfect one, and policy science should be studied, so to speak, as a whole.

(“Nōseigaku." Teihon 28: 192)

According to this understanding, public policy science should represent the perspective of the state, which supposedly exists independent from local perspectives of its parts. 
Yanagita's emphasis on agricultural policy derives from a deeper concern, shared by many other bureaucrat-intellectuals and their academic mentors, that Japan's relative backwardness made the challenge of industrialization more formidable, but chance to preempt social ills associated with it was also greater. Many Japanese scholars and bureaucrats feared that the seeds of social unrest were brewing in the countryside as a result of the rapid growth of industry and commerce at the expense of the agricultural sector and the encroachment of capitalist relations into rural communities. They had learned from the experience of the West, particularly that of the United Kingdom, that the decomposition of rural communities, while necessary to supply cheap labor to the industrial and commercial sector, constituted one of the root causes of various social and political ills that plagued industrial societies. If the transition from agrarian to industrial society was orderly prosecuted, however, Japan could be able to nip a root cause of future problems in the bud. In that sense, the relevance of agricultural policy was not limited to the agricultural sector but extended to national economic and political stability (Pyle 1973). Yanagita shared this concern and hope, as suggested in the following passage:

Among nations around the world, Japan is an exceptional case in terms of the large number of small farmers, merchants, and artisans. In addition, since there was an abrupt importation of Western knowledge and products in the wake of the Restoration, no traditional industrial organization has escaped its impact, and the further accumulation of capital and the increase of wage laborers is a clear and inescapable trend. Therefore, it is truly a matter requiring immediate attention to prevent a social crisis in advance by proper means such as industrial cooperatives. [emphasis added] (“Saishin sangyō kumiai tsūkai.” Teihon 28: 10) 
In order to justify a broader scope of the state's role than warranted by the orthodox economic theory, enlightened despots in non-Western societies needed a new theory of the state. In his early texts on agrarian policy, Yanagita tried to offer such a theory, which is the topic of the following section.

The State and the Household

Yanagita grounded his justification for a wider scope of the state's role on the claim that it had an obligation to protect the public interest. He denied that the public interest was merely the aggregation of private interests and defined it in terms of the obligation to the temporal others, who were not born yet. An often-quoted passage from Nōseigaku reads:

A nation's economic policy of a country transcends and is independent of struggles based on these private interests of classes and must be decided on some other basis. The purpose of the state itself should never merely reflect the collective desires of the majority of its people or of a particularly powerful class. In other words, the sum of private interests does not constitute the public interest. To take an extreme case, even if the people of the nation in a particular era were unanimous in desiring a particular thing, the securing of that thing should not necessarily be adopted as national policy. That is because the people (jinmin), whom the state represents and whose interests it must defend, are not limited to those now living. The state also includes their countrymen who will be born in later generations, so there might be times when the interests of contemporaries will have to be sacrificed for the good of the country's future residents. Of course, national goal and the national interest 
cannot exist apart from the people (kokumin), but the interests of the whole country have an entirely different basis from that of any particular part or class. [my emphasis] ("Nōseigaku." Teihon 28: 195-196. Translation from Koschmann 1985: 137-138)

Yanagita's definition of the state membership is clearly intended to endow the government with the authority to override the will of powerful social classes or even the majority in defining the public interest. After mentioning the liberal principle that the exercise of governmental power against the will of an individual is justifiable only to prevent harm to others, he writes:

From the point of view of the possessor of rights, the state is one of others. Because the members of the state who will live in the future can also be said to be others, they are entitled to refuse to be harmed by the exercise of rights on the part of the currently living people. However, because they are of course unable to make claims by themselves, it is a duty of the state to make provision against [the infringement of the rights of the unborn] on their behalf [emphasis in the original]." "Nōseigaku."

\section{Teihon 28: 196)}

In other words, just as spatial extension makes it difficult for each individual to figure out what consequences his or her action entails for others, temporal distance tends to discount heavily the interest of future generations. In both cases, the state is justified to step in to guarantee that equal consideration is to be given to its present and future members.

It is probable that Yanagita, when he wrote the passage quoted above, had in mind the following passage from Mill's On Liberty: “[T]he sole end for which mankind are warranted, individually or collectively, in interfering with the liberty of action of any of 
their number, is to self protection. That the only purpose for which power can be rightfully exercised over any member of a civilized community, against his will, is to prevent harm to others" (Mill 1991: 14). However, Mill suggests that certain actions to prevent or correct injuries to others could be compelled against the will of an individual and that failure to do so may be counted as an act of injury (pp. 15-16). Thus, by dint of a unique conception of the state as an intergenerational community, Yanagita managed to convert Mill's harm principle into a justification for the interventionist state, whose function expanded from reactive and regulatory to more proactive and preventive ones.

As will be discussed in the fourth chapter in detail, Yanagita's emphasis on the interest of temporal others is partly based on his Malthusian notion of space as the natural limit on resources available to human exploitation. He distinguishes what are today called renewable and non-renewable resources and justifies state intervention principally for the "rational" exploitation of the latter- that is, "rational" from the point of view of the temporary eternal and spatially organic state ("Nōseigaku." Teihon 28: 197-198). In a sense, therefore, the inclusion of the unborn in the membership of the state can be understood as a rhetorical device to temper the excessively optimistic view, inherent in progressivism, that most, if not all, existing spatial limits would disappear with the passage of time. Although it has a conservative implication, its general spirit can be said to be forward-looking. Equally, while Yanagita's notion that the state represents the interest of the unborn may raise eyebrows, most liberals today accept the state as a 
positive power to coordinate social actions as long as it does so for progressive purposes. $^{28}$

However, Yanagita's formulation definitely takes a conservative turn when, in Nōgyō seisakugaku, he unceremoniously includes not only the unborn but also the dead in the membership of the state: “The state [kokka 国家] cannot be said to be composed solely of those living now. ${ }^{29}$ Our dead ancestors are part of the nation [kokumin 国民] as well and their wishes should be taken into account. Moreover, because the state is an eternal entity, our offspring to be born in future makes part of the nation, and their interests should be protected as well" ("Nōgyō seisakugaku." Teihon 28: 294). The apparently subtle expansion of the state membership carries profound political implications, given that it runs counter to one of the basic tenets of liberalism privileging the will and interests of the living over inherited traditions. ${ }^{30}$ Although Yanagita neither

${ }^{28}$ For example, see John Rawls' (1999: 251-258) discussion on inter-generational justice.

${ }^{29}$ Nōseigaku and Nōgyō seisakugaku were based on the lecture notes Yanagita prepared for the courses of agrarian policy he taught at Waseda University and Senshū University, respectively. Although both texts were published almost simultaneously, he started teaching at Waseda in 1900 and at Senshū in 1902. That is because the definition of the national membership given in Nögyō seisakugaku is thought to be an improvement upon the one given in Nōseigaku.

${ }^{30}$ For example, Thomas Jefferson's Letter to Samuel Kercheval (http://teachingamericanhistory.org/library/index.asp?document=459, accessed December 9,2010 ) defended each generation's right to revise the constitution and denied that the living had the obligation to respect the wish or interest of the dead:

But the dead have no rights. They are nothing; and nothing cannot own something. Where there is no substance there can be no accident. This corporeal globe, and everything upon it, belong to its present corporeal inhabitants, during their generation. They alone have a right to direct what is the concern of themselves, alone, and to declare the law of that direction; and this declaration can only be made by their majority. That majority, then, has a right to depute representatives to a 
offers any explanation for the change nor elaborated on its implications in the text, his move is a deliberate one, because from that point on he stuck to the same definition of the state, as suggested by the following passage from Jidai to nōsei:

Although one half of the nation plus one constitutes the majority, it does not mean that the interest of the other half minus one could be ignored. Moreover, even if the entire nation wishes the same thing, the interest of several billions who are not yet born should be taken into consideration in advance, because the life of the state is eternal. In addition, we have millions of compatriots whose bodies were dissolved into the soil, but whose spirits have infinite interests in the enterprise of happy development [of the nation]. ("Jidai to nōsei," Teihon 28: 256-257)

If the passage is taken literally, the will of the dead, as well as the unborn, is now counted as a determinant of the public interest.

Apparently, Yanagita's view of the state is informed by the popular conception of the state as family or household (ie 家) writ large. For him, the household is not only a private organization but also has important public functions, because "for a national character such as the Japanese one, connection between each individual and ancestors - namely, the awareness of the household — is simultaneously a link between the individual and the state" (p. 39). Again, he does not elaborate, but by implication, it means that a person is connected to the state as a member of a household, not as a

convention, and to make the constitution what they think will be the best for themselves.

Jefferson is discussing inherited constitutions in this passage, but other forms of inheritance from the preceding generations - traditions, customs, conventions, etc. - are the major targets of scrutiny by Enlightenment thinkers. 
solipsistic rational individual. In fact, although Yanagita defends rural-urban migration as a healthy economic trend on the ground that it is driven by rational calculations on the part of unemployed or underemployed farmers, his endorsement comes with one reservation: his expressed concern with "the question of household preservation [ie no eizoku no mondai 家の永続の問題]” (“Jidai to nōsei.” Teihon 16: 38). According to Yanagita, urban life encourages individualism because, by physically separating migrants from their respective households back home, it weakens the idea of obligations to ancestors and descendents and undermines the significance of the household. As a result, their perspective becomes narrowed down to the immediate space and time, here and now of each individual's life. Because the majority of urban residents are migrants, the spatial and temporal horizon of the urban population is substantially shorter than that of its rural counterpart. Yanagita deplores this situation in the strongest terms possible:

In contrast to [Japanese religions' tolerance toward suicide], there existed severe social sanctions against the suicide of the household. Nay, if we take unborn descendents into consideration, domicide —i.e., the homicide of the household—is not suicide but murder, even when no member of the current household opposes it. If those who kill their own children are accused of murder, why are not those equally guilty who condemn the descendent to lose the awareness of their genealogical lineage while they are still alive? Is it up to the discretion of a family head to destroy in the space of day a household whose length of life is only second to the state? Moreover, today, moving permanent residence to big cities almost certainly results in domicide - namely, the homicide of the household. I refrain from handing down a judgment here, but want to exhort those who migrate to cities for 
their own calculation, for their own convenience, to think it over. ("Jidai to nōsei."

Teihon 16: 38-39)

Yanagita's analogy between murder and what he called domicide certainly seems overblown, but it reflects his concern with the political ramification of urbanization: if one's awareness of belonging to a household is "a link between the individual and the state" (p. 39), the growing cases of domicide could potentially lead to the murder of the state.

Yanagita was hardly unique in viewing the state in analogy with the household. Rather, his view was in line with the dominant nationalist discourse that portrayed the state as a family writ large. It was a popular and effective mode of representing the state, partly because the Japanese word for the state, kokka (国家), is a combination of two Chinese ideographs, kuni (国), a country or homeland, and ie (家), the household or family. However, Yanagita's analogy had a different emphasis than the one in the dominant nationalist discourse. For the latter, the appeal of the analogy lay in the fact that the structure of the household was thought to be an organic hierarchy paternalistically presided by the household head. By presenting constitutional monarchy as akin to a household, the government could draw on Confucian ethics or popular custom to demand from the imperial subjects the same kind of obedience and deference to the Emperor and his servants as those due to their fathers.

Yanagita did not share this view. ${ }^{31}$ Instead, his focus was on the psychological security the household historically offered to each individual. First, belonging to a

31 In a speech made at an elementary school in 1930, Yanagita criticized the Imperial Rescript of Education, which had become the official statement about moral principles 
household provided the minimum level of material security. It was the responsibility of the head of a household to maintain the livelihood of the family members. "Materially, it was the guarantee that the minimum amount of food would be supplied. No one was left starving" ("Nihon nōmin shi." Teihon 16: 218). However, what becomes the main concern for him is the second kind of psychological security:

[S]piritually, it was the conservation of memories. This has something to do with [the people's] connection with land, because villagers, from top to bottom, had names only if they had cultivated lands. The inheritance of a name from generation to generation would be rendered meaningless once the household moved to another place. Within the national tradition of worshiping ancestors and being worshiped by descendents, one cannot comfortably get old and die without a conviction that the family members would welcome him or her in bon and higan [when the spirits of ancestors are thought to be returning to their home]. This is the so-called kesshoku [血食 the practice of ancestor worship], and the Oriental idea of the household always had the exchange and chain of affection and yearning [aibo no kōkan to rensa 愛慕の交換と連鎖]. This point, if not others, is moot in the Western concept

that the subjects were expected to learn through mandatory public education. It emphasized Confucian ethnical values such as loyalty and filial piety along with loyalty to the state. Yanagita later explained his discontent as follows: "[The Rescript] does not mention a sense of public duty [kōtokushin 公徳心] and public morality [kōkyō dōtoku 公共道徳]. True, it mentions love for one's country [aikokushin 愛国心], but not love for one's village, one's prefecture, and one's region. It says nothing about an attitude toward the general public" (quoted in Tsurumi 1998: 94). In other words, He rejects the thesis that the state is a family writ large and private ethics is equally applicable to political relations. Instead, genuine patriotism must be cultivated from bottom up by expanding one's horizon from the local and regional to the national level. 
of home, which dissolves in every generation. [my emphasis] ("Nihon nōmin shi." Teihon 16: 218-219)

The living are motivated to sacrifice their own interest for the sake of the unborn only if they are assured that the unborn will eventually recognize their sacrifice. Because the unborn stand to the living exactly in the same way the living stand to the dead, only by paying due respect to their ancestors could the living convince themselves that the their descendents will do the same in their turn. In this view, therefore, ancestor worship is interpreted as a sort of intergenerational pact to preserve a household as the reservoir of memories of contributions and sacrifices made by preceding generations. It is likely that Yanagita's addition of the dead to the membership of the state is inspired by this "exchange and chain of affection and yearning" between the dead, the living, and the unborn, institutionalized in the practice of ancestor worship. Despite its backward-looking rhetoric, it is conceived as a complementary conceptual device to motivate the living to look beyond the limited spatial and temporal horizons of the individual. As will be discussed in the following chapter, even when he later became disillusioned with the impartiality and foresightedness of state bureaucracy and academia, he retained the household as a crucial institution linking the individual to the nation.

\section{Yanagita's Critique of Enlightened Despotism}

The publication Jidai to nōsei (Our Age and Agrarian Policy) marks the end of the agricultural policy period of Yanagita's long intellectual career. It is a collection of essays published between 1906 and 1909 and shows both continuities and discontinuities from his earlier writings. He retains the conception of progress as the gradual victory of human 
will over nature and the notion of sciences (gakumon 学問) as instruments to promote progress by complementing the limited spatial and temporal horizon of the individual. What recedes notably is the notion that the state is the principal agent of progress, and, instead, criticism of political and economic centralization and the one-size-fit-all policy becomes a more explicit theme, indicating that he was distancing himself from the statism of his fellow bureaucrat-intellectuals. Although the difference between the earlier and later writings may be partly due to the fact that the former are written for pedagogical purposes, Yanagita's personal experience also seems to have prompted this shift.

As mentioned before, Yanagita's early writings already contain a harbinger of his anti-statism. While granting a sweeping authority to the state in theory, in practice he was critical of the heavy-handed way in which the government was imposing its will upon the rural population and tried to temper the exercise of governmental power. For example, he contends that the government should play a greater role in the distribution of wealth, especially land, but warns against excessive intervention in production on the grounds that it would reduce the farmer's incentives and might be counterproductive. On the basis of this reasoning, he limits government intervention in economy to the case of market failure resulting from what economists today call incomplete information and bounded rationality. A passage from Nōseigaku reads:

If humans are most quick to take measures for one's own interest and everyone but a few lazy and unlawful fellows works diligently for one's own livelihood, one might ask why the state needs to be troubled with legislation and administration [of necessary measures]. This is because human wisdom is so far away from God, and in confusion and by mistake, humans often take actions that are ignorant, 
unknowledgeable, and harmful. Therefore, the primary purpose of economic policy in this respect must be cultivation and guidance (kaihatsu yūdo 開発誘導), by direct or indirect educational means, leading the people to the point of making right decisions without being forced (self-help [jijo 自助]). Coercive, police-like commands or plain subsidizing measures have little effect and much potential for abuse, and, hence, should be avoided as much as possible if not urgent and necessary. ("Nōseigaku." Teihon 28: 241-242)

The final sentence of the quote above is thought to be an indirect allusion to Sakō Tsuneaki (酒匂常昭), reformist Director General of the Agricultural Affairs Bureau of the Ministry of Commerce and Agriculture, whose heavy-handed policy stance was known as “sāberu nōsei [サーベル農政 saber agricultural policy]” because of its heavy reliance on coercive force (Kawada 28-48).

Yanagita's criticism of paternalism becomes even more overt in the essays included in Jidai to nōsei. Yanagita's complaints are directed to two aspects of agricultural policy science and the government's agrarian policy: The connivance of sciences with power and the narrow empirical basis of modern knowledge.

The Connivance of Science with Power

Yanagita's criticism of the bureaucratic developmental state is closely related to his personal experience in the government. Although the details remain unclear because of his general reticence about his experience as a government official, indirect evidence indicates his growing dissatisfaction with the way agrarian problems are dealt with by the 
government and academic authorities. His discontent is largely because his proposals for agrarian reform literally fell on deaf ears. To his dismay, they were shunned by the bureaucracy-academia complex, not because his arguments were refuted on the basis of rational argumentation and empirical facts, but because it fell victim to factional politics to which policy science was supposed to be immune. His frustration was discernible in the following passage from the preface to Jidai to nōsei: "I had never seen any [written] objection to my opinions [except once], but occasionally heard some through the grapevine. However, they are very fragmented opinions. I do not know which part [of my view], but an expert in Komaba [supposedly referring to Yokoi Tokiyoshi (横井時敬 1860-1920), then a professor of the Tokyo Imperial University and an authority in agrarian economics] reportedly said, 'Yanagita's opinion is odd.' And a famous prefectural governor was heard saying, 'I do not understand what that man [Yanagita] says"” (Teihon 16: 4). Shunned from the bureaucracy-academia circle, Yanagita's proposals largely fell into oblivion. ${ }^{32}$ In order to understand why his proposals were so thoroughly ignored by bureaucrats and scholars, it is necessary to turn to the contents of his diagnosis of agrarian problems and solutions to them.

Yanagita's diagnosis of agrarian problems was largely Malthusian. ${ }^{33}$ He believed that as a result of the relatively rapid population growth during the early modern period

\footnotetext{
32 Tōhata Seiichi, a prominent agricultural economist, later described Yanagita's agricultural policy science as "a solitary cry in the wilderness" (Tôhata 1961). In the postwar period, however, his nōseigaku in general and his proposal for balanced development in particular were recognized as farsighted and anticipating the postwar agrarian reform.

33 Yanagita mentions Malthus by name and endorses his law of diminishing return in Nōseigaku (Teihon 28: 202-203) and Nōgyō seisakugaku (Teihon 28: 307). However,
} 
from the seventeenth to nineteenth century, the rural sector was suffering from the relative scarcity of arable land. The result was the progressive subdivision of cultivated land into smaller plots and the proliferation of smallholders who barely scraped a living off their lands. The symptom of overpopulation and the underutilization of labor forces manifested itself in persistent rural poverty, occasional famines, the practice of infanticide and granny dumping, and the increasing number of rural-urban migrants. Under the condition of overpopulation, the replacement of feudal relations with the market system did not necessarily solve "the problem of feeding the infinitely growing population with the finite territory" (Teihon 28: 207). It even exacerbated the problem by facilitating the concentration of land in the hands of few landowners.

The solution Yanagita proposed was the rationalization of land use, at both macroand micro-levels, from the national point of view. At the macro-level, he rejected both agrarian country-ism (nōgyō kokuhonron 農業国本論) and commercial/industrial country-ism (shōkōgyō rikkokuron 商工業立国論), which divided the public opinion at that time. The former defended the agricultural sector as the basis of the Japanese nation in not only an economic but also political and cultural sense. It criticized the corrupting influence of urban culture on the traditional virtues of the rural population such as frugality, diligence, loyalty, simplicity, and physical sturdiness. What worried agrarian country-ists particularly was the accelerated pace of urban emigration, which Yokoi Tokiyoshi attributed to “city fever (tokai netsu 都会熱)”- namely, an irrational frenzy

John Stuart Mill's economic thought is also influenced by Malthus, and it is possible that Yanagita came to know the Malthusian theory through Mill's main text on political economy, Principles of Political Economy. 
that spread among the rural youth lured by rumors about fancy urban life. To prevent a further disintegration of rural communities, they advocated protective measures for the agricultural sector even at the cost of commercial and industrial interests. In contrast, commercial/industrial country-ism regarded agriculture as little more than a supplier of food and raw materials, and, to lesser extent, a market for commercial and industrial products. As such, the agricultural sector was substitutable with foreign suppliers and consumers. Thus, commercial/industrial country-ism asked for a laissez faire policy toward the agricultural sector so that the price of food and raw materials could be kept low.

Yanagita's position can be summarized as the advocacy of balanced development. He argued that both agriculture and commerce/industry were important from the national point of view and that their interests should be understood as mutually complementary, rather than irreconcilably antagonistic. Moreover, in his view, favoring a particular segment of the national economy over the rest was contrary to the public interest. A passage from Nōseigaku reads:

Although there is no doubt that even today agrarian policy occupies a central position among economic policies, it is very dangerous to jump from this fact onto agrarian country-ism. The public opinion tends to assert that Japan is either an agricultural or commercial/industrial country and, from this bold dogmatic judgment, tries to infer national policy. However, because it is a plain fact that under the current economic condition it is impossible for either of agriculture, commerce, or industry to be the livelihood of the entire nation, and hence no one would dare promote one of them and completely destroy the others. Or, does that 
mean that we should put emphasis on one kind of national livelihood and leave others to rise and fall as nature dictates (probably resulting in constant decline), or that we should take it as a natural tendency that the relapse of agriculture, commerce, or industry that accompanies the disproportionate prosperity of one sector and refrain from efforts to coordinate or assist [declining sectors]? No one can tell that either of them is acceptable. ("Nōseigaku." Teihon 28: 193-194) In other words, the interest of any particular economic sector cannot be taken for the public interest, unless it is harmonized with the remaining part of the national economy, just as the eyes and hands are placed in their proper places within the entire body.

In a more specific political context, Yanagita's critique of agrarian and commercial/industrial country-isms derived from his view that both of them were actually an expression of growing power of large landowners and urban capitalists, respectively. For that reason, he directed his criticism not only to the proponents of commercial/industrial country-ism but also to increasingly vocal advocates of agrarian country-ism, including Yokoi and Sakō. What was completely neglected in the dichotomous opposition, in Yanagita's opinion, was the interest of small farmers, who actually constituted the majority of the nation.

At the micro-level, Yanagita believed that although Japanese agriculture was already very intensive in terms of land use, there remained "slack" to be tightened by means of the consolidation of cultivated land holdings, the elimination of unnecessary ridges, the improvement of irrigation systems, and the selective adoption of new crops, improved varieties of seeds and technologies, and so on. However, his boldest suggestion was the proposal of land redistribution aimed at the creation of independent mid-sized farmers. 
As is discussed above, he believed that a root cause for agrarian problems was overpopulation, because "[i]t is just impossible from the beginning to settle more than four million farming households on about five million $c h \bar{o}$ [one $c h \bar{o}$ is approximately one hectare] of paddies and fields and try to support almost thirty million, including landowners themselves" ("Chūnō yōsei saku." Teihon 31: 413). During the feudal period, the government had been able to maintain this state of affairs by harsh measures aimed to keep the level of peasants' consumption artificially low, but these measures were impractical in the modern age, when farmers had become more self-conscious and started asking why they remained so poor in spite of all the hard labor. Moreover, in the face of foreign competition, agriculture needed to invest in both human and physical capital to improve its productivity, but petty farmers, who barely survived at the subsistence level, could not afford to defer consumption to save part of their meager income for capital formation. To make the situation worse, whatever surplus remains was taken out of the countryside by the centralized national financial system to invest in urban sectors or overseas colonies (“Jidai to nōsei." Teihon 16: 40).

The only fundamental solution, Yanagita maintains, is to thin out farming households so that the remaining farmers could afford parcels of land large enough to make farming a viable business. In his opinion, "[t]he decrease in the number of farming households is not necessarily lamentable. In a country like ours, where the area of cultivated land is very limited, what is lamentable is the increase" (p. 413). Yanagita estimates that at least two cho of cultivated paddies or fields are necessary for farming to be a viable business for an average-size household. Because the agricultural frontier of Japan is limited, the number of middle-sized farmers could be increased only by easing 
millions of households out of farming ("Chūnō yōsei saku." Teihon 31: 412). Commerce and industry should be promoted to absorb those who give up farming.

Even in such a case, Yanagita prefers the development of industry and commerce taking place as part of each rural economy. In an article titled "The Economic Missions of Towns (Machi no keizaiteki shimei 町の経済的使命),” he classifies the approximately 1,100 existing towns into three types in terms of their historical function within the national economy. The first type is the consumption or tourist town, where "people come to spend money" ("Jidai to nōsei." Teihon 16: 78). It is described as heavily dependent on the consumption of unproductive classes and their residents as "frivolous" and "untrustworthy" in nature (p. 78). The second type is the market town, where people bring something to sell and buy something else in return. Although this kind of town originally developed as a part of the rural economy, he complains that the development of large market towns, such as Tōkyō, Yokohama, Ōsaka, or Kōbe, has come to occupy a monopolistic position in the national economy and has established the centralized system of distribution so that almost no merchandise reaches local consumers unless it goes through the hands of middlemen residing in those cities. In contrast, the third type of town, which Yanagita calls "production town" (p. 179), is more firmly embedded in local economies in the sense that it directly relies on local labor and materials for its production and has a positive and mutually beneficial linkage with its rural hinterlands. Yanagita's recommendation is to promote the third type of town as an absorber of surplus labor.

Unlike agrarian country-ists such as Yokoi or Sakō, therefore, Yanagita welcomes urbanization as a sign that surplus labor is being transferred from a stagnant to more 
dynamic sectors. Equally, he rejects the thesis that the rural youth is irrationally lured into urban life. In direct allusion to the Yokoi's "city fever" thesis, he suggested that "it is not a mistake, or 'fever,' that young people emigrate from the countryside to increase their income" ("Jidai to nōsei." Teihon 16: 37). In his view, their behavior is completely rational from the standpoint of each individual because it is supported by the sound calculation that their labor could be sold at a higher price in cities than in the countryside, where the overabundance of labor in relation to available land depresses their wages. On that ground, he criticizes the attitude of agrarian country-ists toward the rural population as overly paternalistic.

Yanagita's preference for independent mid-sized farmers has an important political aspect. What concerned him was the growing number of absentee landowners, who abandoned their traditional role as political leaders and representatives of the interest of farmers before higher authorities and were increasingly absorbed in partisan politics at the national and prefectural levels. Yanagita suggested that even though traditional rural communities were far from being egalitarian, they were the communities of farmers in the sense that even landowners used to engage in farming by themselves. Nevertheless, he feared, as the result of the introduction of capitalist relations into the countryside, a sharp distinction between landowners and tenants was developing. Unlike their predecessors, the new land-owning class was not farmers but rentiers and did not share the same identity with the peasant class. As a result, the interest of landowners diverged from that of farmers, and the former could no longer be said to be the representative of the latter. Largely relieved from traditional obligations to their villagers but retaining influential positions over the rural population as owners of the scarcest resources-i.e., 
land and capital, they were no longer farmers but the exploiters of them. His proposal to create a middling class in the rural population was an attempt to contain this trend of class stratification in advance. In allusion to the absentee landowning class, he describes mid-sized farmers as "landowners who have lived in the countryside for several hundred years, own lands inherited from generation to generation, and constitute, in the past and in the future, the backbone [chüken 中堅, literally the middle core] of the nation. Those are payers of the land tax...whose bodies busy themselves with national and prefectural affairs, but whose hearts at no moment stop thinking about the progress of agriculture" (“Chūnō yōsei saku.” Teihon 31: 417).

As suggested by the previous quote, for Yanagita, middle-sized farmers did not only constitute a middling element that mechanically balanced against the polarized opposition of agrarian capitalists and proletariats. They were also the historical carriers of a cultural ethos that Yanagita believes had critical importance to the preservation of the nation. Middle-sized farmers were the backbone of the nation not only as productive force but also as the preservers of the traditional institution of household (ie) and village (mura), without which he believed the state could not survive. In contrast to absentee landowners or tenant farmers, they would be sedentary and continue to work on lands inherited from their parents and pass them on to their children. Their attachment to lands would made them the core constituents of rural communities and the vigilant defenders of their own interests. Their embeddedness in the exchange and chain of affection and yearning through the practice of ancestor worship would serve as a bulwark against the individualizing force of urbanization. 
Beside the fact that the defiant posture of a young official would certainly get on the nerve of his superiors and academic authorities, it is not difficult to imagine what part of his proposal was hard to swallow for the latter. First, his acceptance of commerce and industry as complementary to agricultural development must have seemed a "sell-out" in bureaucratic turf wars. ${ }^{34}$ Equally, his proposal of land redistribution in favor of middle-sized farmers was too radical and ran directly against the powerful agrarian interest of the time. As a result, his somewhat naïve idealism fell victim to the monopolization of knowledge by a small group of academic authorities and high-ranking government officials. In his characteristically oblique statements, he expressed his frustration in the following terms:

Usually, in any policy [field], academic power and administrative power run parallel to each other, and experts hired by the central government are deemed as the most important. Minor officials under their supervision are better off parroting their theories. Nevertheless, studies of agrarian economy are the field most unfit for centralization. ... [i]t is simply impossible for five or eight experts in Tokyo to

\footnotetext{
34 Ann Waswo (1988: 571) briefly mentions a turf war between the Home Ministry and the Ministry of Agriculture and Commerce. While the former saw traditional rural institutions as a hindrance to national integration, the latter tried to co-opt them to promote agricultural development. The internal battle within the Ministry of Agriculture and Commerce, resulting in its breakup in 1925 into the Ministry of Agriculture and Forestry and the Ministry of Commerce and Industry, is documented in Johnson's study of the developmental state (1982: 83-95). In an editorial he wrote for Tokyo Asahi, a liberal newspaper, Yanagita sarcastically pointed out that the breakup was little more than an attempt by political parties to placate the landowning class that had been discontented with the urban bias of the Ministry of Commerce and Agriculture ("Sekkyoku seisaku to nōrinshō mondai." Teihon sup. 1:47-48)
} 
make observations and judgments that reach every corner of this long [archipelago of] Japan. (Teihon 16: 13-14)

What was supposed to be the allegedly impartial and foresighted bureaucracy and academia in theory turned out to be a close-minded clique of paternalistic officials obsessed with their own turf, academic authorities with second-hand knowledge borrowed from the West, and sycophantic followers who were ready to ignore any inconvenient opinion for the sake of their own narrow sectoral interest.

The Narrow Empirical Basis of Theoretical Knowledge

Yanagita's second criticism of the enlightened bureaucracy was directed at the alleged universality of imported "scientific" knowledge monopolized by the bureaucracy-academia complex. In this, he was faithful to the basic tenet of the Historical School of Economics, but extended it further than his German counterparts and Japanese followers were willing to do. For him, the narrowness of imported knowledge is attributable to two causes. First, imported Western knowledge has an innate urban bias. In other words, imported Western concepts and theories grew out of the experience of Western cities and actually represent a particular local perspective-namely, that of the urban literate class in the West. In Nōseigaku, he already complained that even the self-claimed social reformers-an indirect allusion to scholars subscribed to the Social Policy School—had been paying little attention to the rural sector because of the urban bias. "Because even those who acknowledge themselves as social reformers are urban residents and what they observe daily is limited to little more than the living condition of some wage laborers," his complaint goes, "every time they open the mouth, they say "the 
alliance of workers' or 'checking the power of manufacturers,' and limited themselves to advocating national policy for one generation [as opposed to the long-term planning] and concentrating in this kind of partial enterprises [as opposed to the interest of the entire nation]" (Teihon 28: p. 4). He suggests on several occasions that his writings are aimed to broaden this narrow spatial and temporal horizon of self-claimed and potential social reformers among rural residents who are less affected by foreign knowledge (e.g., Teihon 28: 5).

Second, he contends that Western theories' narrow empirical basis is further aggravated by the systematic exclusion of the experience of non-Westernized peoples. As discussed in the previous section, imported knowledge is predicated on the presupposition that every nation will follow the same developmental sequence, ultimately converting into a single form of civilization. In consequence, Japanese scholars and bureaucrats seek valuable lessons from the history of the United Kingdom and other Western societies, instead of inquiring directly into the history and specific conditions of the Japanese population. The result is that the Japanese experience is systematically discounted as valid empirical material for theory making. Instead of testing and improving theories with what is empirically observed, the enlightened bureaucracy and scholars tend to think that whatever is conceived as inconsistent with their own theories is an obstacle for progress and should be removed forcibly.

One such instance in which Yanagita is personally involved is the Shrine Merger Act of 1906. Led by the Home Ministry, another stronghold of reformist bureaucrat-intellectuals, the government aimed at consolidating small hamlet shrines into one central shrine in each administrative unit. As a result of this act, about 40 percent of 
approximately 190,000,000 local shrines throughout the country were destroyed and merged into central shrines by 1913 (Pyle 1973: 60). The policy was part of the efforts to convert Shintō into a centrally administered national religion comparable with the Christian Church in Western countries. The bureaucrats in the Home Ministry speculated that the extreme decentralization of Shintō practices not only promoted parochialism among villagers but also contributed to the shabby appearance of many hamlet shrines, degrading Shintō into a less than prestigious status, compared with Buddhism or Christianity. The centralization, they reasoned, would solve these problems. In various parts of the country, however, the policy was fiercely opposed by local residents, and some intellectuals joined their cause. At the request of Minakata Kumagusu (南方熊楠), a renowned naturalist and fellow folklorist, Yanagita supported the resistance movement behind the scenes from within the government. His major criticism of the policy was that it was informed by an utterly mistaken notion of the Japanese indigenous religion. According to him, hamlet shrines were not comparable with Christian churches or Buddhist temples, because they were believed to be but markers for places where local deities temporarily stayed during the time of festivities. What was important was the place itself, not the artifacts upon it. Though as much appreciative of the role of religion in social integration as the officials of the Home Ministry, he was concerned that the destruction of hamlet shrines, centers of village communal life and closely related to agricultural activities, would be counterproductive, exacerbating social disintegration in the rural sector. Probably, this incident should have served him as a warning against the hubristic intervention by bureaucrat-intellectuals, steeped in the knowledge of and from the West but utterly ignorant of their own homeland. 
Since the power and authority of the enlightened bureaucracy derived from imported knowledge predicated on the modern spatiotemporal order, Yanagita subsequently directed his criticism to the assumption that all nations were situated somewhere on a unilinear developmental sequence. As a result, he came to question the presumption that the West, especially the United Kingdom, could serve as an image of Japan's future. A comparison between an early text, Nōseigaku, and an essay contained in Jidai to nōsei reveals this shift. In Nōseigaku, Yanagita makes a case against national specialization in a particular sector of the economy by using the experience of the United Kingdom as an example not to be followed. According to him, the United Kingdom's error is that it "gave extreme importance to the benefit of the division of labor, and came to apply that theory to international economy" ("Nōseigaku." Teihon 28: 193). He points out that Japan's commercial/industrial country-ism is little more than the imitation of this example. However, he asserts, the theory had already proved wrong, because the British position as the industrial center in the international division of labor was being challenged by the rapid industrialization of nations in the European subcontinents and some others in Asia and America. As a result, "the international division of labor, which the United Kingdom initially believed was everlasting and unchanging, has completely changed in less than one hundred years" (p. 194), and the British economy was left in a vulnerable position in the more competitive international environment. Yanagita concludes:

Although the benefit that the United Kingdom reaped from the policy [of the international division of labor and national specialization in commerce and industry] is large, so is the loss that the same policy caused to the agricultural sector. 
This is because while intensive agriculture practiced in older nations is never capable of competing with extensive agriculture in newly colonized countries with the vast [uncultivated] land, the progress of the means of transportation reduced shipping costs and destroyed the only defensive wall [that intensive agriculture had] in international competition. Moreover, merchants and industrialists tend to welcome international competition because cheap food and raw materials are beneficial to them. Because the main outlet for their manufactured goods is overseas exportation, the reduced economic power of their own nation's countryside is not their problem to mind about. In short, British agriculture waned little by little, not because it was directly oppressed, but because the overemphasis on commerce and industry is left to natural progression. In light of this, it is harmful enough for national economic policy to concentrate its attention on a part [of the national economy]. It is easy to imagine how horrific the outcome would be if to promote the interest of one part, it sacrifices the interest of the rest. This point is applicable not only to the case in which commerce and industry outdo agriculture but also to the case where, in contrast to the example of the United Kingdom, the prosperity of agriculture is prioritized and the remaining sectors were left alone. ("Nōseigaku." Teihon 28: 194-195)

Here, Yanagita is projecting the image of Japan's future on the current condition of the United Kingdom and is warning that the Japanese people should and could avoid the same mistake.

On the contrary, in an essay titled “Inaka tai tokai no mondai (田舎対都会の問題 The Problem of the Country versus the City)," he repudiates what he wrote in Nōseigaku 
on the relevance of the British experience. Taking the specific British example as universal, he suggests, agrarian country-ism wrongly assume that the country and the city are necessarily antagonistic. He points out that even if demographic concentration in cities is a universal trend, its causes and effects greatly differ across countries. Yanagita raises the examples of the United States and France, where, according to him, internal migration did not ruin the rural sectors, and contends that the specific history and legal system of each country should be taken into account before handing down a premature judgment (Teihon 16: 29-31). Concretely, in an essay titled "Machi no keizaiteki shimei (The Economic Mission of Towns)," Yanagita suggests that in the case of Japan, the boundary between the city and the countryside has never been clear-cut as is the case in Western civilization (Teihon 16: 75-76) ${ }^{35}$ By rejecting the universal relevance of the British experience, Yanagita takes a step away from the body of knowledge predicated on the modern spatiotemporal order. Thus, he concludes that imported theoretical knowledge, derived from the narrow experience of the Western metropolis, is not "universal" knowledge applicable regardless of space and time. "What is needed today," he claims, "is not the diffusion of Western agricultural policy science but the development of Japanese agricultural policy science" (Teihon 16: 10).

It is worth emphasizing that Yanagita does not give up the possibility of universal knowledge. Rather, his claim is that Western theoretical knowledge is not universal enough, because it refuses to take into account particular conditions and experiences of non-Western societies. In order to compensate for this deficit in existing knowledge, a

${ }^{35}$ The same theme was further elaborated on in the book Toshi to nōson (City and Village), published in 1929 (Teihon 16: 237-391). 
national policy science has to develop first as a step toward a universal policy science. "What I call science [gakumon 学問] with an air of self-importance," he asserts, "is comprehensive research that covers the entire nation laterally and spans from the past to the future vertically" (Teihon 16: 10). According to him, such a science does not exist yet, primarily because of the lack of knowledge about the Japanese national history and space. In addition to his frustration with the government and academia, it was his innumerable excursions into the interior of Japan and direct encounters with rural folks as internal other that prompted Yanagita's critical reappraisal of the despotism of the enlightened bureaucracy. As a government official and expert of agricultural affairs, he traveled extensively throughout Japan as lecturer and consultant and was struck by the diverse economic and cultural conditions that Japan contained. Equally striking to him was the lack of knowledge of, or even indifference to, those local conditions that local government officials often exhibited. That forced him to rely on local natives for information. Given such an internal diversity, he reasoned, one-size-fit-all policy was not only inadequate but also positively harmful to the public interest because it neglected the interest of minorities, or even the silent majority. A passage from Jidai to nōsei reads: "In spite of the popular contempt for fussing over every trivial detail, from the point of view of those trivial details, it would be very annoying to be left alone for so long without being fussed over. Japan is a rare case in the world in that it is both mountain and island country at the same time. Even remote and lonely islands, if combined, constitute a substantial land mass. Remote mountain villages occupy a half of the national territory. Agrarian policy solely aimed at farmers in flat land simply will not do" (Teihon 16: 19). Accordingly, Yanagita became critical of the centralization of knowledge production and 
state administration, and, in the second period of his intellectual career, he became absorbed into those "trivial details" - that is, people and life in remote mountains and islands of the nation. Far from stranger to rural life, he himself had to admit his lack of familiarity with many rural customs and institutions. In the afterword attached to the 1948 edition of Jidai to nōsei, he confesses that "[e]ven now, when I read [Jidai to nōsei], it contains so many a fact to which I only gave some speculative thoughts but never could explain why" (Teihon 16: 160). He expresses his hope that students of minzokugaku would pay attention to those "mysterious phenomena" (p. 160) and complete his unfinished job, suggesting continuity between his nōseigaku and minzokugaku.

\section{Turning Mill against Mill}

Now that Yanagita's critique of Japanese enlightened despotism is clarified, we are in a better position to examine the paradoxical relations between Mill's On Liberty and Yanagita's apparently conservative minzokugaku. Although there is no direct historical evidence for this claim, it is not difficult to find the Millian spirit in the following aspects of Yanagita's minzokugaku.

\section{An Alternative to Dogmatic Sciences}

Yanagita's criticism of supposedly enlightened academic authorities and bureaucrat-intellectuals is that they only possess the "ape-like [faculty] of imitation" (Mill 1991: 65) and that allegedly scientific truth is actually second-hand knowledge based on the experience of the West narrowly understood. In other words, enlightened despots turn out to be mere imitators, not independent and critical thinkers. Their 
uncritical embracement of imported ideas amounts to little more than the replacement of one set of customs by another, as the new generation of the Japanese elite turns their belief in progress into another dogma to be followed blindly. In fact, the attitude of Japanese bureaucrat-intellectuals and scholars is closer to what Mill describes as a sign of the loss of individuality:

In our times, from the highest class of society down to the lowest, every one lives as under the eye of a hostile and dreaded censorship. Not only in what concerns others, but in what concerns only themselves, the individual or the family do not ask themselves—-what do I prefer? Or, what would suit my character and disposition? Or, what would allow the best and highest in me to have fair play, and enable it to grow and thrive? They ask themselves, what is suitable to my position? What is usually done by persons of my station and pecuniary circumstances? or (worse still) what is usually done by persons of a station and circumstances superior to mine? I do not mean that they choose what is customary, in preference to what suits their own inclination. It does not occur to them to have any inclination, except for what is customary. Thus the mind itself is bowed to the yoke: even in what people do for pleasure, conformity is the first thing thought of; they like in crowds; they exercise choice only among things commonly done: peculiarity of taste, eccentricity of conduct, are shunned equally with crimes: until by dint of not following their own nature, they have no nature to follow: their human capacities are withered and starved: they become incapable of any strong wishes or native pleasures, and are generally without either opinions or feelings of home growth, or properly their own. (Mill 1991: 68) 
Replace "the individual or the family" with "the nation" in the quote above and we get Yanagita's critique of Japanese political and intellectual leaders: They tend to ask first what is usually done in the West, instead of asking what would suit the Japanese character and disposition or what would allow the best and highest in Japan to have fair play and enable it to grow and thrive. Their primary concern is how to make Japan look more like a Western nation-state. The imitative political and intellectual leadership, Yanagita worried, led the entire nation into the state of cultural subordination in which its "human capacities are withered and starved: they become incapable of any strong wishes or native pleasures, and are generally without either opinions or feelings of home growth, or properly their own." Yanagita's minzokugaku is designed as an alternative mode of knowledge production that would replace the mimic sciences practiced by the bureaucrat-academia complex.

\section{Criticism of Centralization and Suppression of Diversity} Yanagita's critique of centralized administration and knowledge production also echo Mill's criticism of centralization:

In many cases, though individuals may not do the particular things so well, on the average, as the officers of government, it is nevertheless desirable that it should be done by them, rather than by the government, as a means to their own mental education —a mode of strengthening their active faculties, exercising their judgement [sic], and giving them a familiar knowledge of the subjects with which they are thus left to deal.... The management of purely local business by the localities, and of the great enterprises of industry by the union of those who 
voluntarily supply the pecuniary means, is further recommended by all the advantages which have been set forth in this Essay as belonging to individuality of development and diversity of modes of action. Government operations tend to be everywhere alike. With individuals and voluntary associations, on the contrary, there are varied experiments, and endless diversity of experience. (Mill 1991: $121-122)$

As discussed in the following chapter, Yanagita tries to redefine rural communities as unique and original human experiments. Experiments vary depending on the natural conditions under which they take place and the course of history that people choose, and it contains both successes and failures. Yet, each is valuable in its unique contribution to universal knowledge about human history. However, after the Meiji Restoration, the centralized government took over semi-autonomous communities and assumed the position of sole planner and conductor of experiments and turned the self-governed communities into mere objects of experiments. As a result, "individuality of development and diversity of mode of action" was suppressed.

\section{Selective Preservation of Customs}

Even Yanagita's criticism against the wholesale renunciation of customs is essentially Millian. In spite of his general antipathy toward customs, Mill readily admits that it is neither possible nor desirable for a new generation to renounce completely what is inherited from the preceding generations and to start from scratch (Mill 1991: 64). "[E]ven in revolution of opinion," Mill concedes, "one part of the truth usually sets while another rises. Even progress, which ought to superadd, for the most part only substitutes, 
one partial and incomplete truth for another; improvement consisting chiefly in this, that the new fragment of truth is more wanted, more adapted to the needs of the time, than that which it displaces" (p. 52). Both wholesale denunciation of the old and uncritical embracement of the new are equally dogmatic. What is important is to keep open the possibility for each generation to consciously choose which customs are to be kept and which are not on the basis of utility for their own purposes:

It is the privilege and proper condition of a human being, arrived at the maturity of his faculties, to use and interpret experience in his own way. It is for him to find out what part of recorded experience is properly applicable to his own circumstances and character. The traditions and customs of other people are, to a certain extent, evidence of what their experience has taught them; presumptive evidence, and as such, have a claim to his deference: but, in the first place, their experience may be too narrow; or they may not have interpreted it rightly. Secondly, their interpretation of experience may be correct, but unsuitable to him. Customs are made for customary circumstances, and customary characters; and his circumstances or his character may be uncustomary. Thirdly, though the customs be both good as custom, and suitable to him, yet to conform to custom, merely as custom, does not educate or develop in him any of the qualities which are the distinctive endowment of a human being. (Mill 1991: 64-65)

Yanagita's critique of the uncritical acceptance of imported ideas and the wholesale renunciation of indigenous customs closely resonates with this passage. Minzokugaku is against both dogmatic affirmation and blind denunciation of customs. Rather, the duty of 
the currently living is the critical examination of inherited customs and conscious selection of what to be preserved and what is to be abandoned.

Thus, Yanagita turns Mill's defense of diversity against his defense of despotic government in non-Western society. In a sense, Yanagita's minzokugaku can be characterized as what Mill describes a local and temporal alliance between the spirit of liberty and the opponent of improvement against the spirit of improvement "aim[ing] at forcing improvements on an unwilling people" (p. 78). However, his conservatism is not the negation of progressivism but a necessary means to conserve diversity and, hence, long-term foundation of progress. Therefore, instead of turning to the bureaucratic-intellectual elite as the guarantor of progress, he tries to rehabilitate the ordinary people as genuine agents of progress. For that purpose, however, Yanagita has to prove that in spite of Mill's claim, the East has history — a history that has never been written and is being forgotten because of the lack of written records. Here, another passage from On Liberty is relevant:

The fact, however, is, that not only the grounds of the opinion are forgotten in the absence of discussion, but too often the meaning of the opinion itself. The words which convey it, cease to suggest ideas, or suggest only a small potion of those they were originally employed to communicate. Instead of a vivid conception and a living belief, there remain only a few phrases retained by rote; or, if any part, the shell and husk only of the meaning is retained, the finer essence being lost. The great chapter in human history which this fact occupies and fills, cannot be too earnestly studied and meditated on. (p. 45) 
One of the tasks of minzokugaku is to study a part of "the great chapter in human history" in which the meaning of a unwritten doctrine of life that informed Japanese beliefs and practices was forgotten and, as a result, what was once a coherent ways of life was fragmented into a set of apparently meaningless customs.

However, one major obstacle to Yanagita's application of Mill's progressivism to the case of Japan is the latter's conception of progress, in which the genius of extraordinary individuals is featured as a main catalyst for a change. The following chapter turns to the question how Yanagita tries to offset Mill's individualistic notion of progressive agency. 


\section{CHAPTER III}

\section{THE HISTORY OF HISTORYLESS PEOPLE}

Yanagita's loss of confidence in the state bureaucracy and official academic institutions prompted him to turn to society - that is, social relations outside the realm of the modern state - in search of progressive agency. His disillusionment with the "impartial" bureaucracy and academia might have taken him away from German statism, more common among his fellow bureaucrat-intellectuals, to Millian liberalism. However, as suggested in the previous chapter, the transition was complicated because of Mill's assertion that " $[\mathrm{t}]$ he greater part of the world [outside Europe and its colonial offshoots] has, properly speaking, no history" (Mill 1991: 78). By this, he meant that non-Western societies had shown little progress because of the shortage or absence of progressive agents and, as a result, the non-West was little more than an extensive but depthless space with no history to tell. By implication, Japanese society lacked progressive agency before the advent of the modern state. In face of this claim, Yanagita needed to redefine non-Western space as a progressive zone by telling an unrecorded history of peoples without history. For that purpose, those denigrated as "backward," "ignorant," "superstitious," or "irrational" in modern knowledge had to be rehabilitated as rational agents and the subjects in knowledge production. He may have shared Mill's belief that "the only unfailing and permanent source of progress is liberty" (p. 78), but, in extending that claim to the non-Western space, he had to confront Mill's individualistic notion of liberty, diversity, and progress. 
In this process, Yanagita's project intersected Marx's materialist view of history in which human life is reproduced in daily and incessant efforts to reorder nature to satisfy their essential needs. According to this view, history is the transformation of nature by human collective acts and progress can be measured by the extent to which social organization adapts the natural environment for the satisfaction of their needs and adapts itself to a limit imposed by nature at a given time. Human agency is exercised by a historically defined collectivity whose scope and internal organization change as human relations with nature are transformed. Both Marx and Yanagita try to reground the economic sphere, abstracted out from anthropological space by classical economics, on the concrete historical existence of humanity. At the same time, Yanagita's appreciation of Marx is limited to the latter's methodological approach. He does not share Marx's ideological commitment and, instead, advocates a reformist and nationalist, rather than revolutionary and internationalist solution, to the problems of global capitalism.

That space can be properly called anthropological in the sense that it is where material conditions for human existence are constantly produced and reproduced by human deliberate action. It is not another realm adjacent to various spheres of human life, but a deeper layer underlying and integrating those compartmentalized spheres. For the urban literate class, it has become a sort of invisible world, which always exists parallel to the visible world, but is buried deep underneath the modern spatiotemporal order superimposed upon it. As a result, anthropological has become an adjective that connotes the world outside or before modernity and anthropology the study of "premodern" societies. Although the contemporary academic division of labor between sociology and anthropology makes the term anthropological unduly restricted, anthropological space in 
the sense used in this study is not a "prehistorical" or "animalistic" sphere of life in which each individual concerned herself with the production and reproduction of its own body, because it requires collective efforts to preserve human space within the cosmos which human beings are at once part of but became alienated from. ${ }^{36}$

\section{Yanagita, Marx, and Marxism}

Yanagita was known to be critical of Marxism throughout his life, but never directly engaged with Marx or Marxism in his writings. However, there is some indirect evidence for his growing interest in Marx's view of history during the 1920s. First, one of his disciples, who attended a course taught in 1924 at Keiō Gijuku University, recorded the following statement of Yanagita in his notebook:

... Out of the similar environment does emerge a similar phenomenon! I cannot question this truth. From this point of view, I believe it impossible to think that our country has its own idiosyncratic [tokushu na 特殊な] history. That is plainly wrong... Historiography, for its research, must take into account mass psychology and individual psychological effects. I think it is a mistake to think about history with an exclusive focus on matter. For, when observed as the question of facts, idea and matter, mind and body are indistinguishable. Although Marx and Engel's view of history is commonly called yuibutsu ron [唯物論 literally, exclusively-matter theory] these days, it is a plain mistake to translate their word materialistische into

\footnotetext{
36 Thus, Yanagita's approach resembles what Henri Lefebvre calls "the history of space" that borders on anthropology and political economy (Lefebvre 1991: 116-117).
} 
yuibutsu. For, at least Marx neither ignores nor excludes mental activities in his historical description. (Hayakawa 1970: 2-3)

Besides the fact that it is a remarkable statement for a person often characterized as a cultural essentialist and an advocate of Japanese exceptionalism, he is here suggesting that universal world history can be written and the history of Japan takes part of it. It is not clear which texts he is referring to when he claims that Marx does consider "psychological" dimensions, but regardless of whether his understanding of Marx is correct or not, it indicates his positive estimation of Marx's materialistische description of history in terms of writing world history.

Second, Yanagita's concern with the daily activities of the ordinary people closely resonates with a famous passage from The German Ideology: ${ }^{37}$

$[T]$ he first premise of all human existence, and, therefore, of all history [is] that men must be in a position to live in order to be able to 'make history.' But life involves before everything else eating and drinking, a habitation, clothing and many other things. The first historical act is thus the production of the means to satisfy these needs, the production of material life itself. And indeed this is an historical act, a fundamental condition of all history, which today, as thousands of years ago, must daily and hourly be fulfilled merely in order to sustain human life. (Marx and Engels 1978: 155-156)

37 The German Ideology remained unpublished until 1932, and it is unlikely that Yanagita read it in the 1920s. My claim here is not that Yanagita was influenced by the text but the theoretical concern he shared with Marx was captured in the quoted passage. 
Like Marx, Yanagita inverts the relationship between theory and practice and seeks to ground human history on the daily activities of the productive class. His minzokugaku can be described as an attempt to excavate a space in which this "historical act, a fundamental condition of all history, which today, as thousands of years ago, must daily and hourly be fulfilled merely in order to sustain human life," whose continual relevance, Yanagita believes, is obscured by advanced social division of labor and the façade of spurious urban civilization. According to this view, no material condition for human life is naturally given, however natural or primitive it may seem to the eyes accustomed to the visibly artificial space. Rather, it is human agency that creates and maintains them. The anthropological space is a persistent, if obscured, reality that underlies even the most advanced civilization.

Another piece of indirect evidence for the theoretical connection between Yanagita and Marx is the fact that dozens of active or former Marxist student activists turned to his minzokugaku in search of either a complement to or a substitute for Marxism. This is partly because his minzokugaku provided an asylum for Marxist activists from the government's persecution, since, due to its apparent conservatism or political innocuousness or Yanagita's public stature as a former high-ranking government official, minzokugaku largely eluded the increasingly intrusive official censorship and other attempts by the government to muzzle potentially dangerous discourses. However, historical evidence shows that those Marxists and former Marxists saw in his minzokugaku not a convenient cloak but a true theoretical potential to complement or supplant Marxism. The earliest example is Hashiura Yasuo (橋浦泰雄 1888-1979), who met Yanagita in 1925 and from then on became his trusted lieutenant in the national 
organization of minzokugaku researchers. He understood minzokugaku as a compatible companion to Marx and Engels' theory and saw no contradiction in being both Marxist and a student of minzokugaku throughout his life (Tsurumi 1998: 19-65). Another example is Fukumoto Kazuo (福本和夫 1894-1983), a leader and chief ideologue of the Communist Party of Japan before his downfall from the party leadership in 1927. In 1942, after serving ten-year term in prison, he met Yanagita, with Hashiura acting as go-between, to ask for advice on a planned fieldwork of his own hometown in Tottori Prefecture. Disillusioned with dogmatism and factional politics behind the communist movement, and with the excessively paternalistic attitude of the Comintern in Moscow, he also saw in the inductive methods of minzokugaku and its focus on kyōdo (more or less equivalent to the American word hometown with a heavy rural connotation) a useful correction to the dogmatism of the mainstream Marxist movement (Tsurumi 1998: 135-166). For other former radical students who completely parted with Marxism, Yanagita's concept of jomin offered a volkisch alternative to the Marxian notion of the working class (Tsurumi 1998: 67-105). As Tsurumi Tarō (1998: 14) points out, those Marxist and former Marxist students turned to Yanagita for different reasons and their relationship with him differ accordingly. Some, like Hashiura, became loyal disciples of Yanagita, while others, like Fukumoto, remained independent. Yet all of them shared a sense that his inductive methods and his notion of jōmin could be complements to or substitutes for Marxist theory. ${ }^{38}$

38 Tsurumi Tarō (1998) documented the relationship between Yanagita and former radical students. The episode is conventionally understood as proof of the capacity of minzokugaku to embrace the diverse array of intellectual concerns as well as Yanagita's personal broad-mindedness toward differing opinions. However, Tsurumi points out that 
The theoretical affinity between Marx and Yanagita does not necessarily mean that the former directly influenced the latter, and, given the lack of any direct evidence, it is foolhardy to claim that Yanagita was consciously in conversation with Marx when he wrote his texts. After all, their thoughts were the products of their respective space and time and dealt with historically specific questions. Yet, even if such is the case, the affinity itself constitutes an interesting puzzle: Why did those thinkers from quite different backgrounds and ideological orientations come to focus on the anthropological space? A possible answer is modernity. The answer relies on the assumption of a parallel between Germany in the mid-nineteenth century and Japan in the early twentieth century. Though this answer may not be totally off the mark, a more specific theoretical connection emerges when we interpret Yanagita's intellectual project as a critical engagement with Mill's philosophy of history. Mill identified both the people of the East and the domestic laboring class in Europe as a stagnant portion of humanity. That is why Marx's efforts to rehabilitate the latter by excavating anthropological space is relevant to Yanagita efforts to redefine the former as the subject in history, in spite of Marx's own prejudice against the East. Marx's notion of the proletariat has a correspondence in Yanagita's concept of jomin. They are both the direct producers of the material basis of society. Another important concern both thinkers share is the relationship between knowledge and the material basis of society. Both of them are critical of modern

the relationship between the master and his Marxist followers bears creative tensions. Some of them came to challenge openly his methods and theoretical assumptions and his reaction to them was often irritable and intolerant. A point of contention concerned Yanagita's reluctance to allow disciples to engage in theoretical debate, which reduced them to the status of fieldworkers gathering data for him. 
knowledge precisely because it systematically exclude the subjective experiences in anthropological space. In their view, any knowledge about human life, if detached from anthropological reality, could be neither objective nor universal. And for both, the neglect is not merely a product of the unfortunate negligence on the part of individual scholars but a reflection of a larger social structure in which mental labor separates itself from manual labor and gains upper hand. Therefore, the self-examining education of the oppressed class becomes a key ingredient in their intellectual and political projects.

All of this does not mean that Yanagita is a closet Marxist. Just like his engagement with Mill, the way he appropriates Marx's thought, if he does it at all, is highly selective and his overall ideological orientation stands in paradoxical relations to Marx's own. Yanagita's historical narrative aims at relativizing and neutralizing class conflicts, instead of embracing them as an inevitable aspect of and driving force for human progress. Most likely, Yanagita found in Marx's materialist view of history a useful correction to Mill's philosophy of history, but considered the Marxist theory as too abstract and Eurocentric. Yet, even if he did not directly engage with Marx, the latter's thought provides a useful point of reference to understand, appreciate, and criticize Yanagita's unarticulated social and political theory.

At the same time, the affinity between Marx and Yanagita's overall problematic also brings differences between them into relief. It is these differences in similarity, not the extent to which Yanagita's thought is influenced by Marx that makes the comparison between the two thinkers a rewarding endeavor. Probably, Yanagita himself was not so much interested in theoretically engaging with Marx, or any other theoretical thinkers for that matter, as in warning younger generations against the danger of an uncritical and 
imitative application of an imported theory to the case of Japan. After all, Marxism is what Michel Foucault names as a prominent example of "totalitarian theories" (Foucault 1980: 80) that tend to disregard local particularities for the sake of abstract universality. ${ }^{39}$ In spite of his general sympathy toward Marxists' concern with the oppressed class, Yanagita would argue that the importation of another theoretical knowledge predicated on the Western experience would simply reproduce in Japan the same kind of social conflicts afflicting the Western societies. Thus, he would be repeating what he had concluded about agrarian policy science: What was needed in Japan was not the importation of Marxism but an endogenous theoretical and practical knowledge for resistance and change. If he appropriated Marx's historical view, he did so in the Millian spirit of self-reliance.

Two clusters of differences can be identified as the most relevant to this study in distinguishing Yanagita's from Marx’s thought. First, Yanagita does not share Marx's belief that industrialization and urbanization is an inherently progressive, if morally ambiguous in the short term, process. Rather, he embraces agrarian society as a model of civilization. As discussed in the previous chapter, however, this does not mean that he is a reactionary agrarian thinker, because he also believes that industrialization and urbanization are desirable for Japan of his time. His appreciation of agriculture as a quintessentially civilizational activity is rooted in a particular understanding of the relationship between nature and human beings. The second cluster of differences concerns the role of culture, or religion especially, in social integration. Unlike Marx, he

${ }^{39}$ It should be noted that Foucault's meaning could have been rendered as "totalizing," rather than "totalitarian," theories. I thank Clement Fatovic for pointing this out to me. 
believes that religious beliefs and practices are essential ingredient for the reproduction of material conditions for human existence-i.e., a historically specific form of human space, because it is by the means of religion that the individualizing force of daily labor is mitigated and a broader spatial and temporal horizon is secured, though tenuously. To use the Marxian terminology, religious practices belongs to the base, rather than superstructures, and the distinction between the base and superstructures is not the same as that between matter and idea. However, it is not any kind of culture, but a set of indigenous practices informed by a particular cosmology of agrarian society—i.e., an understanding of the social and natural world - that contributes to the reproduction of the material conditions. Such cosmology is inseparably embedded in and permeates the daily and local political economy. Culture, in this sense, is specific to each material space. Combined, the two clusters makes Yanagita's anthropological space explicitly heterogeneous in comparison with Marx's. The heterogeneity of space is no longer translated into historical stages and continues to be spatial differences contemporaneous with each other. In other words, he re-spatializes global diversity temporalized by Mill, Marx, and other Western thinkers and redefines each spatial division not as a stage of universal history but as a container of its own time. As will be discussed later, this procedure has far-reaching implications for his conception of global order.

In the remainder of this chapter, I elaborate further on the differences between Marx and Yanagita's anthropological space. The first section deals with the question of labor and stagnant space that discursively connects Mill, Marx, and Yanagita's thoughts. The second section discusses Yanagita's conception of the relationship between nature and human space. Yanagita inherits the Western notion of civilization/progress as the 
conquest of nature by human agents, but not the belief that natural time and space is inherently harmonious and orderly. As a result, his historical view lacks the teleological and deterministic aspects of Marx's progressivism. The third and fourth sections shift the focus to the two major differences between the two thinkers and look into Yanagita's agrarianism and his concept of jomin, respectively.

\section{Stagnant Space and Labor}

In the simplest form, the modern spatiotemporal order divides the world into progressive and stagnant spaces and time is conceived quite differently in each space. In the progressive space, time accumulates itself, so to speak, and the accumulation sediments into history. The accumulation of time in this sense can be measured by the continuous addition of extra units of wealth, knowledge, or other goods in general, and progress can be defined as the accumulation of the good in a particular place. In the stagnant space, in contrast, each unit of time becomes a spent force as soon as it passes off, leaving a few traces behind. Time does not sediment, but dissipates in the air. The stagnant time can be described as cyclical, recurrent, or repetitive, or, alternatively, time itself is converted into a space, since the past, present, and future look almost identical with each other. When Mill declares that non-Western space did not have history, he means that the world outside Europe belongs to the stagnant space in this sense. And, he is afraid that the advent of democracy could put a brake on the accumulation of time and that eventually the history of the West, and with it human history itself, might come to standstill. 
Mill's otherwise surprising equation between the future of Western democracies and the sclerotic ancient civilization of China, mentioned in the previous chapter, becomes comprehensible if it is understood to reflect his concern with the possible decline of Western civilization. The threat he felt came not from outside but from within, as his main concern was the entry of the laboring class into politics. While championing the cause for the extension of franchise to the working class, he was at the same time apprehensive about the prospect of the uneducated masses' becoming the preponderant majority and exercising tyrannical power over minorities by means of class legislation and social pressure (Mill 1991: 8-9). Thus, whereas he considered political participation to be a necessary instrument for the education of the general public, his democratic theory introduced many safeguards against the tyranny of the majority. The social form of the tyranny of the majority would be particularly dreadful for him because the laboring class, he feared, was more prone to be complacent with the status quo and not progressive enough to keep society from descending into conformism and mediocrity.

Arguably, Mill's skepticism toward the laboring class derives from the notion that labor is a merely reproductive activity to satisfy the recurrent bodily needs of the individual. ${ }^{40}$ The products of labor are consumed as soon as they are produced and leave

${ }^{40}$ In Principles of Political Economy, Mill distinguishes productive and unproductive labor. According to his classification, productive labor is that which adds material wealth to society, whereas unproductive labor is that "which does not terminate in the creation of material wealth; which, however largely or successfully practiced, does not render the community, and the world at large, richer in material products, but poorer by all that is consumed by the labourers while so employed" (Mill 1967: 50). He denies the view that unproductive labor is necessarily wasteful, but points out that "its use may consist only in pleasurable sensation, which when gone leaves no trace; or it may not afford even this, but may be absolute waste" (p. 50). While expansion of unproductive labor is a mark of civilization, since it means that an increasing potion of labor is used to satisfy wants of 
no trace behind. In other words, the laboring class is the faceless denizen of a stagnant space with no history to tell. The space to which the laboring class belongs is a China within, so to speak, now threatening to take over the progressive space of the West. ${ }^{41}$ Then, Mill's liberal theory could be understood as an attempt to gradually incorporate this stagnant potion of the population, the barbarian within, into a progressive nation without the latter being absorbed into the former. Western civilization he desired to defend was actually the fruit of "remarkable diversity of character and culture" (Mill 1991: 80) nurtured and protected under the decentralized aristocratic political system. With the advent of democracy, he feared, it would be run over by the faceless and homogeneous horde of laborers. As a result, his acceptance of democracy only comes on the condition that the development of individuality is shielded from the tyrannical majority by the protection of individual liberty. He expected that private autonomy protected by law preserves oasis of aristocratic virtue in the flat social landscape of democracy.

Not surprisingly, therefore, Mill's notion of liberty and progressive agency is highly individualistic. Social progress is a function of the genius of a few exceptional individuals, who, against the social conventions of their respective times, blaze a new trail for the less ingenious part of humanity. What separates those independent-minded,

the community other than mere living, he believes that unproductive labor should not outpace productive labor.

${ }^{41}$ In an interesting twist, therefore, now China, and the East in general, did not represent the past but a possible future of the West. To put it differently, what is allegedly in the past/East is actually present within the present/West. Beate Jahn (2005) points out that Mill's image of the barbarian is a projection of the internal other of the West. "Indeed, the barbarian is civilization's historical self, its contemporary other, its internal other, and its future self" (Jahn 2005: 610). 
convention-defying, eccentric, or even aristocratically insouciant persons from the rest is the critical use of reason. Instead of accepting received knowledge blindly, they examine them critically, explore alternative ideas, and experiment them in action. Their geniuses work best when they are insulated from mundane concerns that preoccupy the minds of the ordinary people. Even though their contemporaries often misunderstand and vilify them, it is they who lead the rest of humanity in the long run into a higher stage of perfection. Mill argues that Europe was able to pull ahead of the rest of humanity in the developmental race precisely because its decentralized social and political institutions offered refuge for talented individuals from social pressures and political persecutions. On the contrary, in China and the entire East, overbearing government and society robbed individuals of opportunities to develop their individuality and withered their potential talents. As a result, society as a whole suffered from the shortage of progressive agency, unless on rare occasions overambitious despots came on the scene and dragged society out of its sleep by force.

To Yanagita, Mill's view on progress must have had disturbing but not easily refutable implications. According to this view, the apparent permanence and the predominance of labor in rural life might be a proof of its stagnant nature. Moreover, it was difficult to argue that rural communities were hospitable to the development of individuality and experimentation with new ideas. Quite to the contrary, they were known for the pervasiveness of oppressive social norms, which were often contrasted to individual freedom enjoyed in cities. In a similar vein, the rural population was depicted as the mass of anonymous laborers who clung to inherited customs out of the irrational worship of the old. In order to rehabilitate rural space as a site of progress, Yanagita 
needed to redefine labor as a progressive activity. It is for that purpose that Marx's view of history may have offered Yanagita a useful hint. However, Yanagita's anthropological space differs substantially from Marx's in various aspects, and the difference can be traced back to his conception of the relationship between the natural and the human.

Time, Nature, and Human Space

Anthropological space is the realm where human life reproduces itself. It is not a static space, though. For both Marx and Yanagita, that is where progress is being made. However, Yanagita's conception of space and time in anthropological space differs from Marx's in an apparently subtle but quite consequential way. For Yanagita, time is neither the succession of empty and homogeneous moments in which history unfold itself nor a preordained journey to a given destiny. Instead, it is full of contingency, unpredictability, and ruptures. Even nature is not immune to drastic changes. In his travel writings, he often notes that natural conditions, which seem permanent from the limited perspective of an individual, have constantly been changing. Sometimes, natural disasters such as earthquakes, floods, tsunamis, or volcanic eruptions suddenly and radically change natural landscapes. Other times, a river gradually shifts its course or silt piles up in a narrow strait converting an offshore island into a cape. Animal populations also wax and wane. A passage from one of his travel writings reads:

It is not only the human world that is changeable. The rapid mutability of nature is equally surprising. Humans grow up in a fixed way, look for spouses, have children, and perish. The so-called four seasons of human life are rather well regulated. Greed and hunger are permanent as well. Such a drastic change as to turn a 
mulberry field into the blue sea cannot be observed in the human world. In comparison with this, the future of the natural world is by far more uncertain.

...The mutability of the animal world deserves grievance dozens of times as much [as that of the human world]. Whereas the traces of human beings fills day by day the space between the site of placenta burial in Dōkan Mountain and the cemetery in Yanaka and Somei [which marks the western and eastern edges of the north Tokyo metropolitan area], changes in the natural world are but transient as everybody neglects and forgets them. ("Mame no ha to taiyō." Teihon 2: 328-329) Thus, Yanagita inverts the conventional relationship between nature and man-made space: Now nature represents transience and society permanence. Nevertheless, he does not think that the relative permanence of human space is a matter of course. Rather, it is only by means of human agency that a lasting spatial order is maintained. In fact, where he and his Romanticist friends in the literary circles had once seen pristine nature, he now sees the traces of human intervention. In allusion to Musashino (武蔵野 1901), an influential Romanticist essay in which Kunikida Doppo (国木田独歩), then a close friend of Yanagita, eulogized the unspoiled beauty of the Musashi Field outside the west of Tokyo, Yanagita writes:

The oak forest on the border with the village that Mr. Kunikida loved was actually a human artifact made in the early modern period, not a remnant of the [pristine] Musashi Field. Two $r i$ [approximately eight kilometers] northwestward from Shibuya, oak trees are replaced by cedar trees. Because cedar trees especially stand close to houses and are carefully administered, no one mistakes them for naturally grown, although they look old. The same can be said of the oak trees. Because there 
was such high demand for fuel in Edo [the old name of Tokyo] as to ship [firewood] from Izu Ōshima [an island in the Pacific], farmers in the neighboring areas, upon calculation, often found it advantageous to plant trees for fuel, instead of clearing and cultivating the land. (Teihon 2: 334)

In other words, what seemed a primeval forest to the urban literate class turns out to be a product of a commercial enterprise of rational farmers and an important part of the economy of urban civilization. Similarly, Yanagita is emphatic that the rural landscape of agricultural society, which seems to the urban literate class natural or closer to the state of nature, is actually a deliberately created and carefully maintained spatial order.

That nature is more mutable than human society does not mean that human life is fully regulated and hence predictable. On the contrary, the vagaries of time affecting human space is one of the persistent themes of Yanagita's travel writings. In a most poignant section of Yukiguni no haru (雪国の春 Spring in the Snowy Country, 1920), for example, he records his surprise in finding that a family-owned small inn he had stayed during his travel to Tōhoku six years before disappeared without any trace. After inquiring the fate of the owner family from villagers, he learned that it was abandoned after the ship the husband was aboard never returned and the wife had moved to a town to work as a domestic servant, and that two children were now separated from her (Teihon 2: 105-111). Not only individual families but also entire town or villages meet a similar fate. Prosperous port towns, which attracted sailors and prostitutes throughout the country, disappeared without leaving almost any trace, because the construction of a railroad nearby made sea transportation suddenly unprofitable. However, the decline often takes the form of the slower and invisible unraveling of spatial order, largely due to unintended 
consequences of internal changes. Like Fortuna in Machiavelli’s The Prince (1992: 67-69), Yanagita's time is fickle and unreliable, and even if subdued for a moment, for the next it threatens to sweep away human traces accumulated in space. The best humans could do is to be vigilant against any sign of danger, prepare for the worst, and pass on to coming generation lessons learnt from past experiences.

For Yanagita, therefore, labor is not merely a mindless and instinctive activity to satisfy the recurrent bodily needs, but also a conscious collective effort to carve out and preserve human space out of unpredictable nature. This conception of labor draws Yanagita closer to Hannah Arendt's critique of Marx. She distinguishes "work" from "labor" on the ground that the former, unlike the latter, "provides an 'artificial' world of things, distinctly different from natural surroundings" (Arendt 1998: 7). Those man-made artifacts are not immediately consumed, but are intended to outlive those who produce them to make part of the world into which their successive descendent are born. Yanagita's conception of labor clearly embraces both "work" as well as "labor" in the Arendtian sense. ${ }^{42}$ As a result, the product of collective labor, human space itself, is no longer a faceless, homogeneous one. On the contrary, each space has its own human face and a distinctive history behind it. It is not mass-produced products but "works."

In Yanagita's view, therefore, rural space is far removed from the state of nature. Indeed, it is an advanced form of political space created by the collective will of a community and maintained with the greatest possible precaution and care. As he inverts

42 It is arguable that Arendt interprets Marx's notion of labor in an unduly restricted way. After all, the accumulation of capital, which is constantly reinvested into the means of production, is central to Marx's theory. For a critique in this line, see Pitkin (1998: 127-144). 
the relationship between the natural and the human, the assimilation of the latter into the former does not guarantee permanence. Rather, it is by means of human active intervention that some degree of permanence is achieved, albeit tenuously. Therefore, a task of historiography, he claims, is "a study of human power vis-à-vis nature" (Teihon 16: 168). This sounds Marxian, but, because of his notion of non-linear time, his progressivism lacks a teleological element characteristic of the Western historiography during the nineteenth century. As a consequence, his historical narrative is less deterministic because the prospect of human progress depends on nothing but human will and action. And for him, the primary form of this historical agency is labor - that is, an act of working in and on nature. Thus, his historiography has more affinity, not with Marx the structuralist, but with Marx who emphasizes the subjectivity of members of classes. Thus, from the late 1920s on, Yanagita shifted his attention from policy science to historiography and, with the help of minzokugaku methods, attempts to write a less deterministic history of human progress that count in the agency of those who are denigrated as stagnant peoples. The unrecorded history excavated in this way, he expects, would serve as the reservoir of self-knowledge_-viz., knowledge of one's relations within and to society and nature, and a practical instrument in political resistance against the imposition of the modern spatiotemporal order.

\section{History without Proper Nouns}

To excavate the anthropological space is to write a history of anonymous persons who collectively produce the material conditions of life, but are never counted as the subject in history in the conventional biographical history, whose main focus is 
extraordinary events and individuals. Because the dominant form of life before and outside modernity is agriculture, the majority of those anonymous persons are farmers. Yanagita points out that they are often represented in old paintings by the myriads of the Japanese phonetic alphabet $h e(\backsim)$, because of the shape of the woven hat they wore, or pill-like circle in the background (Teihon 25: 10). In other words, they are comparable to the repetition of the same symbols, lacking individuality altogether. They matter only in quantity, not quality, and their life makes no difference in the self-perfection of humanity. As such, they do not have any history. However, he points out, each of those represented by a he or circle was the head of a respectable household and political leader back in their hometowns (p. 10) — the mid-size farmer, in other words, who had constituted the core of Japanese civilization. Yet, urban artists and historians systematically misrepresented them as little more than passive elements in the background against which various dynasties waxed and wane through the heroic actions of prominent figures. For the urban class, history exclusively belongs to the class of nobles and warriors with proper nouns, not to anonymous peasants. The situation did not improve much in Yanagita's time, when modern knowledge, while exalting the value of the individual, reinforced the preexisting prejudice against agricultural laborers, as attested by a quip given by a professor of Japanese history at the Tokyo Imperial University, when one of his students expressed his interest in the history of peasants: "My dear, do pigs have history?" (Irokawa 1996: 35). It is against this backdrop that Yanagita felt the need to write "history without proper nouns."

History without proper nouns is primarily an antithesis to the conventional historiography in Japanese official academic institutions. The latter is mainly concerned 
with great historical characters. The history of nobles and warriors is taught in classroom throughout the country as national history, and, as a result, the experience of peasants is completely left out from it. Therefore, history without proper nouns is a history of rural communities in which ordinary peasants have never ceased to be toiling on land to produce and reproduce spatial order until this day. At the same time, theoretically it assumes collective, not individual, agency in the creation and maintenance of political order and can be opposed to the Millian theory of progress, or any kind of political theory that presupposes the abstract individual at the basis of political community. In a sense, rural communities are to Yanagita what Greek and Roman republics are to such Western republican thinkers as Machiavelli and Rousseau — exemplary models from which both positive and negative lessons can be drawn — but his rural communities have neither written down laws nor identifiable individual legislator-no Lycurgus or Solon, no Romulus or Numa. Instead, unwritten customs and traditions function as law and "legislation" is a collective act of innumerable and anonymous individuals, both dead and alive.

The major difficulty, however, is the lack of written records of the ordinary life of the common people. Most old documents pay scant attention to the daily life of the rural population, and if they do, they are written from the perspective of the center and are blatantly biased. Moreover, most preserved records belong to either the late ancient or the early modern period, when the Japanese archipelago was pacified by a relatively centralized government, but scarce written records are preserved from the war-ridden middle age, when Yanagita believes the foundation of autonomous rural communities was laid under a decentralized feudal system. Because of this bias in preserved historical 
records, the philological approach only yields urban-centric history, usually concerned with politics at the center. Meanwhile, another kind of historiography, based on archaeological methods, is mainly concerned with the distant past and its empiricism is often compromised with wild speculations about the origin of the Japanese race. What is missing is the history of rural Japan, in which innumerable communities, unknown to the central authority and the urban class, established themselves as small and relatively independent republics throughout the country and gradually expanded human space - namely, the history of Japanese civilization.

His attempt to rewrite the history of Japanese civilization begins with his reengagement with the agrarian problem in two books published in the late 1920s, Nihon nōmin shi (日本農民史 The History of Japanese Peasants, 1926) and Toshi to nōson (都 市と農村 City and Village, 1929). In them, he adopted an explicitly historical approach to the same agrarian problems addressed in his earlier writings by tracing the long-term historical process, in which agrarian society was differentiated into the urban and rural sectors and corresponding social classes. Although his historical account does not follow the substance of Marx's theory of class struggle, the general style and methods have an affinity with the Marxian approach in a broader sense that they center on the evolution of productive activities and corresponding social relations, rather than a series of events that mark the rise and fall of succeeding governments or acts of extraordinary individuals. It is a history in which human collectivities gradually and imperfectly conquer their natural environment to satisfy its basic needs, but not without generating unintended consequences. 
Yanagita's further experimentation with the history without proper nouns results in Meiji Taishō shi: Sesō hen (明治大正史 世相編 The History of Meiji and Taishō Periods: Social Aspects, 1931). In the preface to the book, he explains that his project derives from the premise that "respectable history can be written simply on the basis of the cross section of modern life, that is, facts that appears and disappear everyday before our eyes" ("Meiji Taishō shi sesō hen." Teihon 26: 129). The book traces the history of the lifeworld subjectively experienced from generation to generation by the ordinary people. It consists of fifteen chapters, apparently arranged to zoom out from the most personal to the most collective experiences. It begins with the history of what the common people see and hear (the colors and shapes of things and sounds surrounding them), what they eat (food), what they live in (housing), and then moves to the history of their immediate environment including landscapes, relations within and between communities, communication and transmission of culture between communities, the function of sake in social life, the art of love and marriage, and the household. The tenth to the fourteenth chapters deal with questions of the national dimension such as production and trade, labor distribution, poverty and disease, associations and self-government, and political leadership. Yanagita further clarifies his intention in the preface:

[B]ecause of the dissatisfaction with the conventional biographical history, this book intentionally avoid mentioning any proper noun... Therefore, Sesō hen is not a book about what heroes thought and did. It concerns only what common persons [jōnin 常人], who fill every corner of this country, can see and hear if they open their eyes and listen intently, and expresses nothing but opinions that occurs to them 
when they meditate a little. I would be troubled if someone views it as the imposition of the diagnosis of an observer with a unique standing. I am in no way a person proud of one's own knowledge, but my opinions are a little bit more original than these [presented in the book]. However, I think it dishonest to force them by the name of lecturing history, and I did not. (Teihon 26: 130)

In other words, Yanagita is claiming that even the subjectivity of the author is sacrificed to write a history acceptable to all. Though the claim of objective history sounds naïve today, it suggests his conviction that the common experience of the ordinary people should be the foundational basis of history.

Generally, the book tells the history of improvement, perhaps with the notable exception of political leadership, as he suggests that although many things have been lost, "what has been gained during the sixty years of Meiji and Taishō is certainly more than what has been lost" (Teihon 24: 226). However, he points out, both gains and losses are not necessarily the results of deliberate plan and coordinated actions but the unintended consequences of uncoordinated behavior of individuals and are not without negative effects on the overall welfare of society. Then, the final chapter exhorts readers to be active and conscious agents, "public citizens [kōmin 公民]" (p. 414), in determining their own fate. The uncharacteristically optimistic diagnosis is likely to be the result of the fact that the book has been written not to convey his own view but opinions that are acceptable to all, but the underlying message is clear: The common people have been making progress without the help of extraordinary individuals or a paternalistic government, but the accelerated pace of social change is outdoing their consciousness. 
Yet, in the preface to the book, Yanagita concedes that the book was a failure. Although originally he thought it possible to write an objective history solely relying on information conveyed in newspaper articles, it turned out that "real society is far more complex than is reported [in overabundant news articles] and newspapers only cover a portion of it" (Teihon 24: 130). Therefore, he was forced to abandon newspapers as the primary source of data and resort to "facts that the reader knows and I also know" (p. 131) and adopt "methods of listing up facts that nobody dare refute so that there is no need to verify the sources" (p. 131). It seems that partly because of this experience that he felt keenly the need of systematizing the methods of minzokugaku. Instead of newspaper articles, minzokugaku relies on an extensive network of fieldworkers who gather relevant information according to the classificatory scheme laid out by Yanagita in two manuals for minzokugaku research, Minkan denshō ron, (民間伝承論 Theory of Oral Traditions, 1934) and Kyōdo kenkyū no hōhō (郷土研究の方法 The Methods of Hometown Studies, 1935). Minkan denshō ron and kyōdo kenkyū are two names Yanagita used to call the academic discipline he tried to establish before he accepted, somewhat reluctantly, minzokugaku as its official name in the mid-1930s. In other words, minzokugaku is a method for historiography that excavates the unrecorded history of social progress and its agents - namely, those who produce human space by working in and on nature. For Yanagita, they are true progressive agents and legitimate owner of a national space. He gives them the name jomin-i.e., the common people. Before examining the concept of jōmin, however, I now turn to his agrarianism to understand the theoretical underpinning of the concept. 


\section{Agriculture and Civilization}

One of the most obvious difference between Marx and Yanagita is the latter's preference for agricultural society over industrial society. In spite of his criticism of agrarian country-ism, he does prioritize agriculture as the basis of the national economy and political community in his own way. Therefore, he does not share Marx's conviction that cities represent a more advanced form of civilization, and favors agrarian society as the model of civilization. In Nōgyō seisakugaku (Agricultural Policy Science, 1902-1903), he already describes agriculture as the integrative fabric of the "modern" state/nation: The state is composed of a people and a territory. Territory is neither a mere container of a people nor the means to make known the reach of the sovereignty [of the state]. It constitutes an element of the state by itself. ... In order to connect a people with territory, it is necessary to settle them on land. Settlement on land is nothing but an element of the existence of the state. The state in the modern sense would not be established without settlement. The origin of the settlement is, in turn, agriculture. In other words, what connects a people to land is agriculture. Floating elements [fuyu bunshi 浮遊分子] among the national population increase as agriculture wanes. Agriculture is the anchor of the nation [kokumin 国民]. ("Nōgyō seisakugaku.” Teihon 28: 302)

Another passage from Jidai to nōsei (Our Time and Agrarian Policy) emphasizes the integrative function of agriculture more explicitly by connecting the individual, the household (ie 家), the village (mura 村), and the state/nation: “If one likens the organization of the national economy to a machine, agriculture is its cogwheel as well as 
its conveyer belt. If one look out from one end to the other, from a nation formed by villages, which are composed of households, which, in turn, are organized by individuals, the most important warp thread running through them is agricultural production" ("Jidai to nōsei." Teihon 16: 9). According to this view, the defining element of the state/nation is farmers who work on land, and relations of what he calls "floating elements"-i.e., those who do not settle on land and do not engage in agriculture - with the state/nation is tenuous at best.

Yanagita emphasizes agriculture in part because in his time Japan was still dominantly agrarian society and the rural population constituted the majority of the nation. However, there seems a deeper philosophical reason for his agrarian bias. In his view, the relationship between nature and human beings is discernible in a most direct and transparent way in agriculture. In other words, agriculture is a quintessential progressive activity. Human labor cannot create anything from nothing, and the production of material goods is little more than spatially rearranging physical substance and energy existing in nature in a way that creates products useful for human needs. In this sense, all essential goods necessary for the production and reproduction of human life are the products made out of nature. Thus, the physical environment constitutes both the basis of and the limit to productive activities. Agriculture reveals most directly this dual relationship between nature and human beings. Unlike hunting and gathering, agriculture not only extracts goods from nature but also deliberately renews available resources. Agricultural society is the producer of the rural space but at the same time a product of the natural environment. It transforms nature, but at the same time has to adjust itself to the rhythm of nature beyond human control. 
Agriculture is also the primordial form of human labor in the sense that almost everyone used to engage in it to satisfy her essential needs. In other words, in the early phase of human civilization, "the history of peasants was almost the entire socioeconomic history" (Teihon 16: 165). A passage from an early text reads:

In the past, agriculture [no 農] was not, strictly speaking, an occupation [waza or $g y \bar{o}$ 業].... [In the seventh century] land was distributed [by the government] so that the people could support themselves, not that each individual occupied it in order to make a profit by the use of free choices. Because of this, from the highest rank of aristocrats to the lowest class of servants, everyone was entitled to his portion [of land]. Each individual offered a part of the fruits of their labor to the government and supported himself with the rest. Only those who had extra energy to spare for other works engaged in industry and commerce. Industry and commerce were already occupations from the beginning ... but that agriculture used to be what should be called the only condition of life. ("Nōseigaku." Teihon 28: 206; see also "Nōgyō seisakugaku." Teihon 28: 330-331)

Meanwhile, agriculture is also a womb of civilization in another sense - that is, arts and sciences, industry and commerce, leisurely activities, the literate class, the state, and other products that characterize urban space. Agriculture makes it possible to accumulate surplus and channel it into other uses than reinvesting in the production of essential goods. The accumulation of surplus wealth results in the differentiation of social structures and the emergence of social classes other than farmers. In this transformation, the state of "natural economy" gave way to a more complex socioeconomic conditions and political institutions and to the emergence of lettered classes and full-time artisans and merchants, 
although, Yanagita points out, the majority of farmers continued to "eat what they cultivated, wear what they wove, and demanded little other than what they produced by themselves" (p. 206) until the Meiji Restoration of 1868.

However, in his view, even in the most advanced civilization, economic activities ultimately boil down to the exploitation of nature for the sake of satisfying human needs, and human beings depend on nature for all essential materials to sustain their life. Commerce and industry, no matter how far they develop, cannot sustain human life without food and raw materials, the bulk of which is produced by farmers. If the growth of non-productive activities in cities outpaces productive activities in villages, the accumulation process is reversed, resulting in the decline of civilization. Furthermore, alienation from agriculture has a profound effect on the psychology of urban dwellers: In my imagination, the fact that [urban residents] do not make what they wear, eat, and live in by their own hand, that is, the helplessness of being separated from the production on the soil, makes people suddenly insecure and sensitive. Today, one can assert vehemently that trade is for mutual benefit and one does not have to give without being given, but various kinds of articles used to be very different in the degree of indispensability. It is self-evident that an owner of commodities that can be done without, that have substitutes, or whose consumption can be delayed, if he wants to exchange them for food indispensable even for one day, cannot afford to wait idly for a the other party to come. ... Every transaction in trade is either one of two cases: passive or active. It is the party with greater needs that actively seeks for transaction, and this is equally applicable from trade in Nagasaki [where Dutch merchants were granted an exclusive right to trade with Japan] during the period of 
national isolation to peddlers who wandered from one village to another. ("Toshi to nōson." Teihon 16: 250)

According to him, therefore, urban aggressiveness to seek agricultural products on favorable terms stems from this weakness. In Yanagita's view, the rapacity of the metropolis, from Western colonialism to the exploitation of the rural population by cities, is driven by this psychological insecurity.

In Toshi to nōson (都市と農村 City and Village), he spells out a historical narrative in which villages are favorably compared to cities. According to it, the construction of Japanese cities was a project made possible by peasants' enthusiasm toward it. They readily sacrificed their labor for them, and in exchange found consolation in the pleasure, the beauty, and the comfort provided therein. They felt some sort of ownership and were proud of towns to which they themselves made contribution. As such, Yanagita even calls a city “the spiritual hometown [kokoro no furusato 心の故郷]” (Teihon 16: 243) of rural folks. However, as cities lost contact with their rural origin, they became a purely parasitic existence living off of productive labor of the rural space. Thus, Yanagita again inverts the conventional relationship between cities and villages: "Many medium- and small-size cities are unable to strike out in a new direction except by coaxing subsidies and uselessly leave the prosperity of the land up to the unhealthy consumption trade. That is because their existence depends on the strength of villages through their residents coming and going freely. People assert the decline of villages, but it is cities that are far more mutable and transient" ("Toshi to nōson." Teihon 16: 246). Moreover, because the continuous influx of immigrants from the rural area, substantial portions of the urban population considered themselves to be temporal residents and did not share the burden 
of preserving urban spatial order. Unlike a village, therefore, a modern city was an amoeba-like organism, lacking a center, and was not equipped with institutions to form collective will. In short, it is not a political community in the sense that a rural village used to be. "A town," Yanagita complains, "is nothing but an agglomeration of residences and a container that can hold both water and oil, whereas a collectivity in a village is like fabrics with a invisible figure on it and newcomers must be woven into this figure" (Teihon 16: 188). In spite of its artificial appearance, therefore, urban life looks closer to the state of nature, where each individual concerned with the satisfaction of one's own needs at the expense of the public good.

Yanagita suggests that the public spirit found in rural residents is due to the fact that the time horizon of the individual perspective is broader in rural communities. For example, in villages west of Tokyo, Yanagita notices that the ladder set to climb the scaffold to bang a fire bell in the case of emergency was made of a conveniently forked cedar tree. It turns out that it is not a naturally grown tree, but villagers grow them purposefully. Upon this discovery, he observes:

In order to grow a tree of the height of a fire-bell scaffold, it takes at least more than thirty years. It would be a nonsensical plan for those who are intent on siphoning off the fortunes that will be made by the coming seven generations or issuing high-interest bonds unredeemable for fifty years. Yet the senior members and others in those villages, in the same manner that we [the modern urbanite] worry about the provision of tomorrow's portion of rice, foresee the future of the villages along with the future of the trees, and plant them from now in order to detect a fire in an 
adjacent village, bang the fire bell, and call on it to express their sympathy. ("Mame no ha to taiyō." Teihon 2: 326)

In other words, in contrast to the selfishness and shortsightedness of the modern and the urban, who do not hesitate to live on money borrowed from future generations, villagers rather sacrifice themselves for their unseen descendents. It is worth emphasizing that this is the reversal of the statist view expressed in his early writings, according to which the farsighted bureaucracy was expected to complement the shortsightedness of society. He continues to offer another example involving an even longer temporal horizon:

Even more surprisingly, in Nasu Mountain of Hyūga region, a bridge is suspended by the longest vines tied to huge cedars standing at the four corners of the bridge. Although the cedar trees, to all appearances, are eighty or ninety years old and still look strong, a young cedar tree of good quality, which seems to have already passed several dozens of years, is planted in each corner of the bridge, next to the old one. Thinking that the entire village may have been replaced by a new generation by the time those trees grow up to be useful, it came home to me how much village life takes its time in doing things. Maybe some people, at listening to this story, think that it is an instinctive act just like an insect inserting its ovipositor into a fruit. Yet, even if farmers are so deprived of consciousness, we must admit that it is even more significant an event that the world has changed so much as to overturn such instinctive prediction. (p. 326) 
Again, Yanagita contrasts the lengths of the time horizon in rural communities with that in modern cities. Villages are ready to sacrifice the present for the future, while cities the future for the present. ${ }^{43}$

Thus, Yanagita redefines rural space as a product of progress - a spatial order that human agency creates, maintains, and protects from the tyranny of time. Labor no longer dissipates in the air, but accumulates into space. And, maintaining a spatial order vis-à-vis unpredictable time requires will and action supported by critical ability, caution, a broader time horizon, and courage to experiment with new things, the proof for which Yanagita takes every pain to excavate in the history of rural communities. Therefore, where conventional wisdom observes the passivity of rural life, he finds active will formation and collective action to carve out human space out of nature. Any lasting rural communities may be stationary, but cannot be static, because given the vagary of natural time, stationariness must be a deliberate choice. And their conservatism cannot be another name for blind obedience to customs.

The activity of rural life is obscured precisely because its time horizon is unusually long - that is, "unusually long" by the standard of modern life - and the exercise of human agency is diffused into a broader time span and a complex web of many individuals unknown to each other. In contrast to Mill, therefore, Yanagita has to argue

43 The long time horizon does not mean that the rural population always made right decision. Rather, Yanagita observed that with the wisdom of hindsight, history seems full of wrong decisions, which results in the unraveling of spatial order. "Their judgment is not always happy one," he writes. "Looking back from now, there are at least several cases in which one wonder whether it is a mistake to have taken this path, whether that path could have been taken" ("Nihon nōmin shi." Teihon 16: 163). However, this is a corollary of underdetermined history and what matters to Yanagita is the extent to which decisions are made consciously. 
that it is a collectivity of anonymous persons, not a few eccentric individuals emancipated from the need for labor, that plays a progressive role. This is in part because the two thinkers have different emphasis in their respective conception of progress. For Mill, on the one hand, progress is defined in terms of the discovery of new possibilities, which are not expected from what has already been known. On the other Yanagita's emphasis is place on the continuous accumulation of what is already known as good by past generations. ${ }^{44}$ Yanagita does not necessarily deny the role of individuals, but suggests that the final outcomes of individual innovations are not necessarily what original innovators ever intended it to be. One example is his discussion of the impressive diffusion of the cultivation of sweet potatoes in Japan during the early modern period. Introduced to Japan in the early seventeenth century, sweet potatoes became an indispensable staple in the Japanese diet. After citing the names of individuals who allegedly contributed to the proliferation of sweet potatoes, he asks to what extent those individuals knew beforehand the social benefits this innovation would bring about. His answer is:

I think that at least that [achievement] was an effect unexpected [by individual innovators]... [i]t seems that they merely thought that sweet potato could be at best a supplementary food to farmers' rice in lean years or a means to alleviate the hunger of those who were banished to islands. Yet, today, it is being cultivated in quite extensive regions and has become an agricultural product that not only the banished but also everyone invariably plants and eats even in normal years. Such a

\footnotetext{
${ }^{44}$ I thank Clement Fatovic for pointing out to me the important difference between Mill and Yanagita's conception of progress.
} 
change in [human] life can rightfully be called a great undertaking. However, it was designed and achieved by no particular person but by two hundred and dozens of years. ("Kainan shōki.” Teihon 2: 224).

On the basis of these observations, he wonders whether "the diffusion of sweet potato was really achieved by great persons, or human need to live inexpensively partly contributes to the popularity of a crop like this" (p. 225). To put it differently, individuals may play a role in the discovery or diffusion of knowledge or technology, which catalyze major social change, but ultimately it depends on socially perceived needs, not the intention or preference of innovators, which knowledge or technology are accepted and adopted at the social level. In other words, society, and not individuals, is the final judge of innovations. Thus, rationality is not a natural property of the individual but is exercised within and in relation to community.

Yanagita's agrarianism also has an implication for the question of diversity. According to him, the most radical difference exists among agrarian ways of life, partly because agriculture is more directly conditioned by diverse natural conditions and partly because human responses to the imperative imposed by nature are fallible and therefore diverse. In other words, the basis of global diversity is not a mere difference of culture, if by the latter term is meant the ideational realm of social life. Instead, it is the earthboundness of human life and a constant struggle by humanity to free itself from spatial confinement that produces diversity. Thus, Yanagita once again inverts the conventionally understood relations between the urban and the rural. Now it is the rural that possesses individuality, whereas the urban tend to become faceless and homogeneous everywhere. It follows that as the entire society moves from agricultural to 
industrial/commercial, it loses its distinctive character. The convergence, however, comes with the negative effects of the abstraction from reality, as increasing numbers of individuals feel alienated from both society and nature. The resulting cosmopolitan society would be a society of faceless individuals suffering from a simmering sense of insecurity.

\section{The Concept of Jömin}

In the late 1920s, Yanagita started to use the term jomin (常民) to refer to progressive agents misrepresented by the urban literate class as stagnant people. It is one of the rare abstract concepts he routinely uses in his writings and it is understood as a key element in his thought, so much so that one's appreciation of his thought, to a substantial degree, depends on how one interprets this confusing concept. It is composed of two Chinese ideographs. The latter half of the word, $\min$ (民), stands for people or folk, while the first half, $j \bar{o}$ (常), stands for permanence as well as commonness. Yanagita's own English translation of the word seems the common people, but he never clearly defined the meaning of it and his use of the word is not quite consistent throughout his career. Although it sporadically appears in earlier texts, it is most heavily used in those texts written from the late 1920s to 1940 (Itō 2002: 122-123), when he attempted to establish the discipline of minzokugaku. In early texts, it was used to refer to farmers inhabiting plains to distinguish them from the inhabitants of mountains, but in the later period it has acquired more positive attributes (Iwamoto 1983: 172). Itō (2002: 123) also points out that the use of jomin becomes more sporadic as another word kokumin (国民), whose 
standard English translations include a national people or nation, appears more frequently in the text written from 1940 on, thus suggesting some conceptual connection between the two terms.

What makes jomin a complex concept is the uneasy coexistence of two meanings. On one hand, it can be understood as the Japanese rendering of the economically exploited class with a rural connotation. On the other hand, it is associated with the German concept of Volk, a classless and culturally or ethnically homogeneous nation. Yanagita himself explains that it is rather the British connotation of common and folk that he wanted to incorporate into the term. When asked in an interview (Minzokugaku ni tsuite: 179-180) why he chose jōmin, instead of shomin (庶民), a more common Japanese term for the ordinary people, he replies that the latter was deliberately avoided because it connotes something “inferior than us, lower than intellectuals [interi インテリ].” In contrast, the British people are emphatic, in fact too emphatic, he points out, because of their desire to underplay class division within the British nation, that the word common or folk in English does not have a connotation of being low or base [iyasii 卑しい]. Therefore, jōmin is not a totally class-neutral notion, at least in the original sense (Iwamoto 1983: 187-188). Rather, it is intended to give a collective identity and a respectable name to a class of people who are economically exploited, culturally denigrated, and politically misrepresented, and it is consistent with his political project to recognize the agency of the rural population. Water is muddied, however, when, in the same interview, he makes a perplexing statement to the effect that jomin includes the members of the Imperial Household as well as the wives of nobles and feudal lords, but 
apparently not their husbands. It is equivalent to say that the British royal family and the wives of the nobles are also commoners and risks rendering any kind of class connotation meaningless. Even worse, the identification of the sovereign ruler with jomin resonates with the ultranationalist discourse of the volkisch nation during the prewar period.

Interestingly, Yanagita fully elaborates the concept for the first time in a report on the welfare of natives in Mandated Territories, submitted to the Permanent Commission of the League of Nations. ${ }^{45}$ The mandate system was established after the First World War to administer territories, mainly former German colonies and regions formerly belonging to the now dismembered Ottoman Empire, in Africa, the Middle East, and the Pacific. In the report, Yanagita identifies the chief beneficiary of the mandate system to be what he calls "the common people" or "the common body," apparently a translation of jōmin. No precise definition is given in the text, but he excludes from it certain classes of residents in mandated territories - those of mixed parentage, foreigners, the heads, chiefs, and notables of tribes and local communities, and those who received foreign education and learn to speak foreign languages (Iwamoto 1983: 184-185). Thus, the category of jōmin does exclude ethnic others, but also is narrower than an ethnic group, as it also excludes indigenous power holders and a class of people in position of mediating between the foreign ruler and the native ruled.

\footnotetext{
45 "Welfare and Development of the Natives in Mandated Territories." Annexes to the Minutes of the Third Session, Thirty-Second Meeting, Permanent Mandate Commission, held at Geneva from July $20^{\text {th }}$ to August $10^{\text {th }}, 1923$, League of Nations. It seems that Yanagita wrote it in Japanese and have it translated into English. The English translation is included in Yanagita Kunio zensh $\bar{u}$ 26: 64-82. The Japanese original text seems to have been lost.
} 
The ethnic marking of jomin becomes further blurred when Yanagita reintroduces the concept into the history of Japanese rural communities. Again, Yanagita does not offer a clear definition, but provides some criteria. First, the core of jommin consists of regular farmers who directly work on land, whether their ownership is legally acknowledged or not by the central authority. It does not include village chiefs and notables, resident Buddhist or Shintō priests, government officials, or other lettered classes sent from outside. Also excluded are landless peoples, such as wandering peddlers, craftsperson, entertainers, and sorcerers and sorceresses, who temporarily reside in or near a village. In other words, they are a middling, not lower, class between power holders and those whom he once called “floating elements [fuy ü bunshi 浮遊分子]." The similarity between the middle-size farmer [chūno 中農] in his agrarian policy science and jōmin immediately comes to mind. The former is defined in terms of the size of their holding, not large enough to spare the owner from the trouble of involving themselves in agricultural labor, but not too small for them to achieve self-sufficiency with respect to essential goods. It is a class largely innocent from the taste for luxurious goods. Yanagita believes that they once constituted the middle core of pre-national agrarian society and should do so in the modern nation. Equally, he suggests that jommin is the defining element of the nation. However, jōmin is a broader category in the sense that it includes farmers with holdings of any size, as long as they are direct producers - that is, they directly work in and on nature. Thus, the attachment to land seems the first criterion of jōmin.

The second criterion is literacy. Jömin are either illiterate or semi-literate and are opposed to the lettered class. Yanagita's suspicion with priests of established religions partly derives from the fact that they are literate. And, in all likelihood, the inclusion of 
wives of nobles and feudal lords in the category of jommin is partly because of the fact that many women from the upper class remained generally illiterate or semi-literate. His apprehension of lettered classes seems attributable to the fact that written languages contain more terms imported from abroad than spoken languages and have served instrument of the dominant classes. In his report to the Permanent Mandate Commission, he turns particularly skeptical eyes to native translators who mastered the language of the colonizer, because he believes they tend to identify themselves with the master rather than their own brethrens and are more accurate at communicating the intention of the colonial masters to the natives than the demands and grievances of the latter to the government. Generally, he fears that those who received Western education constitute a distinct class occupying the dominant position within local society because of their ties to a foreign authority. The same is also true for the case of Japan. At the level of a village, priests of universalistic religions traditionally constitute such a class. At the national level, however, the entire lettered class may fall into this category of "translators." Their language system is heavily influenced by China in the ancient period and by the West in the late nineteenth and the early twentieth centuries. They know better about foreign civilizations than about their own found in the rural area, and serve better in communicating foreign ideas to the natives than the other way round. Modern-day scholars and bureaucrat-intellectuals are not exceptions.

Yanagita does not intend to keep jomin illiterate for the sake of their cultural purity, but he is worried that the existing written language has a built-in bias against jōmin. Because written language is an abstract representation of reality that can cross borders with ease, it is relatively autonomous from material conditions. Particularly, "for any 
people [minzoku 民族], the capital city and the court were always the utmost entry-point for foreign cultures, and it is the characteristics of our cities to quickly grasp and apply them and keep moving from one new thing to another" (Teihon 16: 274). Because of the cultural hegemony of cities, however, the representation of reality is taken for reality itself. He fears that the articulateness and verboseness of the urban literate class puts the illiterate class at a disadvantage and makes it easy prey for cultural colonization.

Therefore, the advent of public education and literacy in the rural area is a mixed blessing in the sense that a language system taught thereby systematically misrepresents the rural population and inculcates in the rural youth a sense of contempt for their parents and themselves. A purpose of minzokugaku, therefore, is to restore self-esteem to the denigrated population by transcribing unstated reasons for what is misrepresented as "superstitious," "irrational," and "ignorant."

The third criterion for jomin is ancestor worship. As is the case of mid-size farmers, jōmin are the collective preservers and transmitters of cultural values. As discussed in the preceding chapter, ancestor worship and the household are identified by Yanagita as critical institutions to maintain political order. Instead of a state bureaucracy, ancestor worship and the household emerge as key social institutions that counter the individualizing effect of urbanization and broaden the temporal and spatial horizon of the members of society. Thus, agriculture, the household, and ancestor worship are an inseparable triangle of political order in rural space. Indeed, he believes that the center of a stateless—namely, lacking the centralized government—rural community is religion by

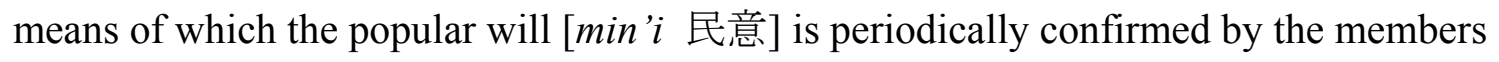
of a community. 
For Yanagita, ancestor worship is also a defining element of the Japanese national character. He finds that the actual practice of ancestor worship, which he believes is the pristine form of the Shintō religion, is extremely decentralized, but still shares a certain degree of uniformity throughout Japan, indicating a common origin of the practice. He links this commonality to rice-cultivation culture (inasaku bunka 稲作文化). On the basis of this assessment, he hypothesizes that the Japanese people are the descendents of immigrants who arrived at the southern islands and gradually moved northward with rice plant in their hands, and that even when the history of this internal migration is forgotten, the memory is conserved in the common religious practice. Therefore, jōmin can be understood as the reservoir of the historical memory of the Japanese people and the legitimate representative of Japanese civilization.

Yanagita's perplexing statement that the Imperial Household also belongs to jomin seems to derive from such a meaning of jomin. Although the members of the Imperial Household are neither farmers nor illiterate, he believes that they are descendents of those who served as mediators between the divine and the human in an ancient agrarian society. In other words, the Japanese emperor is not comparable to European emperors or kings, as the founders of the modern Japanese state attempted to portray, but closer to the farming class. Although the advancement of the social division of labor and the functional differentiation of occupations resulted in the professionalization of the clerical classes, on the one hand, and internal division of the clerical class into subclasses of officially recognized priests/priestesses and a socially stigmatized wandering sorcerers/sorceresses, on the other, the similarity between artifacts and rituals indicates that they share the common origin. The common origin does not mean that they share the 
same religious doctrine or sacred texts, but that they both catered to the spiritual needs of jōmin. In other words, it is jomin and the material conditions they live in that largely shape the contents of the religion, not vice versa. In this sense, Yanagita's apprehension of imported religions parallels his concern with imported languages. It is spurious universalism, other-worldliness, and abstract notions of humanity, rather than foreignness per se, that makes them dangerous to political order. On the contrary, his appreciation of the Imperial Household seems to derive from his hope that it could serve the purpose of nation-building, not as a sovereign ruler, but as a useful symbolic center of a fractious nation of jomin.

Finally, from this understanding of jōmin, Yanagita's special emphasis on women becomes less perplexing. As a matter of fact, a concrete model of jomin he has ever mentioned is his own mother, Matsuoka Take. She was semi-literate and because of her illiteracy was largely innocent from the abstract knowledge possessed by her husband. However, Yanagita personally witnessed that his mother's "common sense" was socially more effective than his father's knowledge of Confucianism and Shintō. In an interview, he suggests that women like his mother played an important role in the governance of rural communities:

If one half of the village were the intellectual class and the other half the uneducated, the village would naturally be led by the former. But, if the entire village consists of the non-intellectual class, except a resident Buddhist or Shintō priest, what moves the village is the judgment of those without knowledge [mushiki no mono 無識の者]... There used to be women who could say respectable things ... there used be such women among those who could not write. In fact, my own 
mother never wrote a letter throughout her life because she feared that her children would laugh at her, but she had an excellent memory and was good at detecting the defects of others and correcting them.... I must confess that I still admire my mother. She gives reasons [rikutsu 理屈]. She says them with such poor words that they would not make any sense if written down literally, but she was able to convince others with such reasons. Such reasons are a dominant force, not only until the early days of the Meiji period, but also after elementary schools were built. (Yanagita Kunio Taidan shü: 185)

In his view, women, and not men, possess more jōminness for various reasons. First, women are laborers, at least as much as men are. As a matter of fact, Yanagita, who often turns compassionate eyes in his travel writings to the plight of women exploited by their fathers and husbands, suggests that they are burdened with a disproportional share of labor in both senses - that is, they not only work on land as men do, but also bear and rear children. Second, they are also the chief guardians and transmitters of customs and traditions in rural society and the chief educational agents concerning ethical values.

Indeed, Yanagita believes that women used to play a central role in the Japanese religion, chiefly as mediators between the divine and the human, because they were recognized, even by male counterparts, as more innocent of vices. In his assessment, women's role becomes more important when many men work away from home during a good part of a year as seasonal workers. For example, he concludes the essay "Yukiguni no haru (雪国の春 Spring in the Snowy Country)" as follows: “Will the tradition [of nightly story-telling by the fireside] eventually become extinct? Or will it continue for long as unspeakable bliss? [The continuity of the tradition] ultimately depends on what 
young women in the snowy country study and is influenced by the flow of their emotion. As a growing number of men are far away from home [to work in cities as migrant workers], time for contemplation has come. The maintenance of calmness and beauty in spring of the snowy country has long been put into the hands of women" (Teihon 2:

16-17). Paradoxically, therefore, it is the confinement of women to what is today categorized as the private sphere that makes women formidable agents in anthropological space.

Jōmin is a quite amorphous concept with blurred boundaries, but its defining core is consistent with Yanagita's project to rehabilitate the subjectivity of the people without history. It is the name of the neglected subjects in history who carve out human space from nature. Or still better, it is not so much the subject as a spatial category, "a constant womb" (Irokawa 1996: 17), from which the subjectivity of human beings are nurtured.

\section{Diversity in Uniformity}

There are two theoretical implications in Yanagita's turn to anthropological space as a true site of human history. The first implication is the reconsideration of the role of labor in human progress. The Western intellectual tradition long denigrated labor on the ground that its aim is the satisfaction of recurring bodily needs. Protestantism and Lockean liberalism partially reversed this tendency, but not without individualizing the cause and effect of labor. Against this intellectual tradition, Marx rehabilitates collective labor as the driving force for progress. In a broad context of intellectual history, it can be argued that Yanagita's thought belongs to the post-Marxian discursive field. The second implication of his turn to anthropological space is the location of human agency. 
According to him, it is not the individuality of eccentric individuals, as is expected by Mill, but the diverse individuality of collective life that provides the basis of global diversity. Equally, it is not the reason possessed by the solipsistic individual but collective rationality that conditions knowledge production and human progress. Therefore, it is not enough to guarantee individual rights to exercise one's own reason, and, in consequence, the explanation for diversity expands from the purely biological and psychological to the social and institutional dimensions of opinion-formation and political judgment. As a result, deductive theories relying on abstract conceptions of human nature must be replaced by inductive theories based on historical experiences of concrete human institutions.

However, Yanagita's anthropological space differs from Marx's in two crucial aspects. First, it is not uniform but heterogeneous space, partly because of diverse natural conditions to which human life must adapt itself and partly because of the fallibility of human intellect. In his view, human life is inevitably cultural from the very beginning and there is no universal history of humankind that could be deductively constructed from any hypothetical conception of human nature. For him, therefore, human history is a history of various collective experiments whose successes and failures inscribed in space, and diversity is but an inevitable outcome from these varying experiments. In that sense, global diversity is not a reflection of diverse humanities, but diverse expressions of a common humanity, which is not easily dissolved into an abstract and individualistic notion of humanity. 


\section{CHAPTER IV}

\section{CIVILIZATION AND WANDERING}

Yanagita's minzokugaku provides methods to excavate a progressive history of jomin. However, there is another motif in his minzokugaku: the history of wandering people (hyōhakumin 漂白民). ${ }^{46}$ Tsurumi (1998: 250-255) identifies seven categories of wanderers that appear in Yanagita's historical narratives: 1) disseminators of religious faith such as wandering priestesses/priests (miko ミコ/hijiri ヒジリ); 2) groups of technical experts such as makers/repairers of brushes, baskets, straw rain-capes, or umbrellas, producers of wooden tableware known as kijiya (木地屋), or founders and smiths; 3) performing artists such as blind bards (zatō 座頭), dancers/singers/prostitutes (yūjo 遊女), monkey showmen (sarumawashi 猿回し), lion dancers (shishimai 獅子 舞), and puppeteers (kugutsushi 傀儡師; 4) mountain people (yamabito 山人) including mysterious nomadic peoples known by the name of sanka (サンカ); and 5) travelers such as Sugae Masumi (菅江真澄) and Matsuo Bashō (松尾芭蕉); ${ }^{47}$ 6) professional

\footnotetext{
46 My argument in this chapter is partly informed by Tsurumi Kazuko's (1998: 240-274) reconstruction of Yanagita's theory of social change in terms of interaction between settlement and permanent and temporary wandering. "On the one hand," she writes, "jomin, as settlers, are awaken and invigorated by encounters with wandering people. On the other, jōmin, who usually live in a fixed place, are prompted by some opportunity to embark on temporary wandering and expand intellectual horizons and regain vitality. In order for jomin to be agents for social change, either they theselves have to go through the cycle of settlement-wandering-settlement and/or they have to experience shocking encounters with wanderers" (Tsurumi 1998: 246).

47 Tsurumi distinguishes permanent and temporary wanderers. The latter refers to temporary travelers who have fixed places of residence and travel back and forth between
} 
wanderers such as peddlers and those who travel in search of livelihoods - i.e., seasonal workers and migrants; and 7) deities (kamigami カミガミ) that travel between mountains and villages in flat land or between different communities. They are known by various names but all of them except deities are what Yanagita once called "floating elements" ("Nōgyō seisakugaku" Teihon 28: 302) within the state living on the margin of agricultural civilization. In his own words, they are "anyone but those who belong to the classes of court-nobles, samurai warriors, priests, monks, and peasants - in other words, the entire class that do not make a living off land" ("Iwayuru tokushu burakumin no shurui." Yanagita Kunio zenshū 4: 500). Lacking land to cultivate, wanderers are condemned to cross borders from one place to another to supplement their livelihood with a tiny share of surplus agricultural products in exchange for whatever they could offer. Even when they settle in, they become the objects of systematic discrimination on the part of jomin, often marked as racially or ethnically distinct or even less than human. Yet, they maintain their shadowy presence and play a crucial role throughout the history of jomin precisely because of their lack of spatial affiliation. From the point of view of jomin, wandering people are strangers, but at the same time they are the major link to the outside world. In Yanagita's view, their existence is "the most important factor in the transportation of culture" (Teihon 24: 402) and it is through them that a common culture has been transmitted from one place to another throughout the Japanese archipelago and possibly beyond. In other words, they unintentionally serve as a countervailing force against the innate parochialism of semi-autonomous republics of jōmin.

it and other places. She suggests that Yanagita himself may belong to this category (Tsurumi 1998: 252). 
Hyōhakumin are in many senses the Other of jömin — the "barbarian" within, so to speak, in agrarian civilization. First of all, they are the external other who comes from outside and does not belong to jömin's space. However, they also constitute the internal other, because they represent the suppressed self of the civilized - mobile, free from monotonous labor, and unbound by overbearing social norms, although their freedom comes at the cost of the material and psychological security offered by civilized life. Yet, they are also the temporal other of jömin in the sense that they are what jōmin used to be before they settled on land and what they will become if they are severed from the soil. As such, wandering people also provide a link to the forgotten memory of the past, when the Japanese people arrived at the Japanese archipelago and spread over, and to the imminent future, if, as Yanagita fears, the disintegration of rural communities continues.

Although they are defined as the opposite of jomin, wandering people, in Yanagita's historical narratives, are far from being a superfluous population parasitic of agricultural civilization because their relationship with jomin has a certain degree of mutual complementarity in the history of civilization. ${ }^{48}$ Overall, the livelihood of wandering people depends on the explicit or implicit admission on jomin's part that their community cannot be a completely closed system because of its embeddedness in a wider spatial order that exists prior to the foundation of their own republic. Historically, founders of any agricultural community must come from some other place. Although

48 Tsurumi identifies three aspects of the relationship between wanderers and jömin. First, wanderers are the object of discrimination and contempt. Second, however, they are partners in commerce and exchange, as they offer the products and services not produced in villages. Third, they are the objects of admiration because of their association with the spiritual world (Tsurumi 1998: 246-249). 
jōmin's consciousness of the pre-foundational origin is often expressed in mythical terms, their communities have passed down, from generation to generation, oral traditions indicating that their ancestors had been wanderers, personified by either mythical heroes, noble princes banished from Kyoto, or defeated samurai commanders, before they settled in. Even relatively new villages often try to embellish their ancestry by linking their foundations to nationally renowned personalities. Spatially, jomin recognize that their control over what happens within their space is limited and does not hesitate to resort to some external intervention whenever necessary. Even deities other than their own are invited to solve a problem at hand, be it draught, epidemics, or insect plague, if such deities are deemed more capable of doing it.

However, it is the question of birth and death—that is, where each person comes into this place and where he or she goes afterward — that persistently besieges the mind of the civilized people but cannot be addressed in the context of daily life. For Yanagita, the question of afterlife is not simply an otherworldly concern because he believes that the material reproduction of a this-worldly community would be impossible without giving some answer to the question, lest the living would lose the sight of a reason for all sacrifices demanded for the preservation of civilized life. The daily life in civilization, in which humans struggle to satisfy immediate needs, exercise an inexorable evervating effect upon human vitality, because the immediacy of everyday life's goal tends to individualize the temporal and spatial horizons of the laboring class and alienate them from nature and community in spite of the embeddedness of their existence in the latter. Yanagita finds that the monotonous and repetitious days of labor (ke ケ) are punctuated by seasonal festivities (hare ハレ) in which all the members of a community share in 
commemoration of local deities (ujigami). The temporal suspension of social statuses and contacts with outsiders (wandering priests/priestess, entertainers, artisans, beggars, etc.) often characterize hare occasions, serving as a reminder of the situatedness of one's existence in larger temporal and spatial contexts. What is more interesting, etymologically, the concept of the political (seiji 政治) in Japanese was associated with that type of collective religious practice (matsurigoto 政). In other words, hare is a moment to confirm "the exchange and chain of affection and yearning [aibo no kōkan to rensa]" (Teihon 16: 218-219), which motivate people to sacrifice the present for the future, the individual for the communal. ${ }^{49}$

The consciousness of the pre-foundational origin and the impossibility of fulfilling spiritual, or psychological as Yanagita rather would term, needs in the sphere of daily life create demand for goods and services that can only be provided by outsiders, and wandering people, associated with the outer space that exists prior to civilization, are particularly suitable for that purpose. From jomin's point of view, therefore, wandering people are linked to a larger cosmos with which the finiteness of their own communities is contrasted. In other words, jōmin's attitude toward hyōhakumin reflects their consciousness of openness of a particular community to a wider spatial and temporal

49 Yanagita documented various practices associated with the distinction of hare and ke in Shokumotsu to shinzō (食物 と心臟 Food and the Heart) and other writings, but did not develop coherent theory and concepts of the distinction. My account of hare to ke draws on the work by Sakurai Tokutarō (1987), one of Yanagita's disciples. Sakurai proposes that the term ke was originally understood as life energy or vitality and kegare (ケガレ，穢れ), the term ususally understood as uncleanness or impurity, often associated with menstruation, originally meant the drying up (kareru 枯れる/涸れる) of ke. Hare is an occasion to replenish the lost energy. See also the discussion by Trsurumi (1998: 257-261). 
order from which all good and bad things beyond its control come. Thus, wandering people are attractive as well repellent to jömin.

On that account, it is not surprising that Yanagita's representation of wandering people as the mirror image of jomin reflects his ambivalence toward civilization and progress. He recognizes that the civilization of jomin, whose progressive history he tries to excavate, does not escape the tendency toward conservatism, conformism, and mediocrity, and hence decline. ${ }^{50}$ Moreover, material and psychological security in civilized life comes at a price: It demands the sacrifice of individuals for the sake of the common good. As a young poet, he was influenced by European Romanticism and his initial engagement with wandering people, especially yamabito, seems to be motivated, at least partially, by his desire to project the image of the internal other of the civilized self into external others. In the course of his intellectual evolution, however, his Romantic identification with wandering people gave way to an effort to integrate them within a common historical narrative, in which both jömin and wandering people are assigned proper places in the progressive history of human civilization, and, as a result, the division between them is dissolved in the flow of time. The theme of wandering is even more important for this study because he incorporates temporary wandering-i.e., traveling - as a method for knowledge production and political education.

\footnotetext{
50 Yanagita comments on oppressive social norms prevalent in agrarian communities as follows: "Conformity to the opinion of the majority means lapsing into mediocrity. Because people tend to favor an old known way whenever they have to choose, it takes a lot of persuasion and patience to introduce a new species of crop or adopt a new technology. Overall, persons with progressive ideas are put down. Therefore, there is little hope that human talents are utilized. Then, often time an entire village suffers from ignorance" ("Nihon nōminshi." Teihon 16: 186).
} 
The importance of wanderers in Yanagita's thought is relevant to the question of space and time discussed in the preceding chapters. His re-spatialization of global diversity risks dividing anthropological space into small, semi-autonomous communities, each governed by a distinctive spatial order, and the possibility of communication between them is severely restricted by the exclusion of those "contaminated" with foreign culture. As a result, even an allegedly homogeneous nation like Japan is redefined as a radically heterogeneous space tenuously held together by the coercive means and monetary incentives dispensed by the modern state and a spurious universalistic culture invented by the urban literate class. Yanagita's search for an underlying commonality in the heterogeneous national space led him to the cosmological world of jomin, but wandering people played a crucial role in unifying and invigorating it. In his historical narrative, the Japanese medieval period, from the late twelfth to the early seventeenth century, witnessed the decline of the relatively centralized Yamato dynasty, the dissolution of large manors, and the emergence of a large number of displaced people, and the establishment of small, self-governed agrarian communities. ${ }^{51}$ Yet, those semi-independent republics of farmers were also loosely connected through a common culture transmitted by wandering people. His interest in wandering people partly derives from the peculiar role that they played in the cultural unification and refinement of Japanese civilization.

51 In a passage, Yanagita speculates that from two thirds to three fourths of the approximately 180,000 villages that exist in his time were founded during the Middle Age (Teihon 16: 173). 
For Yanagita, the dialectical relations between sedentary civilization and wandering are not a past event but a continuing process to his day. The saturation of the countryside with the growing population has forced many farmers to abandon their own native lands and emigrate to cities, but the persistence of parochial identities of jomin and the urban-rural divides, aggravated by the advent of modernity, prevents the rational reorganization of national spatial order. In his assessment, the overscription by the state bureaucracy and the urban literate class of an abstract national space upon a heterogeneous one is interrupting the spontaneous development of a national culture nurtured in interactions between settlers and wanderers. As an alternative to nation-building from above, Yanagita exhorts jōmin to exile themselves temporally from their own communities, explore the neighboring villages and beyond, and compare diverse ways of life without any presumption of superiority of one's own. He expects that, just like wandering people before them, traveling researchers can play a leading role in the production and dissemination of a common national culture.

The task of this chapter is to clarify the role that Yanagita assigns to the act of wandering in his unstated theory of civilization and method of knowledge production. The first section examines the major source of his wariness toward civilization — that is, a Malthusian notion of spatial limits to progress. Given this limit, progress eventually reaches the point at which the accumulation of human time in space comes to standstill or is even reversed. However, this spatial limit is partially overcome by those who brave the uncertain fate of wandering to find a new land. Therefore, the second section reconstructs his unstated grand historical narrative in which local Malthusian traps are overcome by successive waves of emigration and the imminent return of cyclical time in human 
history is temporarily averted by the spatial expansion of human civilization, if not before civil wars and foreign interventions brought misery to the vanquished. The third section turns to the question of wandering people and their dialectical relations to jōmin. In the fourth section, I will explain how the methods of Yanagita's minzokugaku are built upon his historical narrative introduced in the preceding sections. The final section offers concluding remarks about how his methods redefine the relationship between global diversity and universal knowledge.

\section{Spatial Limit to Progress}

As shown in the previous chapter, the major aim of Yanagita's project is to write the progressive history of "historyless" people. Yet, his historical narratives lack any teleological element and progress is not regarded as an automatic or preordained journey to a given destiny. Instead, his narratives are almost always marked by innumerable setbacks, many of which are the unpremeditated consequences of well-intended human actions. For example, a passage from Momen izen no koto (木綿以前の事 Before the Advent of Cotton, 1939) reads:

We cannot blame our ancestors for not being thoughtful enough even if [their decision] eventually results in an unendurably bad outcome after the passage of years. We can only learn one thing from their experience: that in the human world controlled by chance in so many ways, we cannot afford to be at ease assuming that progress is always heading for the good. Even a forceful trend, in which all the people are streaming in one direction with nothing in their way, or a change of a nation apparently as smooth as the growth of a tree or the downward flow of water, 
carries loss and gain, if one ponders it calmly. Even if one does not regret the loss because one does not notice it or just leaves it alone because it is no use regretting, the end of that long thread [of our ancestors' decision resulting in an undesirable outcome] is nothing but the reality before our eyes and dogs us around. (Teihon 14: 11)

Chance, so much emphasized by Machiavelli and deemphasized by subsequent modern political theorists, is a crucial element in Yanagita's conception of history, because while negating the possibility of any self-sustaining order, it also creates room for human agency. In his view, civilization, understood as "the conquest of nature by human agents" (Teihon 28: 292), is impossible without active human action and complacency is a sign of corruption.

Even though Yanagita is critical of many aspects of civilization, he seems to maintain an optimistic attitude toward modernity and is ready to defend the Meiji Restoration and subsequent social change (e.g., Teihon 16: 167-168). Nonetheless, he is not convinced that civilization is universally good. As Tsurumi Kazuko aptly describes, "Yanagita is well aware that social change and modernization is full of paradoxes. His way of thinking is not linear. Whenever there is something revealed, there are always concealed things. With every good thing there comes a bad thing. He always sees internal connection between the revealed and the concealed, the good and the evil.... One of his assumptions is that nothing gets better or worse without a contrary effect" (Tsurumi 1998: 232-234). Neither does he believe that the consciousness of the people keeps up with the consequences of such complexity of social change and modernization. To the contrary, he suspects, the dissolution of households (ie) and villages (mura) and resulting 
individualism makes it harder for them to regain collective control over social change and hence puts in jeopardy spatial order that made civilization possible in the first place. Atomized individuals tend to make decisions without much meditation on the possible consequences beyond their immediate spheres, and causal relations between their action and its effects are lost in a myriad of unconscious individual decisions. The result is the loss of control by human collectivities over their own fate. As a result, the increase of individual freedom comes at the expense of collective freedom from the contingency of life and the continual accumulation of human time in space is interrupted.

A main source of Yanagita's wariness to sanguine progressivism is a Malthusian notion of the natural limits to progress. According to Malthus, "the increase of population is necessarily limited by the means of subsistence" (Malthus 1992: 43) and the improvement of material conditions will at some point reach its limit. When that point is reached, the population growth is checked by famine, disease, and war. A famous passage from Malthus' An Essay on the Principle of Population (1798) reads:

Famine seems to be the last, the most dreadful resource of nature. The power of population is so superior to the power in the earth to produce subsistence for man that, unless arrested by the preventive check, premature death must in some shape or other visit the human race. The vices of mankind are active and able ministers of depopulation. They are the precursors in the great army of destruction, and often finish the dreadful work themselves. But should they fail in this war of extermination, sickly seasons, epidemics, pestilence, and plague, advance in terrific array, and sweep off their thousands and ten thousands. Should success be still 
incomplete, gigantic inevitable famine stalks in the rear, and with one mighty blow, levels the population with the food of the world. (Malthus 1992: 42-43)

That is because space is far from being infinitely malleable to human will and sets conditions to human existence. First of all, productive activities require the exploitation of nature, but natural resources available for human exploitation are not limitless. New scientific knowledge and technological innovations temporally expand the exploitable frontier, but they have not been able to completely get rid of the spatial limit on human life as long as humans are bound to the Earth. The Malthusian wariness is a persistent theme throughout Yanagita's writings and seems to constitute an implicit literary plot in his historical narratives.

Nevertheless, Yanagita does not accept Malthus' diagnosis uncritically. In his own diagnosis, the scarcity of arable land and hence the means of subsistence, observed in some localities, is attributable to artificial spatial divisions hindering the movement of labor. In an essay titled "Japan's Population Problem" (1925), he criticizes Malthusian theory in the following terms:

A scholar by the name of Malthus who lived one hundred years ago was so aggrieved to witness this kind of scarcity before his eyes that he even tried to predict that people would eventually be forced to reduce their number by one means or another because of the limited means of subsistence. Given that the earth's surface is finite, it is mathematically correct to say that there is a limit to population growth. However, scarcity observed until today is not an outcome after a new way of production and distribution has been attempted. Way before reaching that point, the anxiety of scarcity and competition emerged within one narrow class or region, 
and that produced enough misery among people. When nations only harbors animosity toward each other and cannot taste their own happiness but by comparison with the suffering of others, this misery torments us even more easily. (“Nihon no jinkō mondai" Teihon 29: 107)

Yanagita goes on to argue that the population problem has acquired a global dimension partly because of international order based on the territorial sovereign state. A passage from the same essay reads:

As a matter of fact, many discussions on the population problem start from the assumption that such an international organization and mode of territorial possession as exists today is fixed and unchangeable. If movement between one country and another were not restricted and people could move freely, like the wind blowing in the air or the current running on the surface of the ocean, there would be no need for a nation or two to passionately inquire into population policy and, accordingly, it would take long before the entire world needs to treat [overpopulation] as a problem. (p. 97)

Furthermore, he blames Western colonialism and the enclosure of global "ownerless" land for the problem of local scarcity in a country like Japan. He continues:

Whereas it is known that there has long been a demarcation between "our land" and "their land" within a county or a municipality and it is not easy to borrow [land], even if it is more spacious in one and wanting in the other, there was, until quite recently, a swath of supposedly ownerless land in the international space and any people [minzoku 民族] desiring a piece of it just set out and took possession of it. Japan ... was a little bit late in setting out, and the vast North Asian continent has 
become Russian territory and many Pacific islands British and French, etc. As a result, ... there has emerged a stark national difference between country A, which possess spacious land in relation to population, and country B, such as Japan, in which the population problem becomes an issue demanding an urgent solution. (p. 97)

Thus, in his diagnosis, the enclosure of global open space by sovereign states and colonial powers artificially hastens the advent of the Malthusian limit to human progress in some nations. In other words, the immediate barrier to further progress is not natural, as Malthusian theory suggests, but man-made. As such, it can be changed by human agency. $^{52}$

It is worth remembering that he applied a similar diagnosis to the problem of persistent poverty in the Japanese countryside in his writings on agrarian policy science. The population problem is an unintended consequence of past progress but it is aggravated by maldistribution of land resulting from fixed and rigid boundaries between communities and between private properties. And, one of his proposed remedies is the redistribution of land and the creation of independent, mid-size farmers and promoting region-based small and mid-size cities absorbing the surplus labor eased out from agriculture. In other words, Yanagita's solution to the agrarian problem is to redraw the existing boundaries and rationalize the use of land from a wider - that is, national—spatial perspective. Also, it should be reminded that in the early texts, he

52 Ironically, the first victims of the localized Malthusian limit would be the most advanced civilizations whose progress induced rapid population growth in the past. Yanagita does not explicitly state this, but not only Japan, but also China, India, and other densely populated civilizations in Asia would have been the case. 
conditioned the claim for territorial sovereignty on the productive and efficient use of land to support human life. Indeed, he once seriously considered whether the emigration of Japanese peasants to uncultivated land in the Pacific islands as a means to alleviate, if not solve, the population problem in Japan (e.g. "Imin seisaku to seikatsu antei" Teihon 29: 80-81). His complaint about the enclosure of global space by Western colonial powers can be understood in this context. For him, colonial empires are equivalent to landlords who amass large tracts of arable land to the exclusion of many landless people.

He is well aware that given international cultural hierarchy and racial prejudices, his proposal for the rational allocation of labor to land - that is, migration of landless people to underutilized space — was even less likely to be accepted by international society. In an editorial of Tokyo Asahi, for example, he expresses dismay at the enactment of the US act of immigration of 1924, which bans the entry of Japanese immigrants:

Even in such a humiliating and disappointing moment, we were able to pick up invaluable [lessons from the] experience... First of all, there have been thick national boundaries within humanity up to today; second, friendly relations between the civilized nations adorned with colorful diplomatic language are not without a silly limitation of politicians' convenience; and finally, the lofty ideal of international mutual aid among the working class turns out to be a mere token slogan, and one party not only is an onlooker of a misfortune of the other but also actively guard against and try to expulse the latter. (Teihon sup. 1: 6)

On the basis of the observation, he concludes that "at least in the present day, [mutual] aid based on patriotism [aikoku shin 愛国心] is necessary for our own happiness” (p. 6). In other words, as long as the principle of territorial sovereignty remains sacred, the 
problem of overpopulation must be solved within the framework of a nation-state, rather than by appealing to lofty but hollow internationalism, either liberal or socialist. In the long run, however, he is hopeful that the accumulation of knowledge about common humanity and the elimination of racial prejudice will facilitate a "rational" solution to the premature closure of human progress caused by the enclosure of open space. Nevertheless, such a notion of common humanity must be inductively constructed from concrete historical experience of all the members of the human race.

Thus, Yanagita's progressivism is tempered by Malthusian wariness, and as a result, a cyclical motion is reintroduced into progressive time, as the linear accumulation of human time in a particular place, when having exhausted the limited gift of nature therein, results in a setback or even a complete reversal. Spatial limit means that today's prosperity may be purchased at the expense of the future's progress. Although he does not presuppose a complete trade-off between present and future gains, because some resources are renewable by human hands, he does fear that the prosperity in today's urban space is built upon the sacrifice of spatial and temporal others. Not only the current productive class in the rural area is footing the bill of the extravagance of the urban unproductive class, but also the future generation of the entire humanity will end up paying back the debt accumulated by the preceding generation.

One example of Yanagita's non-linear time is given in his discussion of overpopulation in the Japanese countryside. He traces the root cause of population growth to the early modern period (from late seventeenth century through the Meiji Restoration of 1868), when the pacification of the country and reestablishment of a relatively centralized political order boosted agricultural production and made austere 
rural life more comfortable and gentle (Teihon 16: 318-332). Yanagita readily admits material prosperity and population growth is a sign of social progress. In the preface to Nihon nömin shi (The History of Japanese Peasants), for example, he welcomes the increase of love ( $a i$ 愛), pleasure/comfort ( $r a k u$ 楽), and beauty ( $b i$ 美) as the major benefit of the advancement of civilization. "To change is not the same as corruption," he declares. "On the contrary, in many cases, it means that there are prospects for the further increase of happiness and nobleness. In fact, even today there are innumerable things that nobody doubts has become better than before. Children are [more] loved. Many people get [more] pleasure/comfort. And there are more beautiful things. The truth is that few think ill of those facts" (Teihon 16: 167-168).

However, overpopulation is partly a consequence of this increase of love, comfort and beauty. In the past, the institution of household and primogeniture used to check demographic pressures by restricting the subsequent division of property into smaller plots and concentrating the right to inherit the means of production, especially land, in the hand of the eldest son. Other male siblings became servants of a household, either their own or other's, or married into another households in need of a male heir. As a result, fewer people could have garnered enough fortune to establish large families. ${ }^{53}$

53 Yanagita contends that the household system based on primogeniture was firmly entrenched in the Middle Age partly because of military needs in a disorderly time. During the Middle Age, when there was no centralized government and hence no security for property, the concentration of power and land in the hand of the household of a single proprietary lord (daimyo and shōmyō) best ensured the means of protection from external military threats (Teihon 16: 191-192, 319). Here, there is more than a distant echo of Adam Smith's argument on the origin of primogeniture in the second chapter of the Book III of The Wealth of Nations (Smith 2000: 413-414). Smith believes that primogeniture not only makes no sense but also has become unreasonable and unjust in the modern age when security is provided by a centralized government (pp. 414-415). Yanagita also 
Nevertheless, as social norms became lax as a result of relative material prosperity and security from violence, the latent "conflict between care for the [invisible] household and love for visible children and grandchildren" (Teihon 16: 191) became a salient question for the head of a household. As parents' love for children other than the eldest son often overweighed the necessity of preserving the household, other siblings were given plots to sustain their own life and were allowed to establish branch families (bunke 分家), which were nominally subordinate to the head family (honke 本家) but often came to claim independence and parity. As a consequence, a large household was dissolved into more individualistic households in the course of time, and accordingly a collectively cultivated land was subdivided into smaller plots (Teihon 16: 201-202). The final outcome is the gradual but irreversible downfall of collective farming and the proliferation of smallholders brimming the rural space and barely scraping by on their respective tiny plots. According to the narrative, therefore, material prosperity, the equalization of social status, and the increase of parental love temporarily relieved the pain of unfortunate offspring, but in the long run, it had negative consequences on the general welfare of the farming class. ${ }^{54}$

acknowledges that when internal peace was achieved under the auspice of the relatively centralized Tokugawa regime and the sharp distinction between peasant and samurai classes were institutionalized, primogeniture became an outmoded institution for farmers, except some descendents of former lords that tried to preserve their social status (Teihon 16: 191-192, 319). However, Yanagita believes that the household and primogeniture has various functions other than military defense and does not share Smith's judgment that "nothing can be more contrary to the real interest of a numerous family, than a right which in order to enrich one, beggars all the rest of the children" (Smith 2000: 415).

${ }^{54}$ Yanagita, it should be reminded, does not mean that the decentralization and democratization of the political and economic structure of rural communities should not have happened. On the contrary, his historiography focuses on the vibrant culture of 
In spite of his Malthusian wariness, however, Yanagita generally maintains a progressive outlook in the foreseeable future, because immediate obstacles to progress are not natural but artificially made and the further admancement of humanity is up to human agency to remove them. In other words, whether time is linear or cyclical is not determined by nature alone because it substantially depends on human will and action. A major man-made obstacle to further progress, according to him, is various kinds of boundary that compartmentalize humanity into discrete entities - be it villages, regions, sovereign states, ethnic nations (minzoku 民族), or civilization—and hinder the rational reallocation of labor and capital, especially land. Yet historically, Yanagita hypothesizes, the local Malthusian limit has been overcome by those who decide to leave a crowded place, cross borders, find a virgin soil, and found a new community and there is no reason humans cannot repeat the same process, hopefully before descending into another internecine struggles and the segregation and stratification of the victorious and the vanquished. Therefore, he remains cautiously optimistic that the same solution would become more acceptable with the proper understanding of human history of migration and resettlement. Such history of migration and resettlement constitutes a grand historical narrative that underpins his conception of global diversity and knowledge production. The next section turns to this narrative.

semi-autonomous and self-governed peasant communities that emerged as a result of the dissolution of feudal manors, nominally owned by sole proprietor lords and governed by single military and political leader, into more egalitarian villages. His point is that while those changes brought about many good things, they also introduce another set of problems hardly expected by those involved in that change. 


\section{History of Migration and Resettlement}

Yanagita is critical of any "theoretical or conjectural history" and never wrote any

grand history. ${ }^{55}$ His historical narratives are always so tentative in attempt, so ambiguous in meaning, and buried in so many particular details that it is difficult to identify a single

55 The terms "theoretical or conjectural history" is originally used by Dugald Stewart in his Biographical Memoir of Adam Smith to describe Smith's approach to history (Stewart 1811: 49). It is conjectural because it supplements the lack of historical facts by the deductive application of principles to infer what human actor would behave under certain conditions. "In this want of direct evidence," Stewart writes, "we are under a necessity of supplying the place of fact by conjecture; and when we are unable to ascertain how men have actually conducted themselves upon particular occasions, of considering in what manner they are likely to have proceeded, from the principles of their nature, and the circumstances of their external situation. In such inquiries, the detached facts which travels and voyages afford us, may frequently serve as land-marks to our speculations; and sometimes our conclusions a priori, may tend to confirm the credibility of facts, which, on a superficial view, appeared to be doubtful or incredible" (Stewart 1811: 48; See also the discussion of the text in Meek 1976: 231-234). Stewart here is referring to Smith's The First Formation of Language, which was later included in The Theory of Moral Sentiment, but he points out that the same approach is used in all his other works (p. 46). He suggests that "inquiries perfectly analogous to these may be applied to the modes of government, and to the municipal institutions which have obtained among different nations" (p. 50) and hints that that is exactly what Smith did in The Wealth of Nations and his lectures on jurisprudence, when the latter claims that the mode of subsistence determines institutions and ideas of a particular age and that human civilization advances through the four modes of subsistence-hunting, pasturage, agriculture, and commerce. Yanagita never used the terms "theoretical history" or "conjectural history" and there is no evidence indicating his familiarity with Stewart's text. By stating that Yanagita is critical of "conjectural history," I do not mean that he was directly criticizing the approach Stewart describes, but that his critical assessment of mainstream historiography is directed to an approach similar to what Stewart describes as "theoretical or conjectural history." I would argue that it is not a mere coincidence because, as discussed in the first chapter, "four stages theory" was an expression of the modern spatiotemporal order and laid a foundation for the nineteenth-century discourse of world history, which Yanagita found inadequate and problematic. Meek is somewhat skeptical of the view that the "four stages theory" is conjectural history and argues that it was intended as "a broad generalization of the historical facts as they saw them" (Meek 1976: 238). However, he admits that Smith and other proponents of the four stages theory may have unwarrantedly presuppose that the life of contemporary "savage" peoples was comparable to that of ancient barbarians and may have translated temporal order into cultural hierarchy (pp. 240-241). 
grand narrative that pierce them together. In fact, his insistence on inductive methods seems to derive, at least partially, from his dissatisfaction with conjectural grand historical narratives offered by Western progressive historians such as Henry Buckle, François Guizot, H. G. Wells, and probably Marx, in spite of his appreciation of the latter's materialist view of history. For example, in reference to Wells' popular The Outline of History (1920), he complains: "I suppose many people have read world history by Englishman Wells. The white people, since when they finally realized that the earth is round, have often wanted to write books of human history or world history. That is partly their habits dating back to ancient Greece — namely, they tend to think that it is okay to write as much as they know from their ethnocentric perspectives under such grandiose titles. Yet, they have no excuse when someone objects that theirs is not true world history. Then, when they start afresh and attempt to write how entire humanity has lived and what changes they have undergone, the best thing they can get is something like the book by Wells" (“Kyōdo seikatsu no kenkyūhō," Teihon 25: 168). In spite of his antipathy to abstract progressive historiography, however, Yanagita's historical narratives are by no means innocent of any grand hypothesis. At least, the Malthusian storyline - the cycle of a founding, progress, overpopulation, decay, emigration, and a new founding - seems to serve as a persistent underlying plot in his narratives. To put it differently, if his fragmented historical narratives were assembled into a coherent narrative of Japanese civilization and possibly beyond, it would certainly seem to follow the Malthusian storyline described above. Overpopulation - that is, the excess of labor in relation to arable land — creates underemployed and hence underfed laborers, who eventually give up their native land and start wandering in search for new livelihood. In a sense, the 
possibility of emigration offers a safety valve to the local Malthusian trap as long as open space is available for new settlers. Partly because of difference in natural environment and partly because of isolation from the mother community, a new community develops a different set of practices and symbolic order and the historical memory of the ancestral land fades into myths and folklores. The cycle was repeated again and again until the Japanese people have been dispersed throughout the archipelago and differentiated themselves into distinctive communities barely aware of each other's existence.

Yanagita has long entertained the hypothesis that the direct ancestors of the Japanese people first arrived on the southern islands and went northward, as the limited space of each small island was filled up in turn. The portion of an overcroweded community, perhaps young and the most enterprising, broke insular mentality and braved the wrath of the sea in the search of an unknown shore. When they reached the southern tip of Kyūshū or other parts of the mainland, the same cycle was repeated within the lager islands of the Japanese archipelago, until the Japanese people reached the northern tip of Tōhoku. Thus, they filled up almost all the inhabitable space, from the remotest island to the steepest mountain, and dispersed into diverse and semi-secluded agrarian settlements. ${ }^{56}$ In this process, each agrarian settlement became a sort of small independent republic and their common ancestry was largely forgotten. However, along with the history of migration and resettlement, there is always the presence of wandering

${ }^{56}$ Yanagita points out that the Japanese term for islands, shima (シマ, 島), was also used, and is still being used in certain localities, to refer to inland agrarian communities. He associates shima with the adjective semai (セマイ) or narrow and concludes that it originally meant "my/our own place" or "my/our village" regardless of whether it is on the sea or land (Teihon 15: 573). 
people who, left out from settlers' communities, either voluntarily or involuntarily, travel between dispersed settlements, and possibly beyond the current national borders, transmitting a common culture.

Yanagita is generally reluctant to extend this history of migration and wandering beyond the contemporary border of the Japanese state. However, in his last major book, Kaijō no michi (海上の道 Paths on the Sea, 1961), he throws off that reluctance and explicitly elaborates on the hypothesis that the ancestors of the Japanese people originally came from southern China, having crossing the East China Sea in search for cowries, whose shells were then highly valued as currency and ornaments throughout Northeast Asia (Teihon 1: 25-29). ${ }^{57}$ Thus, he suggests that the entire Japanese nation is the

${ }^{57}$ Before the publication of Kaijō no michi, Yanagita persistently tried to confine the jurisdiction of minzokugaku to the territory of the Japanese modern state, and his reluctance was criticized by more theory-oriented disciples as a sign of cultural exceptionalism or ethnocentrism. However, the reluctance is partly explained by his awareness of the connivance between ethnology and colonialism. In his view, the European discipline of ethnology, also translated as minzokugaku but with a different Chinese ideography zoku (族 tribe), is an attempt to represent ethnic others from the perspective of the outsider, and as such tend to offer justifications for colonialism. As Oguma (1995) documents, the dominant discourse in the prewar period was that Japan was a multi-ethnic nation, and the claim that the Japanese and the Korean peoples shared the common ancestry (nissen dōso ron 日鮮同祖論) was utilized as a justification for the annexation of Korea. There are some textual evidences indicating that in the early days of his intellectual career Yanagita himself had entertained the idea that the Japanese ancestors came from the Asian Continent through the Korean peninsula, but in the course of time, he seemed to lean toward a minority opinion that Japan was a culturally, if not ethnically, homogeneous nation (Oguma 1995: 205-234). However, he continued to think of Japan as a multi-ethnic nation, although he generally downplayed the ethnic origin as the relevant issue for national integration. These episodes suggest that it is for a political reason that he tried to seal the application of minzokugaku to oversea colonies. In fact, whereas Yanagita was able to maintain a distance from Japanese imperialism during the war period, Japanese ethnologists, including his disciples, actively joined the government's effort to justify Japan's expansion into Asia through official research institutes. He broke the seal of comparative minzokugaku only when there was no longer danger of Japanese imperialism. 
descendent of immigrants from southern China. Even before the publication of Kaijo no michi, he, in rare occasions, cautiously explored the hypothesis that the existence of similar myths or folktales in various regions in the world indicates a long chain of cultural intercourse or migration between apparently separate communities through migration or wandering. The first of such instances is Momotarō no tanjō (桃太郎の誕生 The Birth of the Peach Boy, 1933), a collection of essays examining different variations of similar folktales. In the opening essay of the book, he points out that there exist too many similar folktales throughout Japan and the world to be a mere coincidence. An example of which is what is known as Cinderella in Europe, and various variations of a similar fairly or folk tale can be found throughout Japan. He contends that the similarity between European and Japanese Cinderella stories is so striking that the coincidence is unlikely to be an accident. "Either we [i.e., human beings] once lived together and told the story to each other, or because of human nature, we all go through a stage in which a similar kind of imagination is indulged in, and, on top of that, we share the common habit of not losing the memory of such imagination" (Teihon 8: 6). Yet he confesses that no decisive conclusion can be drawn yet for lack of empirical evidence. In another text, Mukasibanashi oboegaki (昔話覚書 Notes on Old Stories, 1943)), he expresses his puzzlement as follows: "It is a unbelievable miracle if those who shared the same bonfire in the immemorial past have passed down [those tales] from generation to generation by word of mouth long after parting company, not only preserving more or less the original forms but also embellishing them in a way that corresponds to each cultural particularity. Or, even if those tales are relayed from one place to another in turn, but without being lost in the place of origin, no one yet accounts for the existence of such large-scale and 
complex intercourse as long as cultural history is concerned" ("Mukashibanashi oboegaki" Teihon 8: 338). However, he is more than open-minded to the possibility that today's distinctive regions, nations, and civilizations could find a commonality, not in an abstract notion of humanity, but in a concrete historical experience.

Yanagita is aware that a grand history of human migration and cultural intercourse requires much more than he has already known about the history of the Japanese people and generally abstains from bold assertions about such history. However, there are several passages that reveal the surprisingly ambitious scope of his historical imagination. One example occurs in the text of Seinen to gakumon (青年と学問 Youth and Learning, 1924):

In the Polynesian elements [in the culture of the southern Pacific], there are traces that I think indicate they came across the ocean from northwest long time ago. Because of life in isolated islands at sea that has lasted for approximately two thousand years, the physical constitution of the Polynesian acquired new characteristics to such a degree that many [scholars] start arguing, as ordinary travelers are already imagining, that their lineage is not so different from that of the Melanesian. Anyway, it is almost impossible to inquire into the [ethnic] origin because of very complex crossbreeding. However, if the seaborne movement of the people originally started at the southern tip of the Asian Continent and if the Polynesian are distant cousins of a great tribe who have moved from there to west [i.e., the Aryan], it is possible that a pre-Christianity, pre-Hellenism, or pre-Vedas burgeoning thought of the Aryan is preserved in some aspects of [the Polynesian's] life. The possibility raises infinitely difficult questions about the fact that a culture 
takes such a different form with the long passage of time and environmental change, present and future confusions and conflicts caused by the clash of different religious faiths and social institutions - each of which is a product of a distinctive environmental condition — and the impact of such confusions and conflicts on the fate of the entire world. (Teihon 25: 100)

In the passage above, Yanagita underplays physical characteristics as a marker of ethnicity and directs the reader's attention to possible cultural commonality that he believes exists between the Polynesian and the Aryan. In so doing, he is advancing a bold hypothesis about a transcontinental migratory process that allegedly took place two thousand years ago. Another example of the scope of Yanagita's historical imagination occurs in the same book, also concerning Southeast Asia and the Pacific.

Even if we are fortunate enough to finish the task of discovering the important law of human growth [by this he probably meant the law of human civilization] in Japan, there remain China and the problem between the Malay and India ...

Dispersed between them, in the vast mountainous regions, are the Shan, who have some resemblance with us Japanese in major aspects of food and clothing, the Karen, and many other tribes, $\ldots$ too many to list up all the names here. Now turning south and pursuing traceless paths on the sea, from island peoples further down from Taiwan and the Luzon, especially young brothers in Micronesia, to many tribes, almost indistinguishable from each other, in Melanesia and Papua, all of them appear to be waiting, wondering whether the advancement of Japanese learning may reveal secret causes for their poverty and misery as well. (Teihon 25: 258-259) 
In this passage, Yanagita explicitly includes Japan as part of a hypothetical history of migration and cultural intercourse in Asia, not only in the past but also in the present. He is vague as to whether similarities between the Japanese and other peoples in Asia and the Pacific are attributable to the same ethnic origin or the similar environment, especially the condition of being shima - that is, being relatively isolated from other communities either by the vast ocean or steep mountains, but he firmly believes that the experience of the Japanese people is not idiosyncratic but directly relevant to other peoples in the similar condition.

Yanagita's interest in the southern Pacific coincided with Japan's inroad into it as a colonial power, and his identification of the island peoples as a "young brothers" evokes the theory of common ancestry between the Japanese and the Korean that was widely utilized to justify the annexation of Korea. However, Yanagita's history of migration is not necessarily limited to Asia and the Pacific. Although he never wrote about them, there were some evidence for his interest in Gypsies and the Jewish people, both wandering peoples in Europe. Yanagita Bunko (柳田文庫), a collection of minzokugaku-related materials donated by him to Seijyō University contains a dozen of books on Gypsies. ${ }^{58}$ He also took an interest in the Jewish people during his stay in Geneva and in 1922 he made a request to the Ministry of Foreign Affairs for a travel expense of his planned trip to the Palestine territory, though the request was rejected by the Ministry and he had to give up the plan (Yanagita Kunio Kenkyūkai 1988: 640).

58 Internet search at the Yanagita Bunko database, http://www.lib-finder.net/seijyo/index.html, returns ten Gypsy-related books (accessed on November 6, 2011). 
Overall, Yanagita's grand historical narrative is the history of the dispersion and differentiation of humanity. The more successful a civilization is, the higher the rate of population growth becomes, and the local Malthusian limit results in the surplus of labor in relation to arable land. The constraint is overcome by migration and the establishment of new settlements, but often not before internecine struggle produced civil war, the subjugation of the vanquished by their own compatriots, and the resulting internal social differentiation and stratification. The victors then rewrote history in a way that denigrated the vanquished or the conquered as the barbarian, and history prior to the advent of a new upper class is left to oblivion. ${ }^{59}$ If the local Malthusian limit is overcome by emigration, emigrants found new political communities and lost the memory of their historical origin. In Yanagita's view, the existing spatial divisions, both internal and international, are the products of such a historical process. His hope is that tracing back the migratory history that cuts across the existing borders would eventually reverse the reification of the boundaries that divide humanity into various compartmentalized spaces.

Islands have a particular place in Yanagita's world history. He suggests that an island reaches the Malthusian limit relatively quickly and results in what he calls "island politics (shima no seiji 島の政治).” Besides the fact that islands are more vulnerable to natural disasters, such as tsunamis or typhoons that instantly sweep away the accumulation of human time in space, the small size of the territory shapes the political

59 One of the examples of such a narrative is the one he gives in Kainan shōki concerning the history of southernmost Yaeyama islands (Teihon 1: 283-284). A chieftain known by the name of Akahachi (赤蜂 Red Bee), who was in the official history of Ryūkyū Kingdom depicted as a tyrannical ruler and a barbarous rebel, was actually the head of a powerful local clan and "a patriot of Yaeyama, or, at least, the leader of an independent party" (p. 283). 
culture of an island in a way that makes it particularly prone to internal strife and foreign intervention. In a passage from Seinen to gakumon (The Youth and Learning, 1928), Yanagita describe the history of Okinawa as follows:

When an island was filled up with people and a scramble [for survival] broke out, it was those who established a relation with a outside country and secured its support that was able to complete the great enterprise of unification, maintained peace in the island, and established a disarmed kingdom. However, there was a cruel struggle for survival immediately before and after the unification and many people died of it. Of course, this is a way to sort out the mess [seiri 整理], because with the size of the population out of proportion to the fertility of land, there is no other choice but to slay each other incessantly or to do away with the problem in that way [i.e., violent unification]. This is, so to speak, the adaptability of an island when human intellect was not sufficiently developed. ("Seinen to gakumon.” Teihon 25: 154-155)

As a limited space is quickly saturated with people, intensive competition for scarce resources breaks out. Although they are all the descendents of migrants who once braved the wrath of the ocean for a better future, the geographical seclusion of an island made them oblivious to the fact that the sea could be a pathway to a new land. The insular mentality and the intense scarcity produce a particularly fierce internecine conflict and invited intervention from an outside power, often at the request of one party in the conflict. Those who won the civil war with the help of a foreign power become the dominant class, and then rewrite history in a way that depicts the vanquished as the barbarian and the victorious as a civilizing force. The victor becomes the upper class (jōry $\bar{u}$ 上流) and tends to hold the foreign civilization supporting it as a model and tries 
to assimilate itself into it as much as possible, creating a huge rift among former brethrens (Teihon 25: 154-155).

Yanagita suggests that the same pattern of island politics is repeated at multiple levels. Even smaller islands south to Okinawa has their own center-periphery relations among them, whereas those islands collectively constitutes the periphery in relation to the main island of Okinawa, where the independent kingdom of Ryūkū was located until it was formally absorbed into Japan in 1879 . Yet the island of Okinawa, the center of the southern archipelago, is now a periphery in the entire Japan and is subjected to the government in Tokyo. Furthermore, Japan is an island in the world, whose dominant class, with the help of powerful external civilizations, first China and later the West, has tried to subjugate the rest of the population. Immediately after the quote above, he continues:

I think that even a large island like Japan was not an exception to this tendency [for internecine conflict and foreign intervention]. Only the case of Japan contains more complex relations and is of wider scope [than the case of Okinawa and the southern islands], and [the entire picture] is not immediately recognizable unless we infer it from the experience of such a [simple] model case [as Okinawa]. The strategy of conquering the inside by the clever use of support from the outside is common, not only in military but also economic wars, and there have already emerged attempts to win the recent ideological wars by the same old means. It seems that the bad habit of sacrificing one's own families cannot be corrected in a short time. (Teihon 25: 155).

In spite of the vague language, it is not difficult to recognize the barb Yanagita throws against the Japanese urban elite that conquered and subjugated their own brethrens with 
technological, economic, and intellectual support from the West. Escaping from the politics of islands requires the transcendence of insular mentality and the fundamental transformation of spatial consciousness, not only among elite but also the common people.

\section{Settlers and Wanderers}

As discussed in the previous section, one way out of the local Malthusian trap and resulting internal strife is migration. As long as there exists open space available to colonization, those who are displaced from land have an option to leave their native community in search of a new land. It may not be an option they happily choose, but as the present misery increases, a hope for better future outweighs the fear of uncertainty. However, when there is no longer vacant space available to newcomers, those who left their native land become permanent wanderers. According to Yanagita, there have existed various types of wandering people throughout Japanese history and the way they interacted with agrarian civilization varies. Yet, they were all landless people, "jōmin who eat but do not cultivate rice" (Teihon 25: 463). ${ }^{60}$ As such, they were forced to sell whatever they could in exchange for rice and other agricultural products. From Yanagita's account, it can be inferred that all the trades wandering people were specialized in - performing arts, and the production and sale of handicrafts, or even

${ }^{60}$ In this quote, Yanagita refers to hyōhakumin as a type of jōmin, but in the later writing, explicitly excludes the former from the category of the latter. See the discussion in the following section. This is one example of inconsistency with which he uses the category, but, as argued above, he believes that the two kinds of people are internally connected both spatially and temporally. 
prostitution - had once been related to the spiritual life of jomin. Because the demand for essential goods in largely self-sufficient rural communities was limited, non-essential goods constituted a major part of commodities wandering people peddled to peasants. In other words, they were "cultural" goods in the sense that they were dispensable for local productive activities, but made the life of jomin more pleasant, beautiful, or fulfilling. Unlike the austere and ascetic culture of jōmin, "new culture" (Teihon 25: 463) transmitted by wandering people was less conditioned by local material conditions and, hence, had more universal appeal, because it reflected the latter's aspirations for what they did not have, what was absent in their everyday life. Or, to put it differently, universality, understood as detachment from particular spatial conditions, was precisely the major attractiveness of those cultural goods.

Yanagita's engagement with wanderers actually precedes his interest in jōmin (Tsurumi 1998: 242-243) and takes place during his second intellectual period. During this period, his attention was diverted from the mainstream agricultural society and farmers in flat lands to those who lived on its margin. Yanagita's interest in wanderers seems to stem, at least partly, from Romantic yearning for wandering life, and this inclination can be traced back to his formative years. Before becoming a bureaucrat-intellectual, he was a sensitive young poet influenced by, among others, the European Romantic literature. One of the characteristics of his prose poems was a nostalgic longing for pristine nature, which was supposed to be found either outside urban space and in the subconscious depth of the interiority of the individual.$^{61}$ Indeed, it

${ }^{61}$ See Karatani (1993) for an insightful analysis of the relationship between modernity and the early Romantic tendency and modern Japanese literature. 
seems that the Romantic inclination sometimes carried him to the point of obliterating the distinction between the real and the imaginary. The tendency is most apparent in the case of his interest in mountain people (yamabito)—-mythical inhabitants of mountains with superhuman strength and primitive manners and frequent characters in folktales throughout Japan. During this period, he formulated the hypothesis, only to abandon it silently later, that mountain people were in actual existence and were the survivors of indigenous civilization that prospered in the Japanese archipelago before the arrival of the ancestors of the Japanese people. Nevertheless, his search for proof of mountain people's existence came to naught and, instead, he shifted attention to the shadowy presence of real wandering peoples throughout Japanese history.

In 1913, he founded, with mythologist Takagi Toshio (高木敏雄), Kyōdo kenkyu (郷土研究 Hometown Studies), a journal dedicated to ethnological and ethnographical studies of Japanese rural life. With the departure of Takagi in 1914, he ended up editing the journal on his own in the official residence of Secretary General of the House of Peers. He was prolific during this period and wrote a good part of articles that appeared in Kyōdo kenky $\bar{u}$ with various pseudonyms, until 1917 when he decided to discontinue it. Those articles demonstrated his growing interest in wandering people. Two representative texts during this period, "Fujo kō [巫女考 On Sorceresses/Priestesses]" and "Kebōzu kō [毛坊主考 On Buddhist Monks with Hair]," which appeared in Kyōdo kenkyū serially between 1913 and 1915, chased the elusive presence of wandering sorceresses/priestesses (aruki miko) and their male counterparts known as hijiri in the history of Japanese religious life. His hypothesis is that wandering sorceresses, who traveled around the 
country to offer cheap spiritual services to jōmin, and Shintō priestesses, who serves at officially recognized shrines, descend from the same class of people before they were differentiated into wandering and settled elements ("Fujo kō" Teihon 9: 296-301). The existence of hijiri, he believes, also predates the introduction of Buddhism into Japan by the Yamato dynasty in the sixth century ("Kebōzu kō" Teihon 9: 423). They belonged to the landless class who made a living by catering to the spiritual needs of jomin.

During the same period, he also showed interest in those subjected to systematic discrimination in contemporary Japan. One of them is a class officially denominated tokushu burakumin (特殊部落民 special hamlet people) consisting of the descendents of eta (エタ popularly understood as unclean or sinful) and hinin (非人 literally, non-human) - two classes of people who had been placed at the bottom of the social hierarchy during the feudal period. In spite of the official abolishment of the status system in 1871 , they continued to be discriminated against, mainly but not exclusively in terms of employment and marriage. In Yanagita's assessment, those discriminated people were the descendents of landless people, who had decided or were forced to settled down on the margin of agricultural villages to specialize in certain types of trade that peasants themselves avoided or in which they lacked technological expertise but for which a substantial demand existed. Such trade includes the handling of dead animals and leather tanning, the cleaning of public roads, prison guard, or grave digging ("Iwayuru tokushu buraku no shurui" Yanagita Kunio zenshū 4: 491-504). Besides them, there were communities or households that were rumored to be "possessed" by evil creatures. Again, in Yanagita's view, they were likely to be the descendent of wandering priests/priestesses who had settled down and the memory of whose spiritual power had been degraded into 
superstitious beliefs in mysterious creatures, as the original meaning of cosmological symbols were forgotten (Teihon 9: 305-317).

After Yanagita's interest shifted back to the life of jomin, wandering peoples receded into the background. ${ }^{62}$ However, the idea that they played an important role as the transmitter of common culture between self-secluded agrarian communities was not abandoned. In his view, the ubiquity of similar oral traditions and practices throughout Japan is largely attributable to them, and, according to his account, wandering people provided semi-secluded rural communities with an important link to the outside world and stimulated social change. If the culture of $j \overline{o m i n}$ provides Japanese civilization with a stable core, the culture transmitted by wandering people embodies its endogenous vitality and dynamism. In an essay published in 1934, he writes:

If it had not been for their wandering, more cultural factors from antiquity would have been preserved in the country. Yet the extent to which external stimuli taught

${ }^{62}$ When this shift occurs and why is an important question in the evaluation of Yanagita's minzokugaku. A number of scholars points out that by shifting his focus from strange, unfamiliar, and marginal people to the mainstream national culture, his minzokugaku either turned its back to the plight of the most discriminated and oppressed elements in Japanese society or prematurely foreclosed the rich potential of his earlier studies that pointed to the possibility of a multicultural or even multiethnic nation (Ariizumi 1972; Tanikawa 1975; Akasaka 1991; Akasaka 1994; Akasaka 2000). Akasaka (1994: 33) examines Yanagita's texts and identifies the period before and after1928 as the watershed. Oguma (1995: 212-217) suggests that his experience in Geneva from 1921 to 1923 influenced the shift of focus. However, if we consider the agricultural science period into consideration, his foray into the origin of wandering people is rather a relatively brief intermezzo, though an important one for the later development of his thought. I do not mean to deny an important change in Yanagita's thinking or the rich potential of his writings during Kyodo kenkyu period, but the critics perhaps exaggerate the extent of rapture. The interpretation offered in this study suggests a more specific form of change in Yanagita's thinking: The status of wandering people shifted from the object of Romantic yearning for spatial and external other to the temporal and internal other of jömin and the important element in the latter's history. 
[Japanese farmers] new lifestyles and ways of thinking and made [their] imagination more colorful far exceeds [the impact of] sporadic intercourse with foreign countries. ... [I]f a portion of the nation had not been these wandering elements and if they had been materially as self-reliant as fishermen living by the sea here and there, the Japanese culture of the medieval period would not have undergone such a drastic shift. ("Bunka unpan no mondai." Teihon 25: 465) In other words, the existence of wandering people made contribution to the progressive history of jomin by breathing new life into the monotony of agrarian life and stimulating new experiments. In terms of national integration, moreover, the conservative and parochial tendency inherent in rural communities was tempered by the transmission by wanderers of a new culture. ${ }^{63}$

In a sense, this is the role that Yanagita points out cities and towns had historically played. The surplus products of agricultural labor were partly channeled into unproductive activities, such as the production of arts, sciences, religions, or entertainment industry in cities that gave comfort and pleasure to peasants. In contrast to cities and towns, however, because of the relatively weak position vis-à-vis their customers, wandering people, for all the fraudulent tricks they employed to seduce them, were ultimately at the mercy of jomin. Thus, although wandering peoples must be the "active" party of the commerce, like the contemporary urban merchant, they had no

${ }^{63}$ Tsurumi Kazuko (1998: 256) argues that Yanagita understood social change as "a process of interrelations and interpenetrations among permanent wandering, temporary wandering [i.e. journey and migration], and settlement." Although he believes that settlement is the starting point of civilization, "wandering people [can] make contribution to social change by [appealing to] the psychological urge of those who took root in a particular place" (p. 256). 
choice but to cater to jōmin's needs. Therefore, their "new culture" did not aspire to supplant or denigrate the culture of jomin, as does the urban literate class today. In other words, in contrast with contemporary Japan, cultural markets in medieval Japan was driven more by the demand of jomin than by the supply-side necessity.

Wandering people had a particular advantage of catering to the spiritual needs of jōmin. A spiritual need is by definition the one that cannot be satisfied at the site of material production and requires intervention from beyond the space of everyday life. In the old cosmology of jomin, the space outside village boundaries was the external world where deities and the spirits of the dead, good or bad, belong, and wandering people coming therefrom were often regarded as the possessors of spiritual power. As a matter of fact, jomin's attitude toward wanderers was ambivalent, and even after the old cosmology was largely forgotten and wanderers were looked on with suspicion, they tended to regard them with a sense of both “contempt and awe (besshi to ikei 萝視と畏敬)” (Tsurumi 1998: 249). At normal time, wanderers were treated as beggars, swindlers, or potential thieves, but during special time of the year such as New Year or other festivities, villagers often invited them to give blessing to their households or communities. ${ }^{64}$ Some types of wandering people were specialized in the production of certain handicrafts, such as tea brushes (chasen 茶笔) made of bamboo. Yanagita inferred from its shape that that they were associated with instruments used by wandering priestess and priests for esoteric religious practice (Teihon 9: 380-382).

${ }^{64}$ Yanagita hypothesizes that a Japanese term referring to beggars, hoito (ホイト), derives from hogibito (祝ぎ人) or those who bless (Teihon 10: 80-82). 
The critical role that Yanagita assigned to wandering people in the spiritual life of jōmin has something to do with its being the latter's internal other. As such, his representation of wandering people reflects his ambivalence toward civilization. He was initially interested in mythical characters known by the name of yamabito (mountain people). The ancestors of yamabito, he hypothesized, were hunter-gatherers who inhabited a wide area of the Japanese archipelago until the rice-cultivating ancestors of the current Japanese people appeared on the scene. Coming under competitive pressure from superior civilization, the indigenous population waned, and, according to him, there are six routes to the extinction of the indigenous Japanese as a distinct people. The first route is to surrender and swear allegiance to the new ruler- "the most dignified way of assimilation" ("Sanjin kō." Teihon 4: 182). The second is to resist and die fighting and the third natural extinction because of low birth rate (shizen no shison danzetu 自然の子孫 断絶) (p. 182). Fourthly, however, they might “reconquer newly arrived farmers through religion and eventually merged themselves with the latter on favorable terms" (p. 182). ${ }^{65}$ The fifth is the most common route, which is a gradual and unrecognized process of settlement and crossbreeding. However, some of them simply chose to retreat into deep mountains and retrogressed into wandering yamabito (pp.182-183).

Yanagita's attitude toward yamabito is a mixture of pity and longing, as suggested by the opening passage of “Yamabito gaiden shiryō (山人外伝資料 Supplementary

65 In this sentence, Yanagita seems to suggest that at least a part of wandering people who catered the spiritual needs of jomin are of distinct ethnic origin. In later period, however, he generally underplays the importance of the ethnic origin of wandering and discriminated peoples. 
Material on Mountain People)," a series of articles published in Kyōdo kenkyū intermittently from 1913 through 1917:

I believe that yamabito are the descendents of the indigenous people who flourished in this island country long time ago. That civilization has already retrogressed. For the past three thousand years, no single history book has been written for them. Only when their tribe seems to be almost in extinction does person like me, who is one of their sworn enemies, plan to do that. They are truly pitiable people, if only for that reason. However, I myself have no idea of who are my ancestors ten generations ago. I cannot declare that I have no blood relations at all with them. Considering that I have an unreasonable liking for mountains and dislike some Japanese compatriots so intensely as to shudder at the sight of them, God only knows, I may inherit yamabito's blood from some lineage. I will leave that possibility out of consideration, nonetheless. I just plan to face their past with the dignity of a descendent of the honorable everlasting conquerors and the similar attitude with which Tacitus once described the German. If I am fortunate to write a book later, it may be a good memorial service for them.

In this passage, he hints that even though the identity of the indigenous people was lost, its genetic and cultural heritages may be weaved into the tapestry of contemporary Japanese civilization. Yet he ultimately characterizes yamabito's ancestors as barbarians vanquished by superior civilization. In other words, while accepting the possibility that the barbarian is within civilization, he ultimately seems to define them as the external other. At the risk of reading too much from literary rhetoric, however, it is tempting to inquire Yanagita's intention to draw an analogy between the Roman/the German and the 
Japanese/the indigenous people, given that the Western Roman Empire was later overrun and replaced by the descendents of the Germanic people supposedly brought into civilized life by the former. Also, it is worth remembering in this connection that just two years before, he proclaimed in the preface to the Tales of Tōno, "Let the people of flat land tremble at [the stories of mountain deities and people]" (Teihon 4: 5). "The people of flat land" here represents the conquering civilization, but this civilization is still terrified and fascinated by the specter of the vanquished barbarian in the form of mythical figures in folktales. In Yanagita's writings during this period, there is a hint of his view that yamabito, monsters, and deities that appear in folktales are expression of the suppressed part of the civilized self and the barbarous within the civilized psyche may eventually reemerge to reclaim a rightful place.

As it became clear that his hypothesis about the actual existence of yamabito was untenable, Yanagita precisely turned to the psychology of "the people of flat land." Although he never explicitly recanted his hypothesis, in Yama no jinsei (山の人生 Life in the Mountains, 1925), he no longer asks whether yamabito really existed and, instead, analyzes the folktales of yamabito largely in terms of jomin's psychology. Yamabito were believed to kidnap people, especially women, from villages, but he points out that there have been many cases of jommin fleeing from the yoke of civilized life into mountains and swelling the rank of yamabito (Teihon 4: 61-79). He suggests that certain types of persons are psychologically inclined for being spirited away (kami kakushi 神隠し) and confesses that he himself got caught on several occasions when he felt like being spirited away during his childhood (Teihon 4: 80-81; "Fujo kō" Teihon 9: 254-267). Romantic poems he wrote as a youth also indicate his wariness toward civilized life. Although he 
later self-criticized the Romanticism of his early years and embraces progressivism and positivist science as the grounding theoretical framework of his intellectual works, arguably his ambivalence toward civilization continues to linger on in his great interest in the spiritual life of jōmin, especially concerning the question of death. As Mishima Yukio (三島由紀夫), a novelist and an admirer of Yanagita, notes, “innumerable cases of death are recounted matter-of-factly in The Tales of Tōno. Minzokugaku is a discipline [gakumon] smelling of death from its very beginning. It is not possible to speak of minzokugaku without touching upon death and community" (Mishima 1973: 198). When Yanagita's interest shifted from wandering people to jōmin, his attention also turns from the sphere of death to the sphere of life. Yet, the question of death always lurks behind the life of jömin depicted by him.

During the Kyōdo kenkyū period, Yanagita seemed to conceive a vague notion of the important connection of the spiritual life of jomin assisted by wandering people with rural economy, but was unable to articulate any coherent discourse that links the former to the latter. When Minakata Kumagusu (南方熊楠), a renowned naturalist/ethnologist and one of the contributors to Kyōdo kenky ü, criticized the journal's (and Yanagita's) excessive concern with wandering people and urged it to refocus on the economic issues of rural life as promised initially, he retorted that Minakata understood the terms rüraru ekonomi (rural economy) too narrowly. Minakata's confusion, he suggested, is because the term "economy" is conventionally understood in too a constricted way in Japan, and he would rather translate "rural economy" into nōmin seikatushi (農民生活誌) (Teihon 30: 335), the literal translation of which can be rendered the ethnography of peasant life. 
The aim of the journal is "to stand apart from the issue of policy direction or the assessment of a project and to concentrate on the description and exposition of [real] situations" (p. 335), and the question nommin seikatushi addresses is, "how did and do the common people [heimin 平民] live?" (p. 337). Based on this understanding, he asked back whether "Fujo kō" is right in the center of nommin seikatushi" because the issues dealt with in the essays "had a major influence on today's rural life and also [even] touch upon the economic issues most narrowly defined" (p. 336). Here we can detect a notion, though inchoate, that the spiritual life of jomin and wandering people is an inseparable part of rural economy.

However, when Yanagita publicly justifies the relevance of his studies of wandering people in other texts, he tends to rely on the discourse of sedentarization and assimilation. A notable example is a 1913 journal article entitled "Various Types of the So-Called Special Hamlet People (Iwayuru tokushu burakumin no shurui 所謂特殊部落 民の種類).” The article is aimed at dispelling the popular belief that the discriminated people are ethnically different from the Japanese, but Yanagita adds two more reasons for the importance of his study. The first is the "antisocial feeling" harbored by the discriminated (Yanagita Kunio zensh $\bar{u}$ 4: 485). He points out that there are approximately 700,000 discriminated people throughout Japan, almost one out of seventy Japanese and warns that they will pose a considerable threat to public order if they manage to unite themselves against society (p. 485). The second reason is that they are potentially an additional source of labor supply and their integration into society may have a substantial impact on rural economy (p. 485). Yanagita's concern here seems that the rural economy 
is already overpopulated and has little capacity to absorb additional labor force, and his underlying assumption is that in order to fully integrate those "floating elements" into the nation, they need to settle down on land. Here, in spite of his sincere sympathy toward the most oppressed class in society, he seems to take part of the state's proclivity "to be the enemy of "people who move around"' (Scott1998: 1), instead of exalting dialectical relations between settlers and wanderers.

Thus, even though Yanagita vaguely conceived a notion of economic life in which sedentary and moving elements interact each other in a complex way and jointly make history, he failed to develop it into a full-fledged theoretical statement about social progress. He was clearly fascinated by the fact that "barbarous" elements continued to exist in the midst of civilization, but could not translate it into something more than an interesting historical narrative. After all, he never doubted that it was the interest of wandering people themselves to be assimilated into the mainstream society. However, his foray into the history of wandering people was not totally inconsequential for his later intellectual development. When wandering people was thrown off as a major subject in his minzokugaku and when his attention shifted from the rift between flat lands and mountains to the cleavage that was being developed within the mainstream Japanese society, the act of wandering reemerged as a major component of his thought. When that happens, however, wandering was no longer an act of Romantic rebellion against unnatural and dehumanizing civilization but a method to produce historical knowledge about civilization and to promote nation-building from below. 
Travel as a Method

As discussed in the preceding chapters, Yanagita's minzokugaku can be interpreted as a project to excavate a progressive history of jomin by redefining the non-urban space as a product of elaborate and accumulative human labor. Nevertheless, his re-spatialization of global diversity leads to another problem. Now that global diversity is redefined in spatial, rather than temporal, terms, anthropological space is occupied by a variety of mutually exclusive political communities, and the universal class of jomin, when applied to concrete history, is broken up into particularistic groups with an insular mindset. Tightly attached to a particular place, jömin develop insular mentality and tend to believe that theirs is the natural or standard way of human life. As a result, they not only are incapable of self-examination, but also tend to interpret any deviation from their own standards as a sign of inferiority. Although they share an objective commonality as jōmin, their self-understanding is very particularistic. If we borrow Marx's terminology, jōmin is a class in itself but not a class for itself. Furthermore, the possibility of moving from the former to the latter seems bleak, given the incommensurability between diverse communities. Even if human history is the one of repeated migration and intercourse, that history is largely forgotten and the memory of the past is fragmented into myths and folktales. Each community claims that its history is unique and self-contained, and, as a result, the progressive history of jōmin is no longer world history, but a collection of local narratives of self-sufficient communities. For Yanagita, the cosmopolitan or nationalist culture originating in urban life is a welcome countervailing force to this parochial tendency of jömin, but unfortunately cities are by no means a disinterested party. Rather, he fears, abstract cosmopolitanism or nationalism is an active instrument to promote 
particular urban interests at the expense of jömin. Moreover, most urban residents were first-generation immigrants from the countryside and carried over their respective parochial identities into urban life and formed region-based factions. As a result, "a city is merely an agglomeration of dwellings and a container that can be filled with oil and water" (Teihon 16: 188). Rather than representing national unity, Japanese cities are little more than a agglomeration of parochial groups and individuals. In short, both jōmin and the urban literate class are partial in both senses of the term and neither of them is equipped with a right disposition to write an "objective" history of humanity.

In order to overcome this problem, Yanagita proposes travel as a method of knowledge production. In essays contained in the volume Seinen to gakumon (The Youth and Learning, 1928), he encourages jomin's younger generations to dissociate themselves from their native places and temporarily exile themselves in unfamiliar lands and among strange peoples. And the major purpose of travel, he contends, is to know hito (ヒト). The Japanese word hito can simply mean a human being, but in this passage, he emphasizes another meaning: hito as people other than one's own:

We have called this vague thing [known as hito] seken (世間), or yo no naka (世の 中), [which literary signifies “in the entire world"], or, even more explicitly, tanin no naka (他人の中) [among others].... What is often expressed by those terms strikes us particularly when we travel. Just as fishes in water or human beings in air become accustomed to water and air and do not feel them, one, surrounded only by familiar people [shüi no hito 周囲の人], takes them for granted. Only when one 
slips out of relationships or makes comparison between before and after does one understand one's relations with them. ("Seinen to gakumon." Teihon 25: 123) Here, it is suggested that the words hito, seken, or yo no naka already connote what a neologism shakai (社会), the Japanese translation of the imported word society, stands for - that is, an impersonal entity composed of diverse peoples and individuals unknown to each other. ${ }^{66}$ Arguably, seken or yo no naka can be contrasted with other terms, such as ie (household), mura (village) or kuni (country, hometown), which refer to personal or communal groups of people with direct and concrete bonds. The fact that jōmin distinguished seken and yononaka from ie, mura, or kuni indicates their consciousness that familiar people do not necessarily represent the entire humanity and being "in this world" is equal to being "among others." Thus, travel (tabi 旅) can be understood as the act of stepping out of one's own ie, mura, or kuni to know a wider world.

In this context, he redefines wanderlust as an expression of natural curiosity about the world one does not know, not Romantic world-wariness.

... I think that travel is a sort of the expansion of what children feel when they start going to school for the first time or when uncles or aunts whom they have not seen for long time finally visit them; after all, it is a human action caused by the same feeling that makes you feel like reading a book when you learn how to read, or, if there are many books, picking up what seems to be the most interesting. ("Seinen to gakumon.” Teihon 25: 123)

66 The Japanese term shakai is the combination of two Chinese ideographs, sha and kai. Sha stands for a local shrine and by extension a local community surrounding it. Kai means a meeting or gathering. Therefore, the Japanese translator understood society as a meeting or gathering of various communities. 
Therefore, now what has motivated people to travel, even though it was a quite painful experience in the past, is the desire to acquire knowledge about hito understood as others. For him, traveling is analogous with reading in the sense that it is motivated by the same desire to know the world outside one's own familiar space and time. Yet, knowledge about other space and time feeds back into knowledge, or the lack of it, about oneself. Self-reflection prompted by the encounter with others leads to a better understanding of one's place in the world and, through the study of unfamiliar others, one can grasp one's spatial and temporal existence as a particular expression of humanity. In other words, to know hito is to understand humanity—i.e., both "us" and "them"—not as an abstract construction but as a concrete and historical existence.

The kind of travel Yanagita proposes contains the similar demand for self-effacement normally required for scientific works in the sense that a travelling researcher is expected to be as objective and unbiased as possible by detaching herself from her own historical community. However, this detachment is required precisely to elicit natural sympathy ( $d \bar{o} j \bar{o}$ 同情) toward the suffering of the same human kind that is suppressed by the parochial tendency of the civilized. For him, civilization actually divides, not unites, humanity by objectifying historically contingent boundaries and translating any difference into a sign of superiority or inferiority. Therefore, travelling also means temporarily abandoning civilizational life and put oneself in the position of solitary wanderers. Solitary wanderers have the advantage of being keen and relatively unbiased observers of jōmin's life because, not belonging to any particular space, they lack a standard model to serve as a point of reference in their comparison between what they observe. Specifically, unlike the urbanite, they do not look down on jömin, and 
unlike jōmin, they cannot afford to take their own customs and traditions for granted. The disposition resulting from the lack of spatial affiliation allows some wanderers to play an important role in the recording of historical facts. An example of this role is Sugae Masumi (菅江真澄 1754-1829), a traveling naturalist during the late Edo period. He was born in Mikawa (Aichi Prefecture today), but for an unknown reason he abandoned his native place at age thirty and spent the rest of life far away from home. He traveled around the northeast region (Tōhoku) of Japan and recorded the climate of the region and the ordinary life of the people with texts and detailed drawings. Notably, Sugae paid unusual attention to what the urban literate class pejoratively called denpu yajin [country bumpkins and savages], the servant class, and children, and the collection of his surviving journals, known as Masumi yüran ki (真澄遊覧記), are highly praised for unbiased and detailed accounts of manners and customs of rural communities in Tōhoku. Yanagita also extols the quality of Sugae's travel writings and attributes its exceptional intellectual achievement to his rare "fate of abandoning one's hometown for almost fifty years and having to bury that poetic mind in the solitude of the snowy country" (Teihon 2: 29). His necessity and longing for human company elicited deep sympathy for rural folks, unusual for a urban literate, and made it possible for him to observe and record their life with detached but sympathetic eyes. As Yanagita abandons wandering people and embraces solitary wanderers like Sugae, wandering is now fully incorporated into his progressive historical narrative as a scientific method of knowledge production, rather than the negation of civilization.

For Yanagita, travel produces not only topological but also historical knowledge. In Yanagita's conception, history is inscribed in space and traveling in space is traveling in 
time as well. In translating spatial differences into a temporal sequence, he is closely following the steps of Enlightenment thinkers before him (Fabian 2002: 2-10), but his minzokugaku introduces two consequential modifications into the unilinear model of social progress. First, because of his non-linear notion of progress, temporal priority no longer means superiority, because the new does not necessarily means the better. On the contrary, what is new may be inferior to what is old and it is quite possible that the "advanced" people can learn lessons from the "backward" people. The measurement of progressiveness is not newness but the extent to which new things contribute to the improvement of the long-term wellbeing of a community in question. The collective ability of a community to decide what is good to itself, not uncritical embracement of whatever is new, is what matters for progress. The correct understanding of the past that has direct bearings on the present and future because in the absence of any preconceived eternal principles, only past historical experiences provide exemplary models. Second, Yanagita's historical narrative implies the existence of more dense and complex cultural diffusion among diverse societies than is presupposed in state-centric historiography and, hence, the higher degree of crossbreeding, both biological and cultural, within and among the existing nation-states. Thus, historical knowledge produced by a method of travel is not a common temporal sequence in which each community develops independent from each other, but the history of the spatial disperson and cultural differentiation of humanity, which is partially checked by persistent cultural intercourse. For Yanagita, historical knowledge the method of traveling produce is far more accurate and empirically solid than the urban-biased conventional historiography, because it neither dissolves spatial difference into an abstract commonality nor rejects outright a concrete historical 
commonality buried underneath the present spatial divisions. He believes that, given the universality of jömin, a solitary traveler, temporally putting herself in the wanderer's place, could discover this concrete commonality among various expressions of humanity.

In a broader theoretical context, the method of travelling is embedded on the assumption that global diversity expressed in spatial difference is indispensable source of information to excavate human history. By mapping commonalities and differences among spatial units, one can reconstruct possible routes by which the human race spread or a particular idea or practice was transmitted. In both cases, the existing spatial division is relativized and dissolved into a common historical narrative.

Although Yanagita does not clearly distinguish, there seem two patterns of cultural transmission, depending on who is the transmitter. First, he hypothesizes that if culture is transmitted from the center to the periphery by wandering people, the oldest form of cultural life is preserved in the place remotest from the center. He finds this pattern in the case of neologisms. In Kagyū kō (螖牛考 On Snails, 1927), he maps the distribution of different regional names for snails and claims that there are consistent patterns in its variation. First, each regional dialect contains variations within it, indicating that it is not a uniform and self-contained language system. Even the languages used in two neighboring communities can differ from each other. Second, two communities from different regions sometimes share some common terminology. He extrapolates from this discovery that the coexistence of intraretional variation and interregional commonality results from the fact that each dialect zone has been much more open to external influence, but at the same time each community within the same dialect zone independently picked and chose what seemed best to it. 
Second, a culture may be transported from one place to another by migrants, and they preserve it even when it is not suitable for new material conditions of life. An example of this type of transmission is festivities related to rice cultivation. During his journey throughout Japan, Yanagita noticed that many mountainous or coastal villages with little flat terrain suitable to rice cultivation still took the trouble of tending small paddy fields. Initially, he discarded the practice as economically irrational, but later came to realize that rice thus produced was destined not for daily consumption but for religious ceremonies, such as the celebration of New Year (shōgatsu 正月). For another example, New Year was also called New Spring (sinshun 新春) and was celebrated with fake rice planting in the middle of snowy winter in northeast Japan. He reasoned that, besides the fact that the replacement of the old lunar calendar with the Gregorian calendar brought forward the advent of New Year by about one month, New Year actually coincided with the beginning of the preparation for rice planting in southwest Japan (Teihon 2: 12-14). Thus, he interprets the ubiquity of the similar New Year custom throughout Japan as proof that the common ancestors of the Japanese people first arrived at the southern tip of the archipelago and went northward. A passage from "Yukiguni no haru" reads:

If they had invented [a custom] anew for their own sake, probably they would not have accepted such unnaturalness and disharmony. The inhabitants of the periphery, when they are severed from intercourse with the wider world [seken 世間], become careless about their personal appearance, letting their beard grow as it pleases or wearing [unseemly] leather cloths, and acquire an uncouth [araarashi 荒々しい] look. Seeing that, people [outside of the region] sometimes forget that they are 
brothers who parted company in the past. However, even if no other evidence exists, there is no cause for worry that those who are so loyal to the old faith and upon knowing that spring has come in the other part of the country [tenka 天下], they start preparing for another year of farming in the middle of winter, without paying attention to the severe coldness in their place, are descended from a different genealogical line. ("Yukiguni no haru." Teihon 2: 13-14)

Although those practices seems irrational from the economic point of view, they serve to preserve historical memory retrievable by minzokugaku researchers.

In Yanagita's estimate, therefore, the Okinawa islands, where the ancestors of the Japanese people supposedly landed first, preserve the oldest and most pristine Japanese culture, uncontaminated from imported elements such as Buddhism. That was a quite radical thesis, given that the Okinawans were often treated as inferior ethnic others by the mainland Japanese. His thesis that the ancestors of the Japanese people came from the south has never been widely accepted and is not supported by later archaeological discoveries. Nevertheless, regardless of the validity of his thesis on a particular route in which the Japanese people spread throughout the archipelago, the theoretical point he is trying to make is still valid: That the existing boundaries that divide contemporary Japan and, by extension, the world into discrete spatial units are actually pierced through by the unrecorded history of mobile people.

Although the two kinds of history of cultural transmission, one by wandering people and the other by migrants, demonstrate different aspects of the Japanese culture, one dynamic and the other static, they together constitutes a common historical narrative in which the Japanese people gradually conquered the natural environment they found at 
the arrival and nurtured a unique but not idiosyncratic culture. Yanagita believes that by excavating such unrecorded history, the parochialism of jomin would give way to sympathy $[d \overline{o j} \bar{o}]$ toward forgotten brothers and sisters sharing common history. As a consequence, a class unconscious of itself could become a self-conscious class capable of self-representation both politically and literally. Only then could a national space be reclaimed by its legitimate owner, jomin. However, as in the case of the entire history of Japanese civilization, wanderers should play a crucial role in producing and disseminating trans-communal culture and knowledge. Minzokugaku provides methods that deliberately organize the efforts of temporal wanderers to produce and disseminate such new culture. Thus, for him, travel constitutes not only a method of knowledge production but also an important political practice to break away from parochialism without being individualized and incorporated into an abstract space imposed by the urban literate elite. In this context, it is worth emphasizing that the main target audience of his writings and speeches are not scholars in academic institutions or the urban intellectual class in general but the growing literate youth residing in the rural area, especially schoolteachers ${ }^{67}$. He exhorts this particular class to think independently, instead of passively absorbing given questions and answers through books, and to play a leading role in the production and dissemination of local knowledge by travelling.

\section{Particular Experience and Universal Knowledge}

67 Yanagita was heard saying that whereas the hypothetical reader for Orikuchi Shinobu (折口信夫 1887-1953), another founding figure in minzokugaku, is a Shintō priest, his is an elementary shool teacher (NIshiwaki 1962: 74). 
In Yanagita's minzokugaku, the producer of knowledge is still a solitary individual who stands apart from the object in question, exercises reason to analyze and dissect it, and transcribes what is observed in the most accurate and precise way. However, instead of achieving neutrality merely by means of methodological asceticism, she is required to gradually move from the personal to the local, from the local to the national, and from the national to the global space. She starts with questions that directly affect her personal life, but are gradually forced to expand her spatial and temporal horizons upon finding that it cannot be explained fully without embedding it in wider spatial and temporal contexts. Instead of applying her own received knowledge to unfamiliar lands and peoples and reducing them to the silent objects of analysis, she is expected to be modest enough to try to understand them in their own terms as much as possible and compare their self-knowledge with her own. Diverse experiences at every level are counted as relevant materials for the production of knowledge, and genuinely universal knowledge about humanity must be constructed block by block from below, so to speak, until global diversity is fully accounted for in such knowledge.

Yanagita's writing style follows this pattern. Besides Meiji Taisho shi: Sesō hen mentioned in the third chapter, his writings generally begin with mundane questions that one encounters in the quotidian life, such as the shape of an object, the name of a place or thing, or an oral tradition explaining the origin of a local shrine. In the course of inquiry, however, those innocuous questions lead to a larger hypothesis about the migratory history of the Japanese people, the cosmology of jomin, or the political life of peasant community. In other words, what seems a purely personal or local experience at first glance reveals itself to be the tip of an iceberg of a long historical chain transcending the 
narrow confine of individual life. As Tsurumi Kazuko (1998: 82) and others point out, many, if not all, of Yanagita's major theses can be traced back to his personal experience during his childhood and youth. For example, his hypothesis that the Japanese people first arrived at the Okinawa islands and went northward is traceable to an experience he had in his visit to Irako Cape, Aichi Prefecture, in 1898. He was strolling the seaside when he found a few coconuts drifting ashore. Its flesh was still raw indicating a sea route that connects one of the southern islands to the central part of the mainland ("Yūkaitōki." Teihon 2: 474). He incubated the idea for almost sixty years until fully articulating it in Kaijō no michi.

In more general terms, it is arguable that his thought itself is motivated by his personal experience. For example, the experience of his biological family seems one of the primary materials for his subsequent effort to define the household as the linchpin of social integration. Being part of but standing apart from an agricultural community, the Matsuokas were eventually uprooted from their hometown and his parents died in a foreign place they had never been able to get used to. All surviving children became successful urban professionals, but the Romantic poems by young Yanagita indicate that he seems to have felt adrift because of his uprootedness, especially after the death of his parents. His decision to marry into the household of Yanagita was most likely motivated by his desire to find a home. It is tempting to speculate that his analysis of the psychology of the urbanite and the role of the household in social integration actually draw on his own personal experience. Also, his experience in Europe had a profound impact upon his thought. In Geneva, the former elite bureaucrat felt like a country bumpkin [aka getto 赤 毛布 or yamadashi 山出し] not least because of the lack of linguistic ability to express 
himself freely before his European colleagues in the Permanent Mandate Commission (Teihon 3: 307-308). Instead of confining this experience to the personal sphere, he connected it to the experience of the rural population in Japan and the native populations in colonies.

Yanagita's inductive methods, therefore, relies on the gradual expansion of one's own spatial horizon without abstracting oneself out of the world in which one's self is formed. Every step outward brings about important insights into not only others but also the self, partly because the former serves as a mirror to reflect the image of the latter, and partly because the comparison reveals historical connections between them. Diverse experience in this sense is indispensable material for the production of universal knowledge about humanity. These inductive methods are opposed to a deductive method in which received theories and concepts are applied to sort out relevant information from an opaque reality, often by arbitrarily carving out an abstract mental space. The compartmentalization of the world into neatly demarcated abstract realms, such as international/national, or political/economic/cultural, that cut across concrete spatial orders has its own political consequences by reducing the actual agents of human progress to the mere object of knowledge. Eventually, abstract spaces become the standards according to which concrete human experience must be organized into. Instead of descending from an abstract mental space to concrete spaces experienced from within, a minzokugaku researcher starts with a concrete historical experience and ascends step by step upward in discovering concrete historical connections between seemingly discrete elements. That is why Yanagita firmly believes that anthropological knowledge is indispensible for a genuinely universal and scientific conception of humanity. 


\section{CHAPTER V}

\section{CONCLUSION}

In light of the interpretation of Yanagita's intellectual biography expounded in the preceding chapters, his intellectual project can be revaluated as a critical engagement with the modern spatiotemporal order that has systematically undercut the empirical weight of global diversity in the production of theoretical knowledge. Instead of counting diverse experiments by humankind as relevant material for universal knowledge and, hence, necessary condition for social progress, modern social and human sciences tends to resort to a preconceived spatial imaginary to draw a sharp line between who is the subject and the object of knowledge. By translating spatial diversity into stages of unilinear development, the producers of modern knowledge deny contemporaneity to the experimentations of those who live outside spaces other than Western or Westernized urban centers, on the ground that they belong to the past that is already overcome. The experimentations by the latter, therefore, may have some aesthetic values and can be valid material for literary or artistic works, but contain nothing new and add little to the accumulation of knowledge. Yanagita's critique is directed at this particular aspect of modern knowledge, which incorporates all the population on earth under the common rubric of humanity but at the cost of introducing moral and intellectual inequality in the relations between different peoples on the basis of spatial affiliation.

For Yanagita, the question of diversity and knowledge production is not only academic but also political one, because knowledge predicated on the modern spatiotemporal order provides a justification for substituting democratic politics, centered 
on public debates, with the application of received knowledge by the knowledgeable few. The political authority of the Japanese bureaucratic and intellectual elite depends substantially on the idea that the West represents the destiny of entire humanity and knowledge of and from the West can teaches its possessor not only where they are going but also how to get there more efficiently. For the possessor of such knowledge, democratic politics is not only unnecessary but also dangerous for social progress, at least until the population become "mature" enough to be benefited from free discussions. Because of this assumption, bureaucratic planning, not public discussion, has become the central feature of modern Japanese politics. Young Yanagita's emphasis on the internal diversity of Japan is related to his criticism of a kind of politics that were emerging at the turn of the twentieth century. Eventually, he comes to believe that the democratization of politics requires the democratization of knowledge, and intellectual democratization demands the recognition of diversity as a fundamental puzzle.

In spite of his dissatisfaction with modern knowledge and politics, Yanagita remains committed to the idea of progress and the possibility of universal science. That is not to say that it is impossible to consume Yanagita's writings as an expression of anti-Enlightenment Romanticism. Indeed, it is not difficult to detect deep-ingrained skepticism toward modernity in Yanagita's writings. However, one of the notable characteristics of his intellectual career is repeated self-criticism and attempts to reconcile various sets of two seemingly opposing elements-e.g., Romanticism and rationalism, progress and tradition, reason and sentiment, scientific rigor and poetic imagination, the Western and the Japanese, and the universal and the particular. If this almost Hegelian dialectical thrust of his intellectual project is appreciated, it is possible to yield a more 
comprehensive understanding of his thought, which redefines him as an intellectual heir to and an internal critic of the Enlightenment tradition, rather than an anti-Enlightenment conservative, with all its merits and disadvantages. He interprets the historical and particular expressions of humanity, not as antithetical to universal knowledge, but as a rich reservoir of empirical evidence from which a universal history of humanity can be inductively reconstructed. He also firmly believes that only by the discovery of genuinely universal knowledge on the basis of historical experience can humanity get rid of prejudices and parochialism and lift itself to a higher stage of human civilization. In this sense, his minzokugaku can be said to be a legitimate heir and a necessary corrective to “conjectural history," pioneered by eighteen-centuries Enlightenment thinkers such as Adam Smith and elaborated by Mill and Marx. Yanagita would argue that, while conjectural history could fill a huge lacuna in human history, left by the lack of empirical evidence, with the deductive application of certain principles, minzokugaku offers a more scientific method to fill the gap and write a more comprehensive and accurate history of human progress.

The method of minzokugaku is informed by an assumption about space and time similar to the one held by Enlightenment thinkers: The past is accessible through travelling in space and it is possible to translate spatial diversity into historical sequence. However, whereas the Western and the Westernized observers find a flat and timeless space in non-Western places, he sees the multiple layers of history waiting to be excavated, just like geologic strata under the surface. Therefore, like the archaeologist who excavates the relics or survivals of the past from the accumulated layers of ground, the minzokugaku researcher can excavate the relics and survivals of the past from deeper 
and subconscious layers of contemporary daily life. What those relics and survivals of the past tells the contemporary is revealing for two reasons. First, the social history of jomin is that of continual, though gradual and not-so-visible, change, often stimulated by external influence, but primarily driven by jömin's physical and psychological needs. Second, the existing spatial divisions are much more penetrated by the movement of people, goods, and information than conventionally supposed. Even though two spatial units, be they the city and the region or different nations, seems to be completely separate entities on the surface, the deeper one digs into the past, some connections can be found. That is because, in Yanagita's conception, civilization has so far tended to divide, rather than unite, the human race and bury common humanity underneath an increasingly thick layer of particular culture. In order to discover common humanity, therefore, one needs to go back to the past, instead of conjecturing it from particular principles and projecting it into an unrealized future. Thus, while many of his fellow-bureaucrat-intellectuals travelled from the periphery to the center- that is, from their rural hometown to Tokyo and from Japan to the West — to retrieve knowledge about universal civilization that was yet to come, he decided to travel from the center to the periphery to retrieve knowledge about universal humanity that have existed throughout history.

Such a reading of Yanagita's texts casts light on an aspect of his thought that has not received enough attention from either Japanese or international scholars. His theoretical background is formed in a much more direct engagement with the Western intellectual tradition than is conventionally thought, and, in fact, he can even be characterized as a direct heir to the eighteenth-century Enlightenment, along with such thinkers as Mill and Marx. That his thought was influenced by Western ideas is hardly 
surprising given the fact that every modern Japanese social and political thinker must engage, though to a varying degree of self-consciousness, with them. However, his thought is directly comparable to Mill's and Marx's, not simply because it belongs to the same discursive field, but also because, rather than accepting uncritically or rejecting outright the Enlightenment tradition, he consciously tried to redeem its democratic potential by revising its problematic aspects. The attempt leads him into a deeper layer of the Western intellectual tradition-i.e., the question of space and time - that runs through underneath superficial disciplinary or ideological divisions and, as a result, his critique of the Enlightenment tradition acquires a transformative potential. When he describes minzokugaku as "a science that organizes and synthesizes [increasingly fragmented and partial knowledge] into a whole" (Teihon 25: 184) on the basis of not received canons but the historical experience of the entire humanity, he is speaking the language of the Enlightenment. Yet, his theory of the relationship between progress and political community definitely calls certain aspects of the Enlightenment tradition into question.

Thus, Yanagita's thought can now be said to suggest a path the Enlightenment tradition could have taken but did not. In fact, the birth of modern anthropology and geography is tightly connected with the notion that global diversity constitute a common stock from which the seeker of universal knowledge could be greatly benefited and that the existing mode of knowledge production was not up to the task of dealing with it. Excitement about a possibility of a new science and dismay at the current state of scientific arts are vividly expressed in one of Rousseau's endnotes to his Discourse on the Origin and the Foundation of Inequality among Men: 
Shall we never see reborn the happy times when Peoples did not pretend to Philosophize, but the Platos, the Thales, and the Pythagorases, seized with an ardent desire to know, undertook the greatest journeys merely in order to learn, and went far off to shake the yoke of National prejudices, to get to know men by their conformities and their differences, and to acquire that universal knowledge that is not exclusively of one Century or one country but of all times and all places, and thus is, so to speak, the common science of this wise? (Rousseau 1997: 210) In the rhetorical question, Rousseau suggests that the current mode of knowledge production is far from being ideal in comparison with his ideal state, which supposedly existed in the ancient period. The inadequacy, according to him, is because existing knowledge about humanity is systematically skewed by ethnocentrism and prejudices against unfamiliar others:

Although the inhabitants of Europe have for the past three or four hundred years overrun the other parts of the world and are constantly publishing new collections of travels and reports, I am convinced that the only men we know are the Europeans; what is more, it would seem that, judging by the ridiculous prejudices that have not died out even among Men of Letters, very nearly all anyone does under the pompous heading of the study of man is to study the men of his country. Regardless of how much individuals may come and go, it would seem that Philosophy does not travel, and indeed each People's Philosophy is ill-suited for another. (Rousseau 1997: 209)

One reason for Philosophy's inability to travel, according to him, is that knowledge about unfamiliar places and peoples mostly relies on observations by four classes of 
people_-"Sailors, Merchants, Soldiers and Missionaries" (p. 209)—who are all ill-prepared for objective observation. In order to overcome the problem, Rousseau continues, travel should be recognized, not as an appendix to other businesses, but as an intellectual activity in its own right.

Let us suppose a Montesquieu, a Buffon, a Diderot, a Duclos, a d'Alembert, a Condillac, or men of that stamp, traveling with a view to instruct their compatriots, observing and describing as they do so well, Turkey, Egypt, Barbary, the Empire of Morocco, Guinea, $[\ldots]$ and all the Wild regions, this being the most important voyage of all and the one that should be undertaken with the greatest care; let us suppose that on their return from these memorable travels, these new Hercules set down at leisure the natural, moral and political history of what they had seen, then we would ourselves see a new world issue from their pen, and would thus learn to know our own. (Rousseau 1997: 211)

The passages quoted above could be a perfect statement of the spirit of Yanagita's minzokugaku, except that the latter expected the ordinary people to be a Montesquieu, a Buffon, a Diderot, a Duclos, a d'Alembert, and a Condillac. ${ }^{68}$

For another example, no one other than Kant, during his precritical period, considered anthropological and geographical knowledge as indispensable part of philosophy and taught courses on anthropology and geography (Harvey 2000: 534).

${ }^{68}$ There exists textual evidence indicating that Yanagita read Rousseau's Second Discourse and hence was familiar with the passages quoted above. In Nōseigaku, he refers to Rousseau in passing in the discussion of land property. The passage reads: "If, as Rousseau and others argue, there existed free and independent ancient men..." (Teihon 28: 218). 
Unfortunately, however, the promise of a new science was not fulfilled and anthropology and geography were established as separate and narrowly defined disciplinary fields with few connections with philosophy. In fact, Kant's critical turn and abandonment of Popular Philosophy (Popularphilosophie), vividly depicted by John Zamitto (2002), seems illustrative of the course the Enlightenment tradition would ultimately take. What was at stake in the debate between Popular Philosophy and School Philosophy (Schulphilosophie) in mid-eighteenth century Germany was nothing less than the meaning of the enlightenment and the status of knowledge in newly emerging social and political conditions. The burgeoning bourgeois reading class demanded accessible and practical knowledge and fiercely attacked what it considered the irrelevant esotericism of university scholars, either theological or rationalist. Partly influenced by British and French Enlightenment thinkers, including, of course, Rousseau among others, Kant emerged as a leader of Popular Philosophy in the 1760s, and his interest in geography and anthropology partly derived from his desire to make philosophy more accessible and relevant to the new reading class. However, Kant finally returned to the notion of philosophy as "rigorous science" and edified a philosophical system that was to shape the subsequent understanding of the scientific. It is one of his best students, Johann Gottfried Herder, who held on the torch of a new science Kant might have inaugurated but did not (Zammito 2002: 15-41). Whereas there is no indication that Yanagita was familiar with Herder's writings, there is striking similarity between their views of world history, though, not surprisingly, the former's entirely lacks the latter's theological language. The similarity points to the possibility that although each of Rousseau, Kant/Herder, and Yanagita's discourses was intended to address a historically specific question, there exists 
a common structural problem in the mode of knowledge production and the democratization of society that runs through all those cases. At any rate, Yanagita's minzokugaku is precisely a project to subject the validity of received knowledge to the full weight of empirical diversity retrieved by the act of travelling. In this sense, it is an attempt to reengage with the unfulfilled promise of the Enlightenment expressed by Rousseau.

If Yanagita is a product and internal critic of the Enlightenment and his project is understood as a direct extension of the Enlightenment tradition, his thought cannot simply be an expression of Japanese cultural exceptionalism. The view that he is a Burkean conservative is more on the mark, but it vastly underestimates the scope of the dialectical thrust of his thought and, and, hence, its progressive side. ${ }^{69}$ The interpretation offered in this study, if not totally off the mark, warrants a substantial revision of the significance of his thought in intellectual history, both Japanese and international. At the very least, the direct linkage between Yanagita and the Enlightenment tradition makes it easier to connect his intellectual project, in spite of his apparently exclusive obsession with Japanese indigenous traditions and customs, with contemporary debates on global order. There are various ways to do this, but my immediate concern here is to sketch out

${ }^{69}$ As far as I know, there is no evidence, either textual or otherwise, that shows Yanagita actually read Burke's texts and was directly influenced by them. Apparently, it is entirely based on similarities between the way the two understood history and political community. I do not deny that Burkean elements in Yanagita's thought is substantial enough to warrant the possibility that he was influenced, directly or indirectly, by Burke, but want to emphasize the equally important influence of other thinkers, including Rousseau, Adam Smith, Mill, and Marx, among others. 
the theoretical implications of his thought for the contents and methods of Political Theory and International Relations.

At the most abstract level, Yanagita's thought can be said to be political in the sense that at the center of his thought is the question of human space and time. It reminds us that there exists an intimate connection between the spatiality and temporality of human existence and the meaning of the political, possibly constituting a defining characteristic of politics as a universal problematic. Yanagita understood the mission of modern science as addressing this universal problematic. On the one hand, being in time means that change is inevitable and that death is a latent possibility for both individual and collectivity. The search for elusive immortality in well ordered space requires the constant revision of knowledge, questioning what is natural-i.e., what is not or should not be amenable to human will—and what is not. Thus, global diversity and historical knowledge retrievable from it — what kind of human experiment has produced what kind of outcomes under given conditions - constitutes an indispensable resource for theory building. Being in space, on the other, means that human existence is both empowered and limited by the totality of what is given to a person or a group of persons at a given time, either external nature or other human beings. In Yanagita's conception, therefore, the possibility of progress rests on not only the accumulation of time in a particular place but also the reconfiguration of spatial order - that is, the internalization of the externalized other. Thus, another function of the history of anthropological space excavated by minzokugaku is to expand the spatial and temporal horizon of the individual beyond his or her immediate space and time. In this quasi-Hegelian dialectics, the 
opposition of Fukuyamian universalism versus Huntingtonian particularism resolves into a common historical narrative in which time and space interact each other.

At a less abstract level, his thought also has implications for questions concerning an ideal global order in the midst of diversity, its institutional underpinning, and a means to achieve it. Although Yanagita never directly addresses those questions, it is possible to make an educated guess about his latent positions on various issues on the basis of his unstated theory of human space and time. First, Yanagita understood the problematic of the contemporary world order quite differently. For him, what was happening during his time was the global expansion of the power of urban centers over rural peripheries. This imaginary of global space is predicated on his grand historical narrative of human spatial dispersion and cultural differentiation. The local saturation of rural space with excessive labor forces gives impetus to the growth of urban industry and commerce to the point that it is now cities that hold the upper hand over the rural population. Driven by insecurity, either material or psychological, cities attempt to establish a hegemonic position vis-à-vis the countryside by incorporating the latter as its hinterland and establishing hierarchical relations with it. In Yanagita's view, this is not necessarily a modern phenomenon, as it has been repeated locally throughout human history. However, innovations in communication technologies made it possible for the European metropolis to expand its reach to every corner of the world and implant its lifestyle and ways of thinking. They readily find eager audiences in non-Western urban elites, who, with the aid of the Western metropolis, defeat their rivals and extend their control over the vanquished. In his opinion, colonialism, either internal or international, Western or Japanese, is but an expression of 
this urban aggressiveness. What has resulted from the advancement of the urban interest is a global multilayered network of center-periphery relations.

Yanagita's imaginary of the early-twentieth century global space is similar to what

John Agnew calls "hierarchical networks," which he describes as follows:

The nodes here are city-regions. The spatial structure in which they are embedded is a world economy of geographical cores, peripheries, and semiperipheries linked together by flows of goods, people, and investment. Transactions based largely on market exchange produce patterns of uneven development as flows move wealth through networks of trade and communication producing regional concentrations of relative wealth and poverty. At the local scale, particularly that of urban centers, hinterlands are drawn into connection with a larger world that has become progressively more planetary in geographical scope over the past 500 years.

Political power is a function of whereabouts in the hierarchy of sites from global centers to rural peripheries a place is located. Time is that which is organized by the geographical scope and temporal rhythm of financial and economic transaction. The spatiality is that of spatial networks joining together a hierarchy of nodes and areas that are connected by flows of people, goods, capital, and information. (Agnew 2003: 130)

Agnew contrasts this model with the conventional imaginary of an international system, which he terms "field of forces" (Agnew 2003: 129-130). In comparison to the latter, the "hierarchical networks" model is better at capturing the dynamics of capitalist development that has its own spatial and temporal logic. To some extent, the formation of the nation-state and capitalist development work in tandem, as both require the bringing 
down of internal barriers that divide society. However, if left unchecked, the space and time of capitalist economy easily becomes out of line with those of the nation-state. And, when that happens, the atomization of communities into individuals and the trivialization of spatial differences have already made it difficult to defend the nation-state in the name of the preservation of global diversity. The seed of what is called economic globalization today was already sowed within the modern spatiotemporal order.

For Yanagita, the global expansion of hierarchical networks is ultimately attributable to the problem of outgrown urbanism. As such, it cannot be uncritically embraced as a sign of progress, because the prosperity of urban centers is being purchased, at least partially, at the expense of spatial and temporal others. In theory, a rational solution to the problem of local overpopulation and its consequences is the redistribution of labor and capital, including land, at the global level in a way that could ensure each household and each community as much self-sufficiency as possible. However, this means some sort of global migration and resettlement policy, and he readily admits that this is not a practical solution in the foreseeable future, given the existing national boundaries, widespread ignorance and misunderstanding about common humanity, and persistent danger of colonialism. As a more viable alternative, therefore, he proposes nation-building from below, in which the jömin of each particular space are expected to break from an insular and parochial mentality and gradually expand their spatial horizon from the local to the national, and then from the national to the global. Instead of breaking up existing communities into atomized individuals, his strategy is to build upon existing social institutions such as the household (ie) or village (mura), which have historically countered individualizing forces, to create a nation. His hope is that 
national consciousness and democratic institutions would empower jomin, the numerical majority, as a major force in politics, who could, in turn, resist more effectively the encroachment of the urban interests by consciously choosing what is best for themselves without blindly following the imitative leadership of the urban elite. In this way, he hopes, Japan could temporally break from the Malthusian trap, not by resorting to colonial expansion, but by means of domestic agrarian reform and population control. In the long run, however, he hopes that a more rational solution to the problem of overpopulation would be acceptable internationally, when each society develops its own minzokugaku and becomes conscious of its position in universal human history.

Yanagita's view would yield a very different diagnosis of the contemporary world order and possible remedy to it than Fukuyamian universalism and Huntingtonian particularism. He would embrace international society consisting of politically, economically, and culturally autonomous nations as an unfulfilled promise and an alternative to the current global expansion of capitalist economy. Yet, the ideal of international society he would embrace substantially differs from the one predicated on the modern spatiotemporal order in several aspects. First, it does not classify societies according to their positions in a uniform scale of political, economic, and cultural development. Second, the territoriality of the modern state has been given an objective foundation, as it is made contingent on the efficient use of economic resources. Those states with relatively abundant economic opportunities would be obligated to accept immigrants, but those immigrants would not be supposed to create an enclave or constitutes a distinct class within the host nation. Third, the internal structure of the nation-state would be politically, economically, and culturally far more decentralized than 
the modern nation-state. Instead of a few large urban centers exercising hegemonic power over smaller cities and the countryside, it is imagined as a loose confederation of economically self-sufficient and political autonomous regions, bonded together by a layer of common but not totalizing culture. Fourth, the political and economic sovereignty of a nation-state is also tempered by the awareness of its historical and spatial connections with other nations. In fact, the nation-state would be but a transitory phase for the further reunification of humanity that parted the way long time ago, because, as minzokugaku reveals historical connections between different nations in a deeper layer of the past, nation-building from below may transcend the existing national boundaries. However, the reunification should not be carried out by the imposition of a totalizing culture by the strong, but the spontaneous act of weaving the existing cultures into a common one. Fifth, nationalism, understood as the expansion of spatial horizon from the local to the national space, is redefined as a progressive force. However, nationalism needed for that purpose is not a reactionary sort that reproduces the modern spatiotemporal order by objectifying spatial differences established by it. Rather, it is nurtured by the desire to cross the existing borders that divides a nation and, by extension, entire humanity. The methods of Yanagita's minzokugaku are designed to promote such a kind of open-ended nationalism, which, by tracing back the history of human dispersion and differentiation, may ultimately reach the common ancestry of entire humanity. Yanagita would claim that such an international society is not perfect, but the best guarantee for the diverse experimentations by humanity to run their respective courses toward progress, while the possibility of a mutually enriching learning process would be kept open by continual border crossing. 
It is debatable whether Yanagita's ideal international society is a realistic or desirable alternative to other possibilities, but, at least, it recognizes the question of cultural diversity as a fundamental puzzle for the construction of world order in the age of globalization. A puzzle is hardly new for Political Theory and International Relations, but it has been so far solved, or "deferred" in Inayatullah and Blaney's (2004: 44) terminology, by Todorov's “double movement” (Todorov 1999: 50). Certainly, this tendency is neither a new phenomenon nor proper to encounters between particular cultural groups, but combined with the Western economic and military ascendancy since the sixteenth century, it led to the worldwide diffusion of allegedly "universal" knowledge that perpetuates the West at the center of the modern spatiotemporal order, with the East and South trailing behind.

Knowledge thus produced has serious political ramifications because it precludes the possibility of reciprocal communication between the West and the Rest by denying the East and the South what anthropologist Johannes Fabian (2002) calls "coevalness." Because anthropology is the discipline that is specifically designed to produce knowledge about the East and the South, his critique of anthropologists' "persistent and systematic tendency to place the referent(s) of anthropology in a Time other than the present of the producer of anthropological discourse" (Fabian 2002: 31) is illustrative of the use of space and time in the modern production of knowledge. Fabian argues that the denial of coevalness amounts to the denial of communication because,

To recognize Intersubjective Time would seem to preclude any sort of distancing almost by definition. After all, phenomenologists tried to demonstrate with their analyses that social interaction presupposes intersubjectivity, which in turn is 
inconceivable without assuming that the participants involved are coeval, i.e. share the same Time. In fact, further conclusions can be drawn from this basic postulate to the point of realizing that for human communication to occur, coevalness has to be created. Communication is, ultimately, about creating shared Time. (Fabian 2002: 30-31)

According to Fabian, however, the possibility of ethnological field research, which places the observer and the observed in coeval position as copartners of knowledge production, is forfeited by temporal distancing of the latter in the process of translating their findings into written manuscripts.

The denial of coevalness is not limited to the practice of anthropologists, but is pervasive in other fields. Todorov (1999) contrasts the "ethnologist" and "comparatist" attitudes toward cultural others as follows:

The comparatist puts certain objects, all of which are external to him, on the same level, and he himself remains the sole subject.... it does not put the Other on the same level as oneself, and does not call into question one's own categories. The ethnologist, on the other hand, contributes to the reciprocal illumination of one culture by another, to "making us look into the other's face," according to the splendid phrase already devised in the sixteenth century by Urbain Chauveton: we know the other by the self, but also the self by the other. [italics in the original] (Todorov 1999: 240)

What Todorov calls the "comparatist" stance is the dominant attitude in many other social scientific modes of knowledge production. Indeed, in modern sciences, universality is explicitly defined as the detachment from any particular space. As a result, the observer is 
required to suspend its own social identities and treat the subjects of analysis as data, not as a communicative partner. A price for this stance, according to Todorov, is so many lost opportunities to know the self through the other.

The effort by Enlightenment and post-Enlightenment thinkers to incorporate global diversity into theoretical knowledge is vitiated by this comparatist attitude, which had an unintended consequence of impoverishing their understanding of the self, the other, and, hence, humanity as a whole. Yanagita tried to correct this defect of the Enlightenment tradition by adopting a more ethnological attitude toward the question of otherness in the sense that he treated others as communicative partners rather than the mere object of knowledge. For him, only knowledge produced by means of more dialogical or conversational methods deserves the name of universal knowledge. This is also a corollary of his application of Mill's defense of diversity in a global scale, though in Yanagita's conception the subject in life experiments is no longer individuals but democratic communities in which not the knowledgeable few but entire citizenry take part in it. Today, when the entire world has undergone Westernization in various aspects of life and there is less "freedom" and "a variety of situations" in collective experiments, not only the West but also entire humanity suffer from the shortage of alternative views. In this sense, modern political and international relations theories may have contributed to the impoverishment of knowledge by narrowing down, rather than enlarging, political possibilities. At the very least, Yanagita's effort to revaluate the political significance of seemingly apolitical aspects of Japanese civilization serves as a reminder of such danger. 


\section{BIBLIOGRAPHY}

Primary Texts and Interviews

Teihon Yanagita Kunio shū. 31 volumes and 5 supplimentary volumes. Tokyo: Chikuma Shobō, 1962-1971.

Yanagita Kunio zenshū. 32 volumes. Chikuma Bunko. Tokyo: Chikuma Shobō, 1989-1991.

Yanagita Kunio taidan shū. Tokyo: Chikuma Shobō, 1964.

Minzokugaku ni tsuite: Daini Yanagita Kunio taidan shū. Chikuma Shobō, 1964.

Secondary and Other Texts

Agnew, John. 2003. "Political Power and Geographical Scale." In Political Space: Frontiers of Change and Governance in a Globalizing World, ed. Yale H. Ferguson and R. J. Barry Jones. Albany: State University of New York Press, 113-130.

Akasaka, Norio. 1991. Yama no seishin shi: Yanagita Kunio no hassei. Tokyo: Shōgakukan.

Akasaka, Norio. 1994. Hyōhaku no seishin shi: Yanagita Kunio no hassei. Tokyo: Shōgakukan.

Akasaka, Norio. 2000. Umi no seishin shi: Yanagita Kunio no hassei. Tokyo: Shōgakukan.

Arendt, Hannah. 1998. The Human Condition. Chicago: University of Chicago Press.

Ariizumi, Sadao. 1973. "Yanagita Kunio kō.” In Yanagita Kunio kenkyū, ed. Kamishima Jirō. Tokyo: Chikuma Chobō, 373-400.

Befu, Harumi. 1997. Ideorogī to shite no nihon bunka ron, expanded edition. Tokyo: Shisō No Kagakusha. 
Bowden, Brett. 2009. The Empire of Civilization: The Evolution of an Imperial Idea. Chicago: University of Chicago Press.

Cumings, Bruce. "Webs with No Spiders, Spiders with No Webs: The Genealogy of the Developmental State." In The Developmental State, ed. Meredith Woo-Cumings. Ithaca: Cornell University Press, 61-92.

Euben, Roxanne Leslie. 1999. Enemy in the Mirror: Islamic Fundamentalism and the Limits of Modern Rationalism. Princeton, N.J.: Princeton University Press.

Fabian, Johannes. 2002. Time and the Other: How Anthropology Makes Its Object, with a new forward by Matti Bunzl. New York: Columbia University Press.

Ferguson, Yale H., and R. J. Barry Jones. 2002. Political Space: Frontiers of Change and Governance in a Globalizing World. Albany: State University of New York Press.

Figal, Gerald A. 1999. Civilization and Monsters: Spirits of Modernity in Meiji Japan. Durham, NC: Duke University Press.

Foucault, Michel, and Colin Gordon. 1980. Power/knowledge: selected interviews and other writings, 1972-1977. New York: Pantheon Books.

Fujii, Takashi. 1995. Yanagita Kunio: Keisei saimin no gaku—keizai, rinri, kyōiku. Nagoya: Nagoya Daigaku Shuppan Kai.

Fukuyama, Francis. 1992. The End of History and the Last Man. New York: Avon Books.

Fukuzawa, Yukichi. 1995. Bumeiron no gairyaku. Tokyo: Iwanami Shoten.

Giddens, Anthony. 1990. The Consequences of Modernity. Stanford, Calif: Stanford University Press.

Grimer-Solem, Erik. 2003. The Rise of Historical Economics and Social Reform in Germany 1864-1894. Oxford: Oxford University Press.

Gunnell, John G. 1968. Political Philosophy and Time. Middletown, Conn: Wesleyan University Press. 
Harootunian, H. D. 1988. Things Seen and Unseen: Discourse and Ideology in Tokugawa Nativism. Chicago: Chicago University Press.

Harootunian, Harry D. 2000. Overcome by Modernity: History, Culture, and Community in Interwar Japan. Princeton, N.J.: Princeton University Press.

Harvey, David. 1989. The Condition of Postmodernity: An Enquiry into the Origins of Cultural Change. Oxford, UK, and Cambridge, MA.: Basil Blackwell.

Hashikawa. Bunzō. 1985a. "Yanagita Kunio-Sono ningen to shisō.” In Hashikawa Bunzō chosaku shū. Tokyo: Chikuma Shobō, 229-328.

Hashikawa Bunzō. 1985b. "Rojin to Yanagita Kunio.” In Hashikawa Bunzō chosaku shū. Tokyo: Chikuma Shobō, 340-345.

Hayakawa, Noboru. 1970. "Hitorigotsu-Yanagi shi he no watashi no kaisōki." Teihon Yanagita Kunio shū geppō 28 (September): 2-4.

Huntington, Samuel P. 1968. Political Order in Changing Societies. New Haven: Yale University Press.

Huntington, Samuel P. 1997. The Clash of Civilizations: Remaking of World Order, Touchstone edition. New York: Simon and Schuster.

Itō, Mikiharu. 2002. Yanagita Kunio to bunka nashonarizumu. Tokyo: Iwanami Shoten.

Inayatullah, Naeem, and David L. Blaney. 2004. International Relations and the Problem of Difference. New York: Routledge.

Irokawa, Daikichi. 1985. The Culture of the Meiji Period. Princeton, N.J.: Princeton University Press.

Irokawa, Daikichi. 1996. Irokawa Daikichi chosaku shū 3: Jōmin bunka ron. Chikuma Shobō.

Ivy, Marilyn. 1995. The Discourse of the Vanishing: Modernity, Phantasm, Japan. Chicago: University of Chicago Press. 
Iwamoto, Yoshiteru. 1983. Mō hitotsu no Tōno monogatari. Tokyo: Tōsui Shobō.

Jahn, Beate. 2000. The Cultural Construction of International Relations: The Invention of the State of Nature. Houndmills, Basingstoke, Hampshire: Palgrave.

Jahn, Beate. 2005. "Barbarian Thoughts: Imperialism in the Philosophy of John Stuart Mill." Review of International Studies 31: 599-618.

Johnson, Chalmers. 1982. MITI and the Japanese Miracle: The Growth of Industrial Policy, 1925-1975. Stanford, Calif: Stanford University Press.

Karatani, Kōjin. 1993. Origins of Modern Japanese Literature. Durham, N.C.: Duke University Press.

Kawada, Minoru. 1985. Yanagita Kunio no shisōshiteki kenkyū. Tokyo: Miraisha.

Koschmann, J. Victor. "Folklore Studies and the Conservative Anti-Establishment in Modern Japan." In International Perspective on Yanagita Kunio and Japanese Folklore Studies, ed. by J. Victor Koschmann, Ōiwa Keibō, and Yamashita Shinji. Ithaca: East Asia Program and Cornell University Press, 131-164.

Lefebvre, Henri. 1991. The Production of Space. Oxford, OX, UK: Blackwell.

Machiavelli. Niccolò. 1992. The Prince, second edition. Trans. and ed. Robert Adams. New York: W. W. Norton.

Malthus, Thomas Robert. 1992. An Essay on the Principle of Population, ed. Donald Winch. Cambridge: Cambridge University Press.

Meek, Ronald L. 1976. Social Science and Ignoble Savage. Cambridge: Cambridge University Press.

Mehta, Uday Singh. 1999. Liberalism and Empire: A Study in Nineteenth-Century British Liberal Thought. Chicago: University of Chicago Press.

Mill, John Stuart. 1967. Collected Works of John Stuart Mill Vol. II: Essays on Economics and Society. Toronto: University of Toronto. 
Mill, John Stuart. 1991. On Liberty and Other Essays. Ed. John Gray. Oxford: Oxford University Press.

Marx, Karl and Friedrich Engels. 1978. The Marx-Engels Reader, second edition. Ed. Robert C. Tucker. New York: Norton.

Matsuzawa, Hiroaki. "Kaisetsu.” In Bumeiron no gairyaku, Fukuzawa Yukichi. Tokyo: Iwanami Shoten, 368-391.

Morse, Ronald A. 1990. Yanagita Kunio and the Folklore Movement: The Search for Japan's National Character and Distinctiveness. New York and London: Garland Publishing.

Nakamura, Akira. 1974. Yanagita Kunio no shisō. Tokyo: Hōsei Daigaku Shuppan Kai.

Nishiwaki, Junzaburō. 1962. "Yanagita sensei no omoide.” Teihon Yanagita Kunio shū geppō 10 (Octorber): 73-74.

Oguma, Eiji. 1995. Tan'itsu minzoku shinwa no kigen [The Myth of the Homogeneous Nation]: "Nihonjin" no jigazō no keifu. Shin'yōsha.

Ōiwa Keibō. 1985: "Preface.” In International Perspective on Yanagita Kunio and Japanese Folklore Studies, ed. by J. Victor Koschmann, Ōiwa Keibō, and Yamashita Shinji. Ithaca: East Asia Program, Cornell University, v-ix.

Okaya, Kōji. 1985. Kizokuin shokikan chō Yanagita Kunio. Tokyo: Chikuma Shobō.

Okaya, Kōji. 1991. Yanagita Kunio no seishun. Tokyo: Chikuma Shobō

Okaya, Kōji. 1996. Korosareta shijin: Yanagita Kunio no koi to gakumon. Tokyo: Shinchōsha.

Pitkin, Hanna Fenichel. 1998. The Attack of the Blob: Hannah Arendt's Concept of the Social. Chicago: University of Chicago Press.

Pyle, Kenneth B. 1973. “The Technology of Japanese Nationalism: The Local Improvement Movement, 1900-1918." Journal of Asian Studies 33: 51-65. 
Pyle. Kenneth B. 1974. "Advantages of Followership: German Economics and Japanese Bureaucrats, 1890-1925.” Journal of Japanese Studies 1, no. 1: 127-164.

Rawls, John. 1999. A Theory of Justice, revised edition. Cambridge, Mass: Belknap Press of Harvard University Press.

Rousseau, Jean-Jacques. 1997. The Discourses and Other Early Political Writings. Ed. Victor Gourevitch. Cambridge: Cambridge University Press.

Ruggie, John Gerard. 1993. "Territoriality and Beyond: Problematizing Modernity in International Relations." International Organization 47 (1): 139-174.

Sakurai, Tokutarō 1987. "Sei to zoku no ronri.” In Sakurai Tokutarō chosakushū 9: minzoku girei no kenkyū, ed. Sakurai Tokutarō Chosakushū Kankō Kai. Tokyo: Yoshikawa Kōbunkan, 49-86.

Satō, Hikaru. 2004. Yanagita Kunio no seiji keizai gaku: Nihon hoshu shugi no genryū wo motomete. Tokyo: Sekai Shisōsha.

Scott, James C. 1998. Seeing Like a State: How Certain Schemes to Improve the Human Condition Have Failed. New Haven: Yale University Press.

Smith, Adam. 2000. The Wealth of Nations. New York: Modern Library.

Silberman, Bernard S. 1982. "The Bureaucratic State in Japan: The Problem of Authority and Legitimacy." In Conflict in Modern Japanese History: The Neglected Tradition. Princeton, N.J.: Princeton University Press, 226-257.

Stewart, Dugald. 1811. Biographical Memoirs, of Adam Smith, LL. D., of William Robertson, D. D. and of Thomas Reid, D. D.: Read before the Royal Society of Edinburgh. Edinburgh: George Ramsay and Company. Google eBooks edition.

Todorov, Tzvetan. 1999. The Conquest of America: The Question of the Other. Norman: University of Oklahoma Press.

Tōhata, Seiichi. 1961. "Nōseigakusha to shite no Yanagita Kunio.” Bungaku 29, no. 1: 40-45. 
Tsunoda, Ryūsaku. 1964. Sources of Japanese Tradition. New York: Columbia University Press.

Tsurumi Kazuko. 1998. Korekushon Tsurumi Kazuko Mandara IV, Tsuchi no maki Yanagita Kunio ron [Collection Tsurumi-Kazuko Mandala IV Essays on Yanagita Kunio]. Tokyo: Fujiwara Shoten.

Tsurumi, Shunsuke. 1973. "Yanagita Kunio no gakufū.” In Yanagita Kunio kenkyū, ed. Kamishima Jirō. Tokyo: Chikuma Shobō, 152-154.

Tsurumi, Tarō. 1998. Yanagita Kunio to sono deshi tachi: Minzokugaku wo manabu marukusu shugisha. Tokyo: Jinbun Shoin.

Umesao, Tadao. 1973. "Yushutsu kanō na kokugaku." In Yanagita Kunio kenkyū, ed. Kamishima Jirō. Tokyo: Chikuma Shobō, 155-157.

Walker, R. B. J. 1993. Inside/Outside: International Relations as Political Theory. Cambridge: Cambridge University Press.

Waswo, Ann. 1988. "The Transformation of Rural Society, 1900-1950." In Cambridge History of Japan, vol. 6: The Twentieth Century, ed. Peter Duus. Cambridge: Cambridge University Press, 541-605.

Wolin, Sheldon. 1968. "Political Theory." In International Encyclopedia of the Social Sciences, ed. David L. Sills and Robert King Merton. New York: Macmillan, 318-331.

Woo-Cumings, Meredith. 1999. The Developmental State. Ithaca, N.Y.: Cornell University Press.

Yanagita Kunio Kenkyūkai. 1988. Yanagita Kunio den. Tokyo: San’itsu Shobō.

Yoshimoto, Takaaki. 1973. "Muhōhō no hōhō.” In Yanagita Kunio kenkyū, ed. Kamishima Jirō. Tokyo: Chikuma Shobō, 191-193.

Zammito, John H. 2002. Kant, Herder, and the Birth of Anthropology. Chicago: University of Chicago Press. 
VITA

TAKEHIKO KOJIMA

June 10, 1969 Born, Machida City, Tokyo, Japan

March, 1992 BA in Political Science

Waseda University, Tokyo, Japan

1993-1996 Embassy of Japan in Colombia

March, 1997 MA in Area Studies

University of Tsukuba, Tsukuba, Japan

1997-2000 Consulate General of Japan in Miami

2000-2003 Embassy of Japan in Trinidad and Tobago

2004 Mitsubishi Research Institute, Tokyo, Japan

\section{PUBLICATIONS AND PRESENTATIONS}

Takehiko Kojima. 2006. "Culture and Democracy: The State, Nationalism, and Democratization in Japan." Paper presented at the 64th Annual Conference of Midwest Political Science Association.

Takehiko Kojima. 2007. "Democratization and the Language of Nationalism." Paper presented at the 65th Annual Conference of the Midwest Political Science Association.

Takehiko Kojima. 2007. "Another Turn to Left?: The Politics of Redistribution and Recognition in Latin America." Paper presented at the Congress of Latin American Studies Association. 